HILTON ALEXANDRE DE OLIVEIRA

\author{
USO DE SIMULADORES HIDRÁULICOS E APLICATIVOS DE \\ GEOPROCESSAMENTO PARA DIAGNÓSTICO OPERACIONAL \\ DE SISTEMAS DE DISTRIBUIÇÃO DE ÁGUA \\ ESTUDO DE CASO: SETOR SACOMÃ, MUNICÍPIO DE SÃO PAULO
}


HILTON ALEXANDRE DE OLIVEIRA

\section{USO DE SIMULADORES HIDRÁULICOS E APLICATIVOS DE GEOPROCESSAMENTO PARA DIAGNÓSTICO OPERACIONAL DE SISTEMAS DE DISTRIBUIÇÃO DE ÁGUA ESTUDO DE CASO: SETOR SACOMÃ, MUNICÍPIO DE SÃO PAULO}

Dissertação apresentada à Escola Politécnica da Universidade de São Paulo para obtenção do título de Mestre em Engenharia.

Área de Concentração:

Engenharia Hidráulica

Orientador:

Prof. Dr. Kamel Zahed Filho 
Autorizo a reprodução e divulgação total ou parcial deste trabalho, por qualquer meio convencional ou eletrônico, para fins de estudo e pesquisa, desde que citada fonte.

Este exemplar foi revisado e alterado em relação à versão original, sob responsabilidade única do autor e com a anuência de seu orientador.

São Paulo, de março de 2011.

Assinatura do autor

Assinatura do orientador

FICHA CATALOGRÁFICA

Oliveira, Hilton Alexandre de

Uso de simuladores hidráulicos e aplicativos de geoproces samento para diagnóstico operacional de sistemas de distribuição de água - estudo de caso: setor Sacomã, município de São Paulo / H.A. de Oliveira. -- ed.rev. -- São Paulo, 2011.

$153 \mathrm{p}$.

Dissertação (Mestrado) - Escola Politécnica da Universidade de São Paulo. Departamento de Engenharia Hidráulica e Sanitária.

1. Redes de distribuição de água 2. Mapas temáticos 3 . Vazamentos de água I. Universidade de São Paulo. Escola Politécnica. Departamento de Engenharia Hidráulica e Sanitária II. t. 


\section{DEDICATÓRIA}

"Dedico este trabalho a Deus e aos meus pais por me tornarem capaz de concluir projetos que, sozinho, sequer ousaria começar...". 


\section{AGRADECIMENTOS}

Ao meu orientador, Prof. Dr. Kamel Zahed Filho, pelas suas recomendações, ensinamentos e pelo voto de confiança que tornaram possível esta realização.

Aos professores e funcionários da Escola Politécnica da Universidade de São Paulo e da Faculdade de Tecnologia de São Paulo por toda a sua tolerância e prestatividade durante todas as etapas deste trabalho.

A todos da família SABESP que, dentro de cada uma de suas especialidades, souberam transmitir conceitos e técnicas que me tornaram um admirador da hidráulica operacional. Em especial, meus agradecimentos aos amigos da SABESP Marcos Aurélio Martins, Antonio Sergio da Cunha Guasco, Antonio Simões Teixeira Filho, Liliana Pedroso Vicentini, Sonia Regina Rodrigues, Carlos Alberto Apparecido, Maria Silvia P. Oliveira, Luis Fernando Moreira, Anderson de Melo Martins, Renato Franzotti, Isabel C. Parreira Oshiro, Jose Ricardo Bueno Galvão, Jairo Tardelli Filho, Francisco Paracampos e aos demais funcionários da Unidade de Negócio Centro e da Superintendência de Planejamento que muito contribuíram em cada estágio deste aprendizado.

Aos meus pais e aos mais caros amigos por me incentivarem a transpor mais um obstáculo em meu desenvolvimento profissional... 
"Se tens de lidar com a água, consulta primeiro a experiência, e depois a razão."

(Leonardo da Vinci) 


\section{RESUMO}

O trabalho apresenta uma proposta de metodologia para diagnóstico de sistemas de distribuição de água através da elaboração de modelos de simulação hidráulica apoiados em aplicativos de geoprocessamento. Utilizando-se de dados reais como o histórico operacional de vazamentos dentro da região adotada durante um intervalo de tempo, espera-se fornecer ao analista um instrumento de análise visual do comportamento hidráulico em função de uma escala progressiva de ocorrências, mapeada através de cores, permitindo avaliar a qualidade do modelo hidráulico como um todo, corrigindo desvios para que o mesmo reproduza eficientemente 0 comportamento da rede de distribuição. Através deste, espera-se avaliar as consequências da variação das pressões e vazões durante o dia, subsidiando tomadas de decisão, permitindo a avaliação das opções de melhoria pela redução de riscos e pela redução de investimentos necessários.

Palavras-chave: Redes de distribuição de água. Mapas temáticos. Vazamentos de Água. 


\begin{abstract}
The paper presents a proposed methodology for diagnosis of water distribution systems through the development of hydraulic simulation models supported by GIS applications. Using real data and operational history of leaks within the region adopted during a time interval, it is expected to provide the analyst a tool for visual analysis of the hydraulic behavior due to a progressive scale of events, mapped by color, possible to assess the quality of the hydraulic model as a whole, correcting for deviations that it efficiently reproduces the behavior of the distribution network. Through this, it is expected to evaluate the consequences of changes in pressure and flow rate during the day, supporting decision making, allowing the evaluation of improvement options for risk reduction and the reduction of investment required.
\end{abstract}

Keywords: Water distribution networks. Thematic maps. Water leaks. 


\section{APRESENTAÇÃO}

Tecnólogo em Construção Civil, Hilton Alexandre de Oliveira, o autor, atua desde 2001 com planejamento e engenharia de operação de água na Companhia de Saneamento Básico do Estado de São Paulo (Sabesp), tendo atuando até então com tratamento de água e com sistemas adutores na Região Metropolitana de São Paulo.

Através do uso dos instrumentos propostos na metodologia do trabalho, espera-se apresentar um instrumento que atenda de forma rápida e visual as necessidades dos analistas na elaboração de um diagnóstico das redes de distribuição de água pela aproximação de informações teóricos e operacionais, trazendo as facilidades da ferramenta para o dia a dia de muitos dos especialistas diretamente envolvidos e que ainda não confiam na ferramenta de simulação hidráulica devido a um grande número de variáveis sujeitas a erros que a determinam e as dificuldades de garantir resultados eficientes. As dificuldades de se obter dados absolutos que permitam reproduzir a realidade de comportamento das águas conduzidas por grandes extensões, por redes secundárias, ainda é uma grande lacuna entre acadêmicos e especialistas.

Com o exemplo utilizado no Estudo de Caso, espera-se apontar as principais dificuldades encontradas na montagem de uma simulação, mostrando que apesar de contar-se com um sistema cadastral moderno, caberá ao analista uma boa interpretação dos desvios de resultado e a investigação das causas que incidam em erros e que possam assim representar dúvidas e investimentos desnecessários. 


\section{LISTA DE ILUSTRAÇÕES}

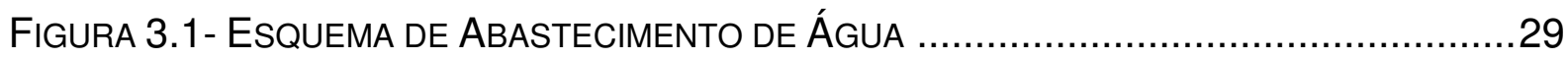

FIGURA 32 - SISTEMA DE ABASTECIMENTO PADRÃO ............................................ 30

FIgURA 33 - ESQUEMÁtico dE ABASTECIMENTO dE ÁGUA NA SETORIZAÇÃo ....................31

FIGURA 34 - RESERVATÓRIOS COM RELAÇÃO dO TERRENO.......................................33

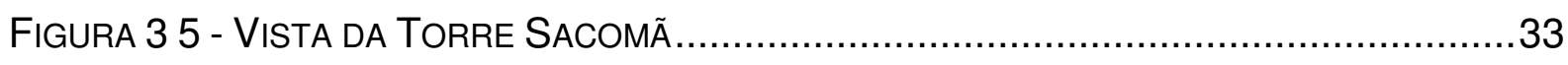

FIGURA 36 - CONJUNTO MOTOR-BOMBA DE ESTAÇÃO ELEVATÓRIA ..............................34

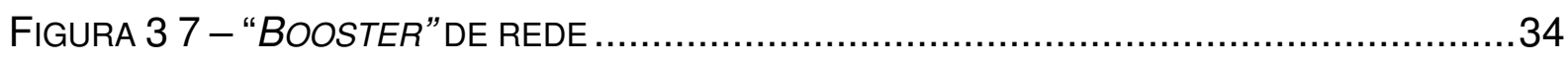

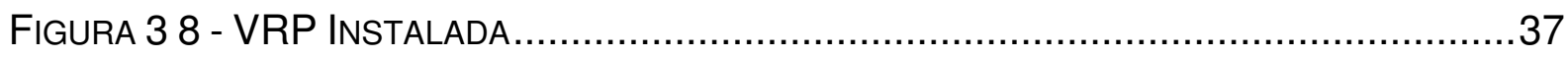

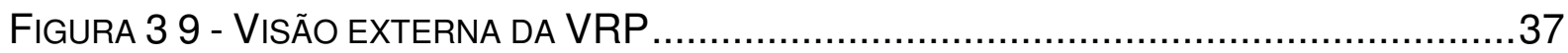

FIGURA 310 - TUBULAÇÃO REABILITADA COM ARGAMASSA DE CIMENTO.......................40

FIGURA 3 11- FAIXA DAS IDADES DE IMPLANTAÇÃO DAS REDES DE DISTRIBUIÇÃO DE ÁGUA .42

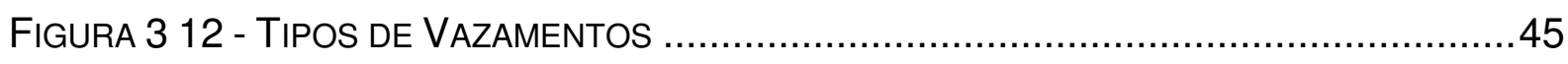

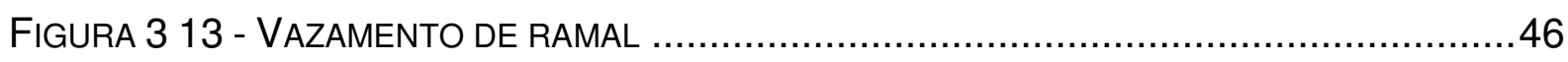

FIGURA 314 - VAZAMENTO DE REDE ........................................................ 46

FIGURA 315 - LIGAÇÃO ENTRE FEIÇÕES (CAMADA), COORDENADAS E ATRIBUTOS (DADOS) 68

FIGURA 41 - CURVA NEUTRA PARA MODULAÇÃO TEMPORAL DE CONSUMO NOS NÓS. 73

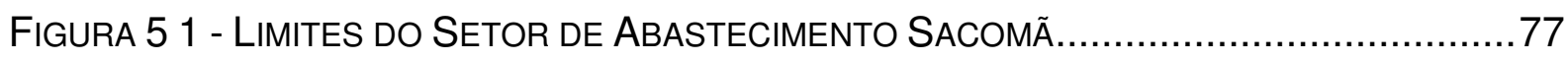

FIGURA 52 - INSTALAÇÕES HIDRÁULICAS DA EEA SACOMÃ.................................. 79

Figura 53 - LiMites do ANTIgo Setor de Abastecimento SacomÃ .........................80

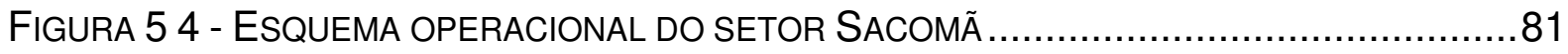

Figura 55 - Vista Geral do Sistema de Distribuição de ÁGua - Setor Sacomã .....82

FIGURA 56 - ORTOFOtO dOS LIMITES do SETOR DE ABASTECIMENTO SACOMÃ...............83

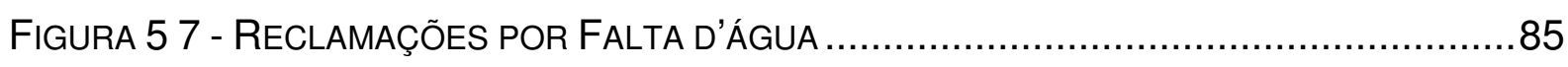

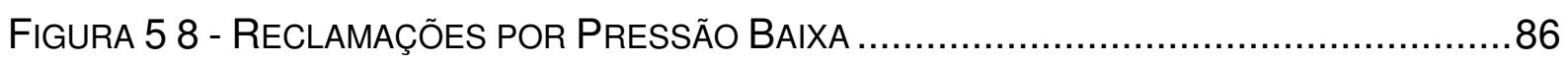

FIGURA 59 - SETOR SACOMÃ ORIGINAL: 1512 TRECHOS .................................... 88

FIGURA 510 - SETOR SACOMÃ TRATADO: 452 TRECHOS ....................................... 88

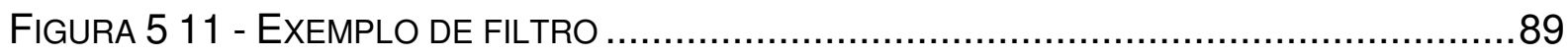

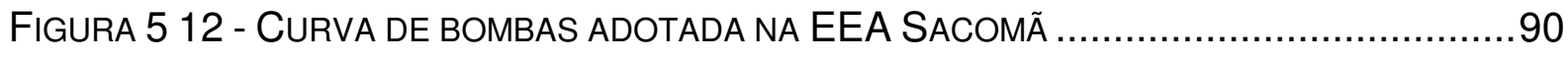


FIGURA 513 - LIMITES DOS NÓS E POSICIONAMENTO DAS REDES DE DISTRIBUIÇÃO (1/5) ...91

FIGURA 514 - LIMITES DOS NÓS E POSICIONAMENTO DAS REDES DE DISTRIBUIÇÃO (2/5) ...92

FIGURA 515 - LIMITES DOS NÓS E POSICIONAMENTO DAS REDES DE DISTRIBUIÇÃO (3/5) ...93

FIGURA 516 - LIMITES DOS NÓS E POSICIONAMENTO DAS REDES DE DISTRIBUIÇÃO (4/5) ...94

FIGURA 517 - LIMITES DOS NÓS E POSICIONAMENTO DAS REDES DE DISTRIBUIÇÃO (5/5) ...95

FIGURA 61 - 1ㅁ VERSÃO DA SIMULAÇÃO TRABALHADA EM ARCVIEW 3.2- MOMENTO: 3H...100 Figura 62 - 1ㄹ VERSÃO dA SimULAÇÃO tRABALHAdA EM ARCVIEW 3.2- MOMENTO: 12H.101 FIGURA 63 - 2 ${ }^{\mathrm{a}}$ VERSÃO DA SIMULAÇÃO TRABALHADA EM ARCVIEW - MOMENTO: 3H........ 103 Figura 64 - 2a Versão da SimULAÇÃO TRABALHAdA EM ARCVIEW- MOMENTO: 12H .......104 FIGURA 65 - GRÁFICO DE FUNCIONAMENTO: CONJUNTO MOTOR-BOMBA № 1 DA EEA SACOMÃ 105

Figura 66 - GráFico de FUnCIONAMENTO: RESERVATÓRIO ELEVAdo (TORRE) SACOMÃ. 106

FiguRA 67 - 3a VERSÃO dA SimULAÇÃO tRABALHAdA EM ARCVIEW- MOMENTO: 3H ........108 FIGURA 68 - 3a VERSÃO DA SIMULAÇÃO TRABALHADA EM ARCVIEW - MOMENTO: 12H......109

FIGURA 69 - MAPA TEMÁTICO DE CALIBRAÇÃO DO MODELO: MOMENTO 12H. 111

FiguRA 610 - MAPAS TEMÁTICOS SOBRE VAZAMENTO dE CAVALETE NO SETOR 1ำ

SEM/2009. 115

FIgURA 611 - MAPAS TEMÁTICOS SOBRE VAZAMENTOS DE RAMAL NO SETOR 1 SEM/2009 116

FIGURA 612 - MAPAS TEMÁTICOS SOBRE VAZAMENTOS DE REDE NO SETOR 1 SEM/2009 117

FIGURA 613 - MOMENTOS DE ENCHIMENTO E ESVAZIAMENTO DO RESERVATÓRIO ELEVADO 119

Figura 614 - COMPARATIVO: CuRva CONSUMO X TEMPO 120 


\section{LISTA DE TABELAS}

TABELA 31 - (AdAPtado) TIPOS DE VAZAMENTOS DE RAMAL. ................................47

TABELA 32 - (AdAPTADO) TIPOS DE VAZAMENTOS DE REDE ...................................48

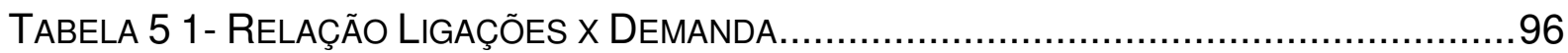

TABELA 52 - FÓRMULA DE DEMANDAS DE CADA NÓ A PARTIR Do ÍNDICE DE PERDAS ..........98

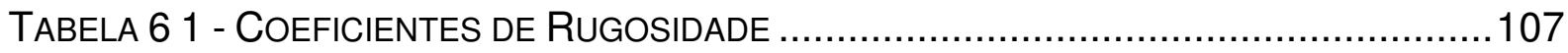

TABELA 62 - DESVIOS EM RELAÇÃO À TOMADA DE CAMPO EM FUNÇÃO DE RUGOSIDADES

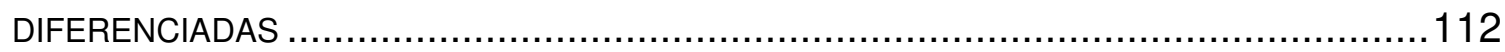




\section{LISTA DE FÓRMULAS}

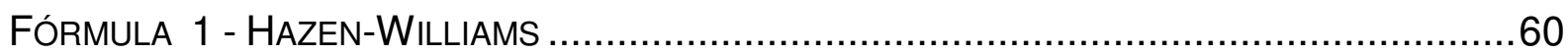

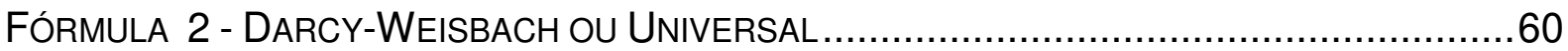




\section{LISTA DE ABREVIATURAS E SIGLAS}

$A G$ - Algoritmo Genético

AWWA - American Water Works Association

BNH - Banco Nacional de Habitação

CESBs - Companhias Estaduais de Saneamento Básico

EEA - Estação Elevatória de Água (bruta ou tratada)

EPA (U.S.EPA) - United States Environmental Protection Agency

ESRI - Environmental Systems Research Institute, Inc.

FAE - Fundos de Financiamento para Água e Esgoto

GIOF - Gerenciamento Integrado da Operação e do Faturamento em Sistemas

Urbanos de Abastecimento de Água

GIS - Geographic Information System

IWA / IWSA - International Water Supply Association

mca - Metros de Coluna de Água (proporcional a $9,80665 \mathrm{~N} / \mathrm{m}^{2}$ ou 0,09674 atm)

MSHDP - Modelo de Simulação Hidráulica Dirigida pela Pressão

ONU - Organização das Nações Unidas

OPAS - Organização Pan-Americana de Saúde

PB - Polibutileno

PC - Perda de Carga

PDAA - Plano Diretor de Abastecimento de Água

PE - Polietileno

PLANASA - Plano Nacional de Saneamento

PNCDA - Programa Nacional de Combate ao Desperdício de Água

PROCEL - Programa Nacional de Conservação de Energia Elétrica

PVC - Policloreto de Vinila

$Q$ - Vazão

RMSP - Região Metropolitana de São Paulo

SABESP - Companhia de Saneamento Básico de São Paulo

SCADA - Supervisory Control and Data Acquisition

SIG - Sistema de Informações Georeferenciadas

V - Velocidade 
VCA - Válvulas de Controle Automático

VRP - Válvula Reguladora de Pressão

WRC - Water Research Center 


\section{SUMÁRIO}

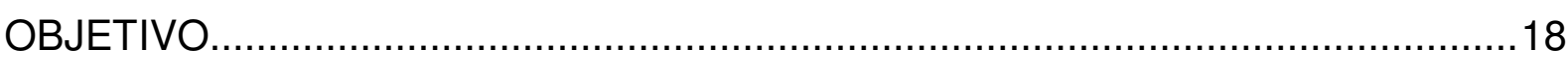

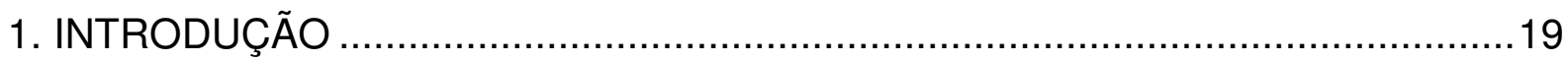

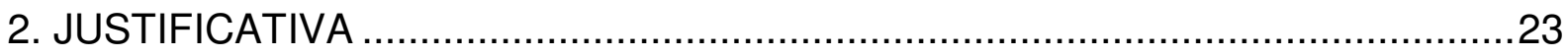

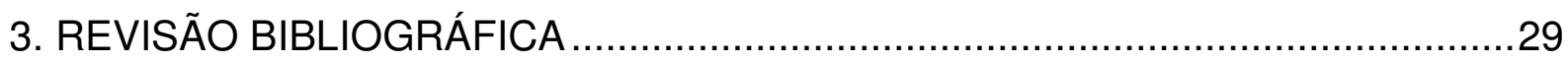

3.1. Sistemas de Abastecimento - Conceitos Fundamentais ..............................29

3.1.1. Reservatórios................................................................................. 32

3.1.2. Estação Elevatória de Água, "Booster" e Variadores...................................33

3.1.3. VRP - Válvulas Reguladoras de Pressão ................................................36

3.1.4. As Redes Adutoras e as Redes de Distribuição ...........................................

3.1.4.1. Desgaste e a qualidade da rede de distribuição .....................................38

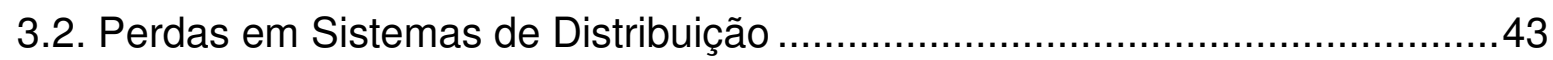

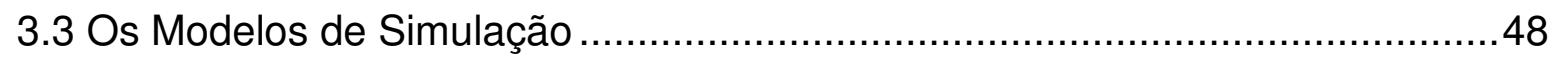

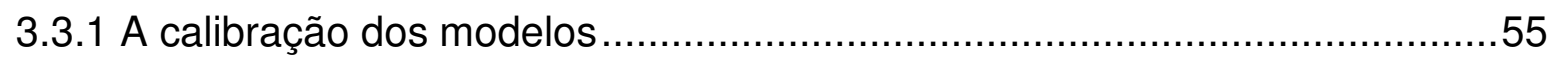

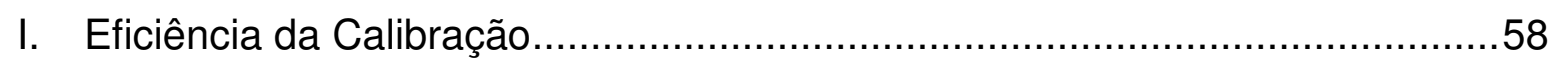

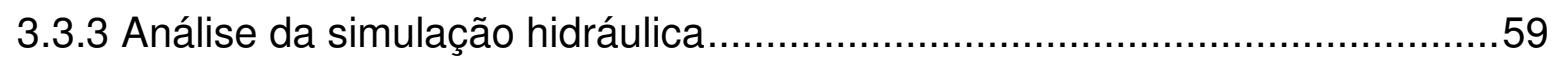

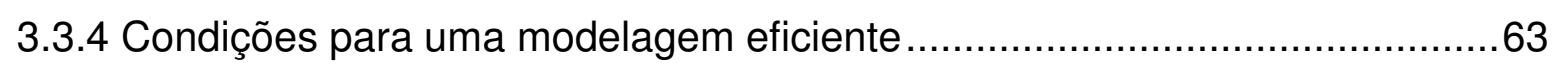

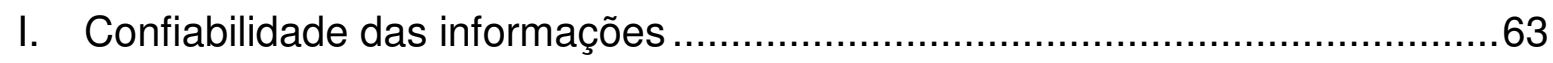

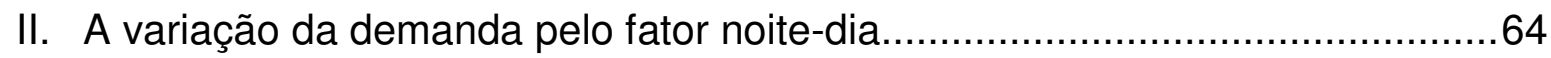

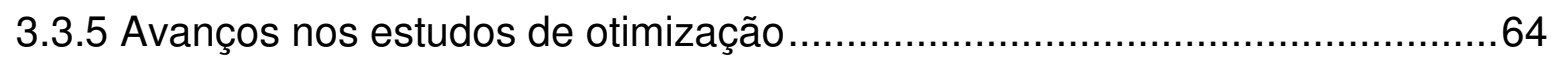

3.4 O Geoprocessamento como ferramenta de gestão de Sistemas de Distribuição

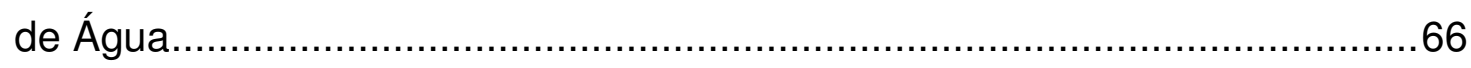

4. DESENVOLVIMENTO E METODOLOGIA..................................................

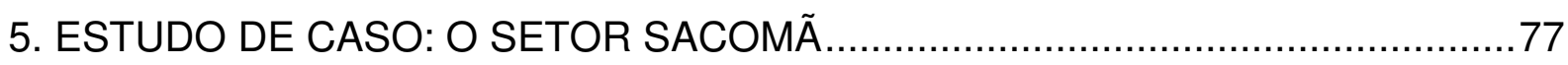

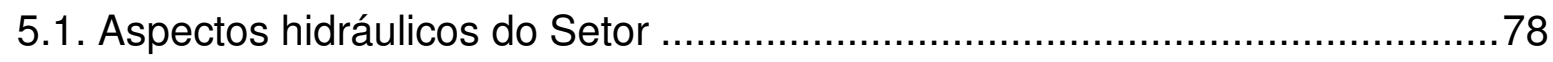

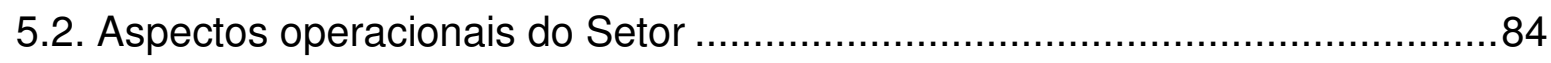

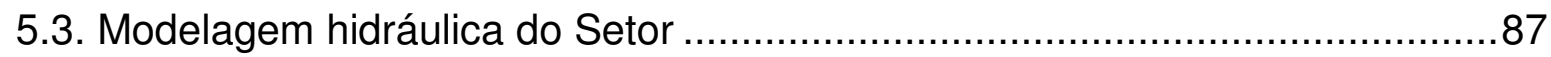

5.3.2. Determinação das demandas de consumo..............................................96

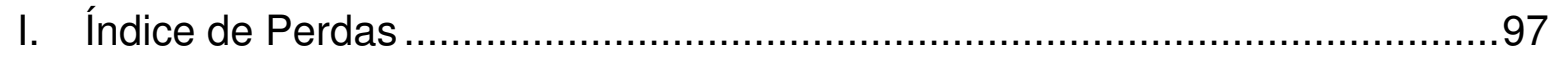

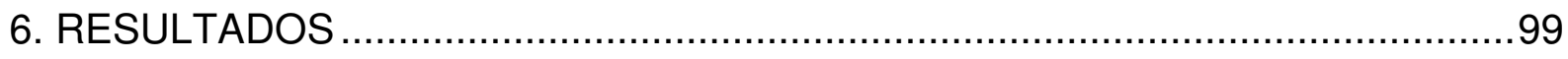




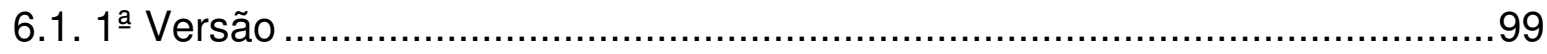

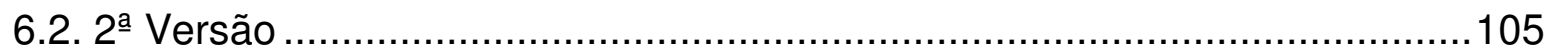

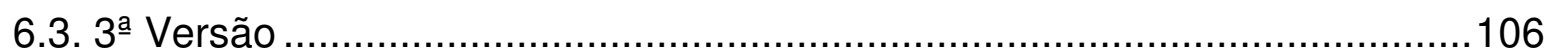

6.4. Calibração in loco ...................................................................... 110

6.5. Modelo x Mapas Temáticos ............................................................. 113

6.6. Modelo x Curva de Consumo para Análise Dinâmica..............................118

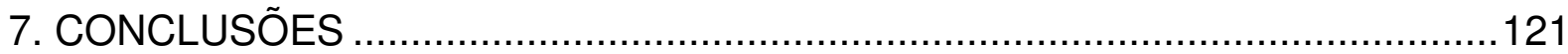

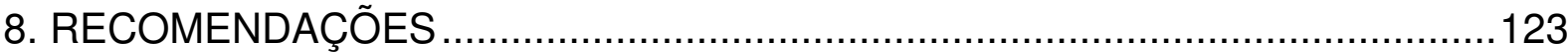

9. REFERÊNCIAS BIBLIOGRÁFICAS ...................................................... 124

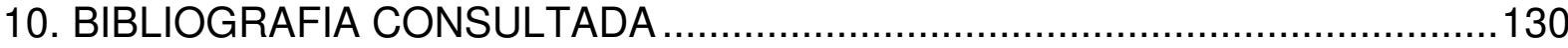

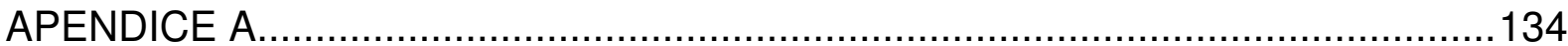




\section{OBJETIVO}

Definir metodologia para a elaboração de simulações hidráulicas, apoiadas em aplicativos de geoprocessamento e de dados relacionados ao histórico operacional da região adotada, conferindo e garantindo à simulação maior confiabilidade como ferramenta de análise e instrumento de suporte à decisão, de forma a buscar eficiência operacional a sistemas de distribuição de água. 


\section{INTRODUÇÃO}

A preocupação com a redução de custos fez com que diversos especialistas por todo o mundo procurassem identificar, ao menos, as principais variáveis dos sistemas de distribuição de água desde sua captação até a sua entrega ao cliente final de forma a melhor controlar todo o volume beneficiado após seu tratamento, monitorando e melhorando a eficiência de todo o processo.

Com o crescimento populacional e a rápida ocupação das periferias, em especial das regiões metropolitanas, de forma nunca prevista em qualquer estudo urbanístico e sem a capacidade de desenvolver infra-estrutura que siga esta mesma progressão (SILVA, 2007), o atendimento à demanda tende a ser progressivamente maior, enquanto a disponibilidade hídrica permanece a mesma, dificultando o atendimento não só de suficiência, mas a critérios normatizados como a qualidade e a pressão mínima exigíveis.

Em se tratando da condição hídrica no Brasil, esta apesar de relativamente farta em comparação a muitos outros países, não possui uma distribuição uniforme por todo seu território. Na Região Metropolitana de São Paulo (RMSP) há uma disponibilidade de 165 mil litros de água anuais para cada habitante enquanto que, comparativamente, nas regiões mais áridas do Nordeste brasileiro, a média é de 400 mil litros por ano (atentando-se que uma média considerada viável pela ONU seja de aproximadamente 1,5 milhão de litros por ano), ou seja, a RMSP conta com aproximadamente $10 \%$ do volume recomendado, desprezando ainda o fato de desenvolvimento e crescimento iminentes durante os próximos anos (Escobar apud MEGACIDADES, 2008).

Historicamente, vale ressaltar o importante papel assumido pelo PLANASA (Plano Nacional de Saneamento) em 1969, que permitiu o desenvolvimento de políticas voltadas ao saneamento - até então totalmente deficitário - contando com índices médios de $45 \%$ da população atendida com serviços de água e de apenas $20 \%$ com a coleta de esgoto e que através do Plano, atingiu, em meados de 1991, índices de 
$87,5 \%$ de atendimento por serviços de água e $64,3 \%$ por serviços de coleta de esgoto a partir de medidas focalizadas no recondicionamento das condições de suprimento das regiões metropolitanas do país e pela criação das Companhias Estaduais de Saneamento (CESBs). Estas receberam a tarefa de atentar ao suprimento de todos os municípios de cada um dos Estados através de esforços para implementação de políticas tarifárias, com a redução de recursos operacionais e capacitação de especialistas. Todo este processo foi custeado com a criação de Fundos de Financiamento para Água e Esgoto, a FAE, através do BNH (Banco Nacional de Habitação), permitindo assim bons resultados ao programa (KLUMB, 1977; PIRES, 1977; MENDES et al, 2002).

Com o fim do PLANASA, o país teve uma redução drástica de suas fontes de financiamento que até então garantiram todo o aporte de recursos, vendo-se obrigado a tomar decisões frente a crescente demanda exigida, culminando no desenvolvimento de cultura e práticas de autogestão. Assim, para conceder financiamentos, organizações como o Banco Mundial exigiram das concessionárias de serviços de abastecimento projetos e ações visando à redução de perdas reais em seus sistemas de abastecimento, onde deveriam apresentar resultados efetivos em relação à redução de seus índices utilizando, em especial, os princípios e as técnicas apresentadas nas séries de relatórios intitulados Managing Leakage publicados pela Water Research Center (WRC). Assim, as agências internacionais foram as primeiras a reconhecer o significado de vazamentos como recurso d'água (ARIKAWA, 2005).

Para garantir 0 atendimento a perspectivas pessimistas, as companhias de saneamento tomaram medidas corretivas para a redução dos índices de água perdida no trajeto, assim como desenvolverem uma política de combate às fraudes de forma a assegurar a confiabilidade necessária a investimentos particulares e preservar assim a continuidade de sua prestação de serviços.

Merece ser observado que a necessidade de viabilizar todo o conceito de distribuição de água considerando fatores que até então eram deixados para um segundo plano seriam imprescindíveis em razão de novos problemas que ainda surgiriam: a questão de conflitos pelo uso da água nas regiões metropolitanas, como 
acontece hoje, conforme relata Escobar (apud MEGACIDADES, 2008) entre a Região Metropolitana de São Paulo e a de Campinas, que disputam os Recursos Hídricos da Bacia do Rio Piracicaba; a ocupação de áreas próximas aos mananciais; a necessidade de grandes investimentos para o tratamento das águas servidas devido aos riscos de comprometimento de qualidade da água que até então era utilizada como meio de arraste e de depuração de esgotos - prática bastante comum em grandes centros urbanos; e o desenvolvimento de políticas de reuso de águas já servidas para muitas atividades, destacando-se as agrícolas e as industriais.

Voltada à condição de aproveitamento máximo dos volumes de águas disponíveis para consumo, foram contratadas consultorias de especialistas por todo o mundo com o intuito de desenvolver grupos de estudo e disseminação de técnicas com o propósito de formar hidráulicos habilitados para promover a eficiência operacional tão esperada. Exemplos podem ser referenciados em programas internos das concessionárias buscando o desenvolvimento de programas piloto como forma de adequar técnicas já comprovadas a condições locais específicas e ao incentivo à produção de relatórios, artigos técnicos e dissertações visando à disseminação e a trocar práticas de melhoria. Como exemplo, no Brasil, foi criado o PNCDA Programa Nacional de Combate ao Desperdício de Água, onde são disseminados métodos, índices e práticas que permitem visando o uso eficiente e o combate ao desperdício.

Neste aprendizado, foram disseminadas muitas das ferramentas que atualmente já são de uso comum, tais como os programas para simulação hidráulica e programas para controle e gerenciamento que hoje, muito ágeis e de fácil interpretação em razão dos avanços tecnológicos, para todas as especialidades a que são destinados (como ao monitoramento de qualidade da água, transientes hidráulicos, etc.), permitem alternativas de adequação em razão de influência econômica ou alternativas tecnológicas. Paralelamente, foram desenvolvidos instrumentos de controle à distância (como os sistemas de telemetria), válvulas, comportas, dispositivos automatizados e painéis que permitem o monitoramento completo, gerindo assim grande parte do comportamento hidráulico de forma a permitir um maior controle sobre as pressões atuantes, sobre o número de vazamentos e que 
estabeleçam com boa confiabilidade, a continuidade do abastecimento em toda a área gerida.

Outra solução que se tornou possível com o advento da tecnologia de informação é a de permitir o armazenamento de informações que podem ser úteis como meio de preservar o histórico operacional de instalações e equipamentos. Tais programas são tão usuais quanto os sistemas de acompanhamento remoto de operação, pois permitem gerir os recursos financeiros a curto, médio e longo prazo e possibilitar a concepção de planos preventivos e de adequação buscando atender a metas e resultados almejados. 


\section{JUSTIFICATIVA}

Com a mudança dos costumes, houve um exponencial aumento da demanda por água potável em todo o mundo, seja esta direcionada ao abastecimento ou para os mais variados fins, sejam estes comerciais, industriais ou agrícolas. A água, que chegou a ser considerada pelo homem até aquele momento como infinita, passou a ter o status de bem e valor em função da sua importância econômica e social, passando então a ser razão de conflitos que se tornam continuos em decorrência de sua insuficiência. É notório que a questão da indisponibilidade tendeu a agravar-se com o passar dos anos, devido ao crescimento populacional e ao desenvolvimento de novas tecnologias e costumes que demandam de volumes cada vez maiores. Se tal condição não for rapidamente atenuada, a insuficiência do recurso acarretará em graves consequências, tais como a veiculação de doenças por falta de serviços sanitários e a uma caótica falta de alimentos.

Por todo o planeta e em especial no Brasil, o poder público tem aplicado recursos na preservação de recursos hídricos que, em grande parte, estavam reduzidos a instrumentos de arraste de resíduos e, que devido à falta de iniciativa anterior (políticas de educação ambiental, preventivas ou de controle) não eram aproveitados para propósitos mais nobres.

Como exemplo, toma-se quanto à possibilidade de recuperação do Rio Tietê na Região Metropolitana de São Paulo (RMSP), espelhada em experiências bem sucedidas como a do Rio Tamisa, no Reino Unido, e a do Rio Sena, na França (Carranca apud MEGACIDADES, 2008), que mostraram que a aplicação de políticas eficazes de reabilitação se comprovam eficazes. Países como o Japão (TSUTIYA, 2004), Austrália (FARLEY \& TROW, 2003) e o próprio Reino Unido (THORNTON, 2002) empenham-se, divulgando experiências de sucesso no tratamento de suas águas e no melhor aproveitamento destas.

Segundo foi publicado pela ONU, no evento Rio+10, ocorrido em Johanesburgo em 2002, metade da população do planeta não terá acesso à água em 2025, caso mantida a mesma demanda atual - o que significa que há necessidade imediata de 
intervenção por parte do poder público para garantir a sustentabilidade dos recursos disponíveis e condicionamento para as próximas gerações. Nos países da América Latina e Caribe, já são 127 milhões de pessoas (23\%) sem acesso a instalações adequadas de saneamento (OPAS, 2007), enquanto que na maioria das regiões metropolitanas a condição de caos hídrico parece ainda mais iminente.

Novas alternativas de suprimento têm sido procuradas em razão dos custos da recuperação, mas são poucas às vezes em que os resultados obtidos representam também aceitável viabilidade econômica (como a técnica de dessalinização ou métodos alternativos como a captação de poços, que, no volume necessário, não seriam a melhor opção pelo menos no atual contexto do Brasil), levando os especialistas a apontar como solução a busca de novos mananciais com o propósito de atender à população. Cabe esclarecer que tais fontes estão cada vez mais distantes e desfavoráveis ao pronto abastecimento, passíveis de limitação de volumes captados na outorga ou contratados a outras finalidades que não 0 prioritário abastecimento humano, justificando embates sociais, econômicos e políticos.

$\mathrm{Na}$ falta de mananciais em volume suficiente para prover satisfatoriamente a população com água potável, cabe ao gestor público procurar meios de adequação por meio da disseminação de práticas de uso racional, cobrança pelo uso da água, de incentivos a prática do reuso, limitação (quantidade e qualidade) dos lançamentos de esgoto nos corpos hídricos e - primordialmente - pelo controle efetivo sobre os índices de água perdidos durante o trajeto entre sua captação e a entrega ao consumidor final originadas, principalmente, de problemas operacionais e por uso desautorizado (fraudes), merecendo contínua atenção. Em muitas regiões do Brasil, a média de águas perdidas nas regiões mais afastadas é descabidamente alta em relação à das encontradas nas regiões metropolitanas apesar de toda a disseminação pelo combate ao desperdício ser exaustamente explorada por toda a esfera pública.

Tratando-se especificamente do contexto deste trabalho, focado essencialmente na gestão operacional dos recursos hídricos, esta é, prioritariamente, avaliada entre dois segmentos: 
Perdas Reais: volumes efetivamente perdidos por meio de vazamentos e extravasamentos durante seu transporte ou armazenamento água que acabam não servindo ao uso;

Perdas Aparentes: volume oriundo da imprecisão de hidrômetros, fraudes, abastecimento de hidrantes, etc. - água que serve ao uso, mas que não gera receita.

Os volumes perdidos, principalmente 0 daqueles já condicionados ao abastecimento, provocam um grande impacto financeiro às empresas concessionárias - responsáveis pelos serviços de distribuição - em razão do valor que esta agrega a água durante o tratamento e pela energia consumida em seu transporte, desde o tratamento até a sua disponibilização ao cliente final. Outra consequência é quanto ao comprometimento da imagem, da qualidade e da confiabilidade do serviço prestado pela empresa concessionária, que também faz parte da contabilização das perdas (BRASIL, 2004). Sendo o volume total de água perdido de difícil quantificação, o mesmo é obtido indiretamente pela diferença entre o volume introduzido no sistema e os volumes realmente utilizados. Conceitualmente, a diferença entre o volume de água fornecido e a parcela referente ao consumo autorizado, num determinado tempo, constitui o chamado balanço hídrico do conjunto (GUMIER, 2005).

Como o principal consumidor de energia elétrica em razão dos custos para o bombeamento de grandes vazões a distantes pontos de consumo, a energia elétrica é ainda majorada em virtude da baixa eficiência dos equipamentos de recalque. Falhas de projeto, procedimentos inadequados para instalação e principalmente 0 desgaste natural dos equipamentos contribuem para a importância deste fator. Segundo o PROCEL - Programa Nacional de Conservação de Energia Elétrica - em 2005, por todo o país, foram consumidos sete bilhões de kWh/ano pelos prestadores de serviços de água e esgotamento sanitário. No mundo, somente os sistemas de distribuição de água são responsáveis pelo consumo conjunto de $7 \%$ de toda a energia gasta (K. James apud GOMES, 2005). 
Fatores mais complexos, mas não menos importantes deverão ser considerados no momento de elaboração de planos de adequação, de forma a atender maior eficiência operacional:

Automação: aumenta o custo inicial de operação, mas permite minimizar os custos totais de produção, gerando maior confiabilidade à operação, reduzindo riscos de acidentes e os custos com manutenção corretiva por falha humana. Inclui-se neste contexto, além do uso de dispositivos automatizados que dispensam o controle manual de equipamentos, os sistemas telecomandados;

Modelagem hidráulica: permite, através de procedimentos matemáticos e por funções de restrição, reproduzir o comportamento esperado em condições reais, podendo ser utilizado de forma genérica na maior parte dos segmentos de estudo hidráulicos a que sejam apropriados. Antevendo resultados baseados em um sistema de programação que representa a sua aplicação propriamente dita, permite ajustes e comparativos diante de diferentes condições impostas, permitindo escolher a melhor opção a ser tomada (adaptado de FONSECA, 1974; GUMIER, 2005);

Programa de Manutenção Preventiva: antecipando-se às necessidades corretivas emergenciais e às consequências oriundas destas, é possível reduzir seus impactos. Pode-se inserir neste contexto a limpeza, relocação, substituição, reforço e a recuperação das redes de abastecimento, válvulas e demais equipamentos hidráulicos que têm desgaste natural e necessidade de readequação por mudança de comportamento (WRC e IWA, apud SABESP, 2008). A grande maioria dos equipamentos implantados e tubulações assentadas, ainda em uso, têm vida útil superior a que foi recomendada pelo fabricante e está sujeita a falhas dependendo da condição em que foram instaladas, cabendo, portanto, priorizar impactos como meio de controle sobre intervenções emergenciais até a implantação de um instrumento que permita garantia efetiva da durabilidade real de todos os materiais e equipamentos;

Aspectos urbanísticos, ambientais e comerciais: É crucial que se atente à intervenção em áreas protegidas ou complexas, preferindo rotas alternativas, 
avaliando aspectos ambientais e sua relevância em qualquer análise de viabilidade ou proposta de adequação. As dificuldades para intervenção em vias públicas são um outro grande gerador de conflitos, assim como os fatores comerciais, em razão de contratos do tipo "firme demanda", onde são exigidos padrões além dos explícitos em norma técnica, com garantias de regularidade, vazões e pressões mínimas, e por uma crescente verticalização imobiliária, quando uma única tomada de água deve atender a um grande número de economias além da inicialmente prevista, além da garantia efetiva de abastecimento alternativo a instalações especiais, como hospitais e delegacias.

Em termos de investimentos e pretensões futuras, tomando-se a RMSP como referência, esta, segundo estimativas, tem a premissa de responder por uma demanda em 2025 de $84 \mathrm{~m}^{3} / \mathrm{s}$ para o suprimento de aproximadamente 22,5 milhões de pessoas e a expectativa de ofertar mais $19 \mathrm{~m}^{3} / \mathrm{s}$ além de sua produção. Deverá ainda gerir investimentos da ordem de 3,2 bilhões de reais segundo seu Plano Diretor de Abastecimento de Água (PDAA, 2006), acompanhada da execução de todo um plano de investimentos que permitirá contabilizar mais $20 \mathrm{~m}^{3} / \mathrm{s}$ originários de programas para a recuperação de volumes perdidos em seus sistemas de distribuição, o que permitirá um mínimo de folga operacional a todo o sistema integrado. A expectativa é de reduzir de forma drástica a média dos volumes hoje perdidos para cerca da metade da hoje contabilizada considerando, no contexto, apenas as perdas reais.

Topologicamente, a RMSP conta prontamente apenas com as águas de suas principais bacias, a do Alto Tietê e a do Rio Piracicaba, e é avaliada a capacidade de uso das suas principais bacias circunvizinhas: a bacia do Alto Juquiá, bacia dos rios Itatinga e Itapanhaú, bacia dos rios Capivari e Monos, bacia do Rio São Lourenço, bacia do Alto Sorocaba e bacia do Paraíba do Sul, a partir de uma hierarquização que contemple além dos aspectos técnico-econômicos, os aspectos jurídicoinstitucionais e os ambientais (PDAA, 2006).

Conhecendo as limitações técnicas e de recursos, de forma a contribuir com uma melhor eficiência operacional para a recuperação dos volumes perdidos durante o 
transporte, redução de custos operacionais e no número e duração das intervenções, disseminação da tecnologia e 0 desenvolvimento de novas metodologias para atender à meta esperada - objetivo este com o qual este trabalho espera contribuir. 


\section{REVISÃO BIBLIOGRÁFICA}

\subsection{Sistemas de Abastecimento - Conceitos Fundamentais}

O sistema de abastecimento é composto por um conjunto de instalações (reservatórios, estações elevatórias), equipamentos (válvulas, medidores) e pela rede de distribuição, permitindo a pronta disponibilização de água tratada ao consumidor final, tendo preservada a mesma qualidade adquirida após seu tratamento, em quantidade e pressão adequadas. Esta demanda é proveniente de estações de tratamento onde, é introduzida num processo de filtragem e adições químicas que garantirão sua adequação para as diversas finalidades a que se prestam. Como meio de promover este transporte, é utilizada preferencialmente a força da gravidade e, na ausência desta, a aplicação de energia movimento, acrescendo pressão e velocidade, promovida por meio eletromecânico (recalque). Estes volumes de água tratada deverão ser conduzidos até centros de reservação de forma a amortecer as variações de demanda durante o dia e de onde seguirão, por meio de novos condutos até chegar ao seu consumidor, assim como ilustra a Figura 3.1 (adaptação de AZEVEDO NETTO et al., 1988).

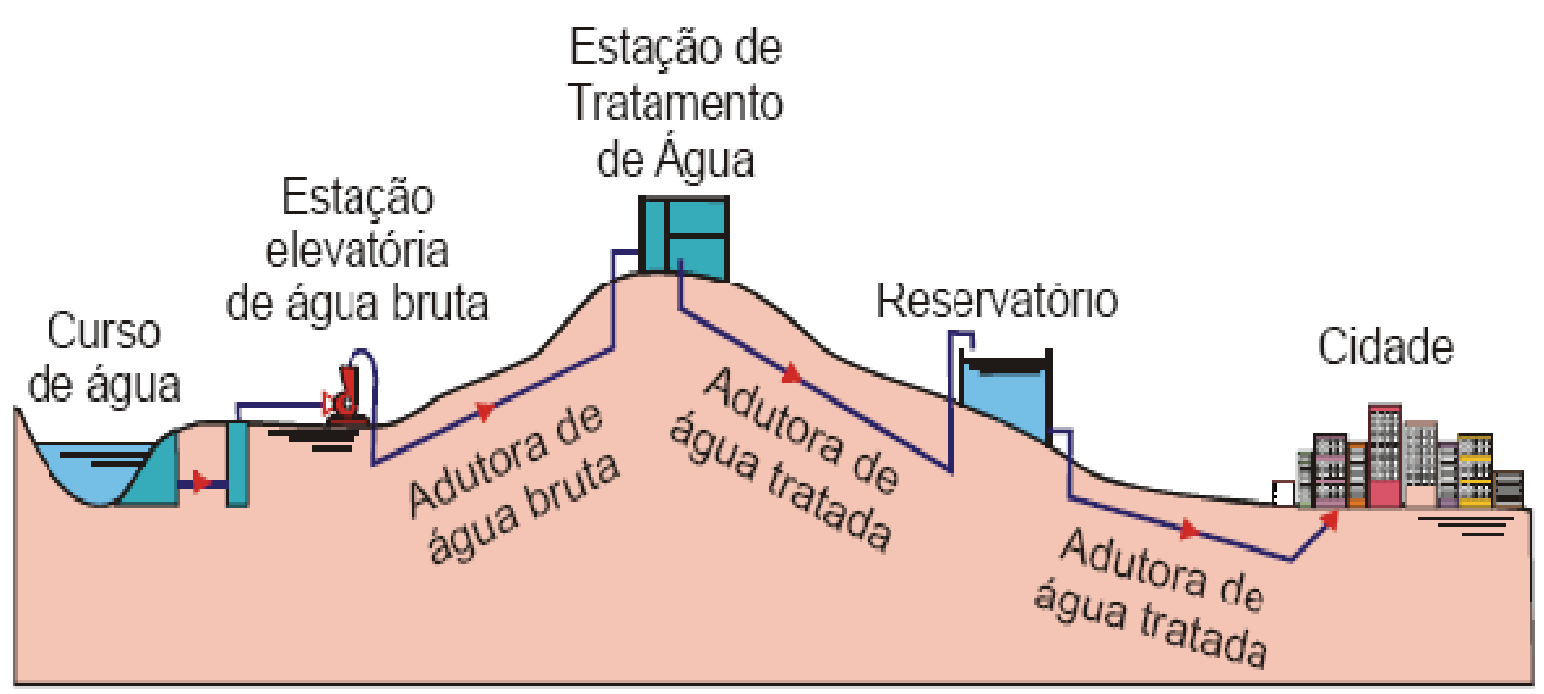

Figura 3.1- Esquema de Abastecimento de Água Fonte: PROCEL (2009) 
Tomando um setor de abastecimento como um sistema independente, com um único ponto de suprimento por meio de uma das adutoras que distribuem a água das estações de tratamento, cada um destes é definido conceitualmente como uma área limitada por meio de válvulas, tendo a sua rede suprida por um único reservatório de distribuição a montante. $\mathrm{Na}$ falta da reservação, o abastecimento é oriundo de uma derivação tomada diretamente de uma adutora que permita o suprimento desta região. Tal procedimento é altamente condenável, visto que um controle efetivo do abastecimento torna-se praticamente impossível diante das grandes oscilações de pressão em virtude da exigência de outros setores piezometricamente favorecidos e pela necessidade de amortecimento da variação horária de consumo, sujeita a picos em algumas horas do dia.

A Norma Técnica NBR 12218/1994 sugere como ideal pressões estáticas máximas nas tubulações de distribuição da ordem de $500 \mathrm{kPa}(50 \mathrm{mca})$, limitando a pressão dinâmica mínima em $100 \mathrm{kPa}$ (10 mca) no chamado ponto crítico. Oportunamente, pressões fora desta faixa podem ser admitidas, cabendo justificativa técnica e econômica. Assim, para a implantação de um sistema de abastecimento, a concepção das zonas de pressão é feita tomando-se por base estas limitações técnicas, justificando a criação de zonas de pressão dentro de um mesmo setor de abastecimento e o número de subdivisões é concebido em função de limitações altimétricas. As figuras 3.2 e 3.3 ilustram tal condição.

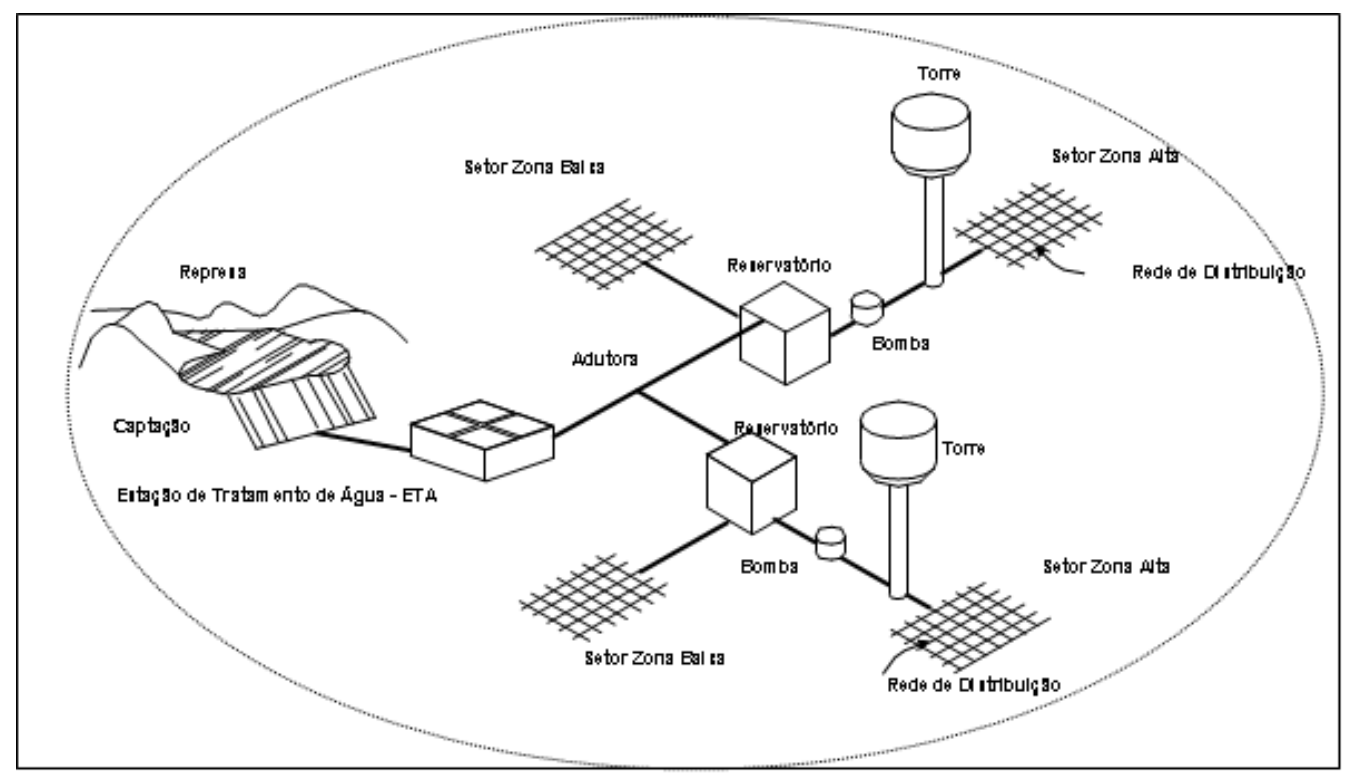

Figura 32 - Sistema de Abastecimento padrão

Fonte: SABESP (2009) 


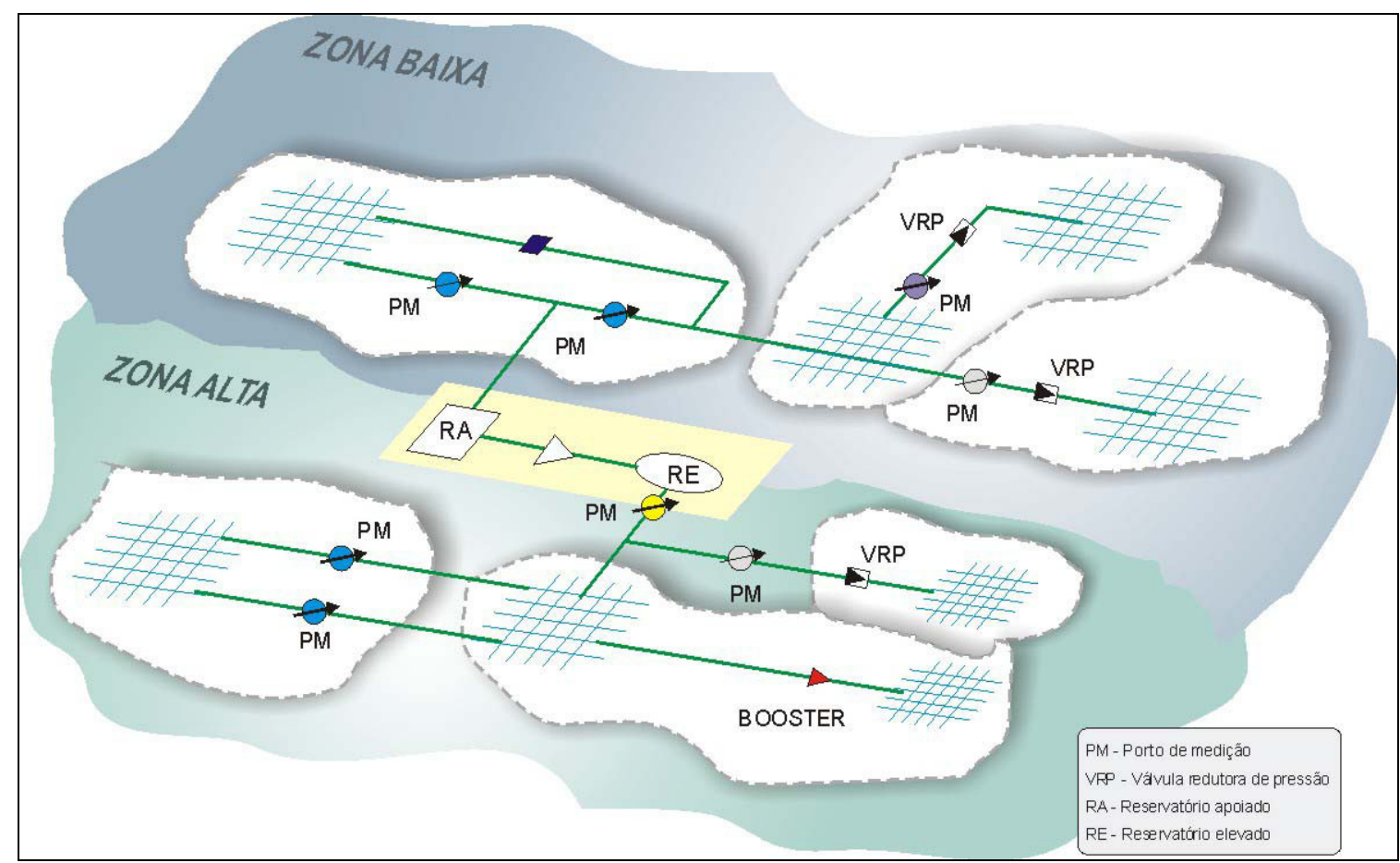

Figura 33 - Esquemático de Abastecimento de Água na Setorização Fonte: ARIKAWA (2005)

Definidos tais limites, cabe determinar a localização dos pontos mais desfavoráveis piezometricamente com o intuído de monitorar e garantir o atendimento aos requisitos técnicos de pressão e vazão. Vale ressaltar que tais pontos não são definitivos, visto que, com o passar do tempo, o comportamento da área muda e os denominados pontos críticos tendem a deslocar-se em função de fatores gerados pela iminente rugosidade da tubulação, pela instalação de novas redes, implantação de válvulas entre diversas outras razões, cabendo avaliar a viabilidade de adoção de novos pontos que garantam o atendimento aos requisitos mínimos de norma.

Para o estabelecimento do setor de abastecimento, é realizado um planejamento quanto a concepções técnicas da área a ser atendida por esta reservação, onde são definidos os limites de cada uma destas zonas de pressão e o fechamento de válvulas que delimitem as zonas de pressão e das válvulas e equipamentos que permitam adequar as vazões e pressões às limitações técnicas, assim como adequar redes que permitam a otimização operacional do setor - a denominada setorização.

De forma a permitir um efetivo controle sobre as variações de comportamento no setor, o mesmo pode ainda ser dividido em áreas menores, independente de sua 
condição piezométrica, temporárias como é o caso de regiões adotadas para o desenvolvimento de projetos-piloto para acompanhamento de resultados quando da avaliação de novas metodologias ou áreas sujeitas à condição especial, de caráter definitivo, como é o caso de áreas que dependam da continuidade de abastecimento aquém de intermitências sem plano de contingência, como é o caso de áreas destinadas a hospitais, delegacias ou ao corpo de bombeiros e afins.

Independente da necessidade que permeou a subdivisão do setor de abastecimento, é necessária a gestão dos volumes de água que as atendam, devendo-se promover seu isolamento diante dos demais setores limítrofes e de cada uma de suas subdivisões, condição esta que permitirá controle sobre a demanda ofertada e a efetivamente consumida, permitindo assim a gestão sobre os volumes de água admitidos, aqueles efetivamente consumidos e a elaboração de um balanço hídrico quantificando o quanto foi consumido e o que efetivamente foi perdido por meio de vazamentos.

Para acompanhar a grandiosidade em termos de números e a complexidade de sua gestão, a RMSP detém um complexo conjunto formado por $28.000 \mathrm{~km}$ de redes de distribuição pelas quais é conduzida uma demanda mensal de aproximadamente 71.000 l/s (PDAA, 2006; SABESP, 2007).

\subsubsection{Reservatórios}

São unidades destinadas ao armazenamento de água para amortecimento dos períodos de alta de consumo, variações influenciadas por fatores como a temperatura, dia da semana, hora do dia e demais razões que gerem altas e baixas, assim como garantir suprimento mínimo provocada pela pane ou manutenção programada do sistema de recalque. Pode ser enterrado, apoiado ou semi-apoiado conforme sugere a figura 3.4, construído em alvenaria ou em aço e dividido ou não por câmaras de forma a permitir menor um impacto por necessidade de intervenção. São representados por tanques como meio de permitir a continuidade do fluxo de entrada no sistema de abastecimento. Apesar de pouco recomendados, também podem ser do tipo elevado na forma de torres (fig. 3.5 ), onde garantam o suprimento 
das regiões mais altas, desfavorecidas piezometricamente. Por razões operacionais, os reservatórios elevados - ou torres - estão sendo gradualmente substituídos por sistemas de bombeamento dotado de variadores de velocidade a partir de reservatórios enterrados e apoiados.

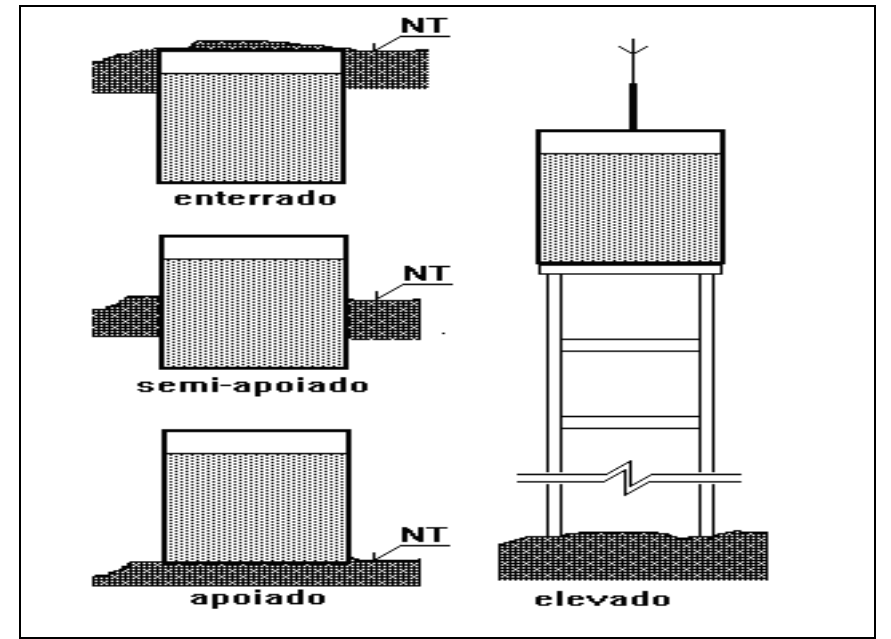

Figura 34 - Reservatórios com Relação do Terreno Fonte: http://www.dec.ufcg.edu.br/saneamento/Reserv01.html

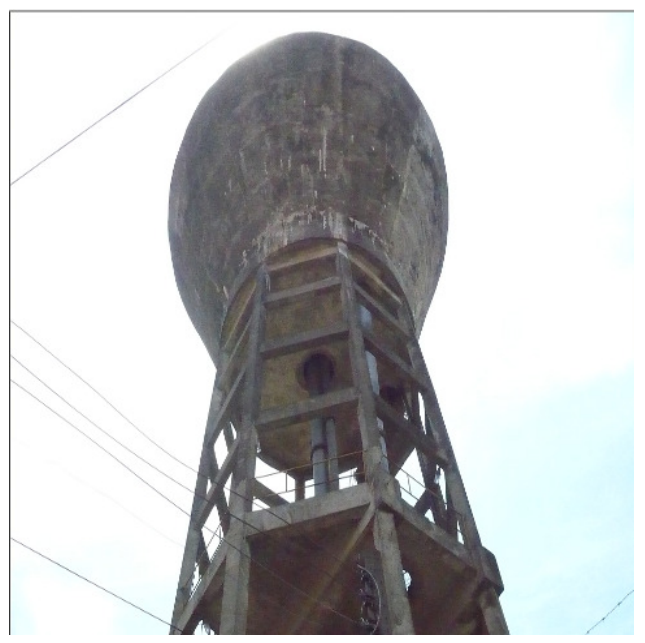

Figura 35 - Vista da Torre Sacomã Fonte: Sabesp, 2009

Um outro tipo de reservação encontrada é a do reservatório de sobras, com fluxo duplo de suprimento e reservação. Tal opção é considerada ruim pela falta de controle sobre as entradas e saídas dos volumes admitidos da mesma forma que a condição de derivações em marcha, atendendo provisoriamente às demandas de consumo, mas impossibilitando um controle eficaz das pressões no setor de abastecimento, continuidade da vazão e proteção de rede contra transientes.

\subsubsection{Estação Elevatória de Água, "Booster"e Variadores}

Um sistema de recalque - ou elevatório - é composto por um conjunto de tubulações, acessórios, bombas e motores (fig. 3.6 e 3.7) necessários ao transporte de uma determinada vazão de água de um reservatório instalado numa cota inferior para um segundo reservatório ou diretamente para um destino estabelecido numa cota mais alta. A energia elétrica ou a energia de combustão interna é assim transformada em energia cinética de pressurização que, cedida ao escoamento e acrescida de todas as perdas de carga distribuídas e localizadas requeridas pelas 
tubulações, permitindo assim seu transporte por meio das tubulações. (Adaptado de PORTO, 2001).

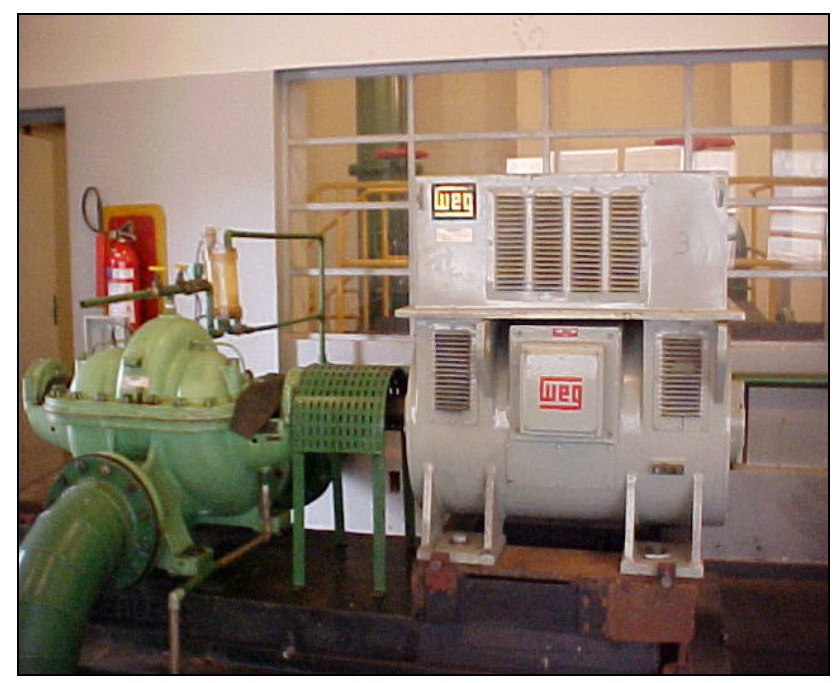

Figura 36 - Conjunto motor-bomba de Estação Elevatória Fonte: Sabesp, 2009

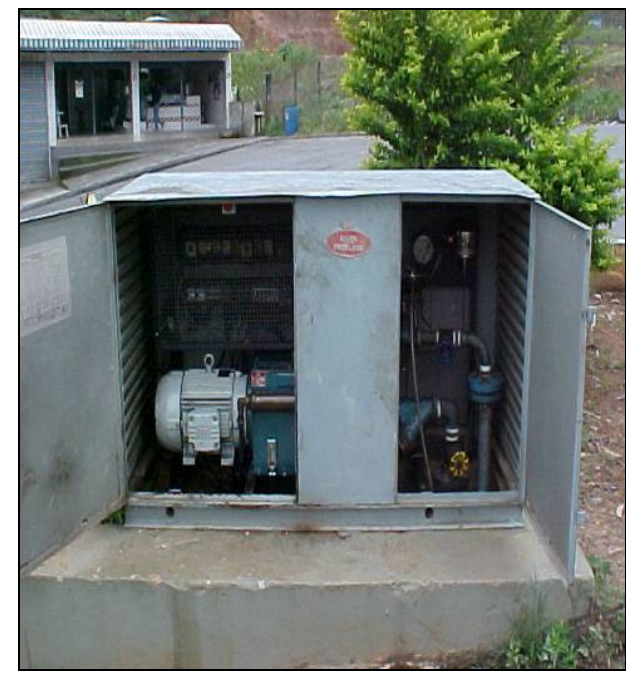

Figura 37 - "Booster" de rede Fonte: Sabesp, 2009

O "booster", por sua vez, é um equipamento auxiliar de recalque que permite reintroduzir pressão a rede, garantindo o abastecimento de pontos desfavoráveis e em regiões acidentadas que, em geral, estão sujeitas a maiores perdas de carga e a despressurização durante o transporte da água. Instalados, são utilizados tanto na adução quanto na distribuição, utilizando-se de conjuntos eletromecânicos dotados, na maioria das vezes, de variadores de rotação, como inversores de freqüência (Adaptado de TSUTIYA, 2004).

Os variadores de rotação são equipamentos eletromagnéticos, inversores estáticos de corrente elétrica, hidrocinéticos e principalmente por inversores de freqüência - o mais utilizado - que através de um sensor à distância permite o controle da variação de frequência resultando na mudança de rotação do conjunto motor-bomba. Este equipamento permite variar a curva de desempenho da bomba, mantendo o rendimento máximo do conjunto motor-bomba através da redução de pressão e vazão de recalque. Como o conjunto trabalhando continuamente, variando segundo a vazão necessária, o equipamento permite ainda o controle sobre o fator de potência da energia solicitado, sem promover picos de consumo provocados pelo acionamento, contribuindo com a redução de custos oriundos da variação deste fator (Adaptado de TSUTIYA, 2004; PROCEL, 2005). 
A utilização de bombas com velocidade fixa, controladas através de pressostatos para ligá-las e desligá-las, apesar de ter um custo de implantação mais baixo que bombas com variador de velocidade, apresentam como principal desvantagem uma potencialidade maior de gerar vazamentos e arrebentamentos na rede de distribuição decorrente da introdução de sucessivos golpes de aríete e da difícil análise de magnitude em virtude das inúmeras condições de contorno envolvidas. As bombas apresentam uma relação inversa da vazão com a carga (pressão), causando um aumento na vazão dos vazamentos nos momentos onde a demanda é menor. Isto pode ser minimizado com a aplicação de uma pressão de saída fixa em uma bomba com variador de velocidade. Portanto, a utilização de bombas com rotação variável, seja por variador hidrocinético ou por inversor de frequência, deve ser cuidadosamente planejada quando aplicadas às redes de distribuição.

Um estudo realizado pela SABESP, em 1989 (BRASIL, 2004), objetivando quantificar a redução de consumo de energia elétrica que um sistema de variador de velocidade, tipo inversor de frequência, apresenta em relação a um sistema convencional de velocidade fixa, chegou às seguintes conclusões:

- redução de consumo de energia em 38\%;

- redução de demanda de energia em $12 \%$, o que representa uma maior disponibilidade de energia na instalação geral e em sistemas de alta tensão;

- melhoria do fator de potência, dispensando a instalação de bancos estáticos de capacitores, o que representa, em algumas instalações, redução dos custos das mesmas;

- eliminação do pico de corrente na partida e, consequentemente, eliminação da queda de tensão, problema atacado com veemência pelas concessionárias, que exigem sistemas de partidas com limitação de corrente e queda de tensão;

- melhoria na condição de abastecimento, em função da limitação da pressão da rede de distribuição, evitando sobrepressões destrutivas nas mesmas, mantendo o sistema praticamente equilibrado; 
- eliminação (ou redução) de vazamento de água provocado por sobrepressão;

- aumento da vida útil do conjunto moto-bomba, em função da temperatura de trabalho do motor e da redução de velocidade do conjunto, apesar do aumento do tempo de operação;

- melhoria do impacto provocado pelo fenômeno destrutivo do golpe de aríete, devido ao desligamento suave através do circuito de rampa;

- retorno do custo de instalação em dois anos e meio, podendo ser menor em função da potência da instalação. No caso estudado, uma potência de 20 CV.

\subsubsection{VRP - Válvulas Reguladoras de Pressão}

As variações topográficas aliadas às perdas de carga de uma zona de pressão favorecem a utilização de válvulas reguladoras de pressão (fig. 3.8 e 3.9), visando manter pressões dentro da recomendação técnica da norma. O princípio básico da válvula reguladora é a manutenção de uma pressão fixa na sua saída. Assim, há três tipos básicos de controle de pressão com utilização da VRP:

1. Pressão de saída fixa (VRP sem controlador): é usado quando o sistema a ser controlado não tem mudanças significativas de demanda bem como perdas de carga relativamente pequenas (menores que 10 mca sob qualquer condição de operação);

2. Modulação por tempo: é usado para controlar um sistema que apresenta grande perda de carga (superior a $10 \mathrm{mca}$ ), porém de perfil regular de consumo. Assim, a válvula irá trabalhar com patamares de pressão de saída ajustadas no tempo; 
3. Modulação por vazão: é usado para controle em sistemas que apresentam grande perda de carga (grandes áreas) e mudanças no perfil de consumo que podem ser do tipo de uso, na sazonalidade ou na população (como no caso de cidades turísticas). Apesar de ser do tipo de controle mais eficiente, necessita de um controlador mais caro, além de um medidor de vazão.

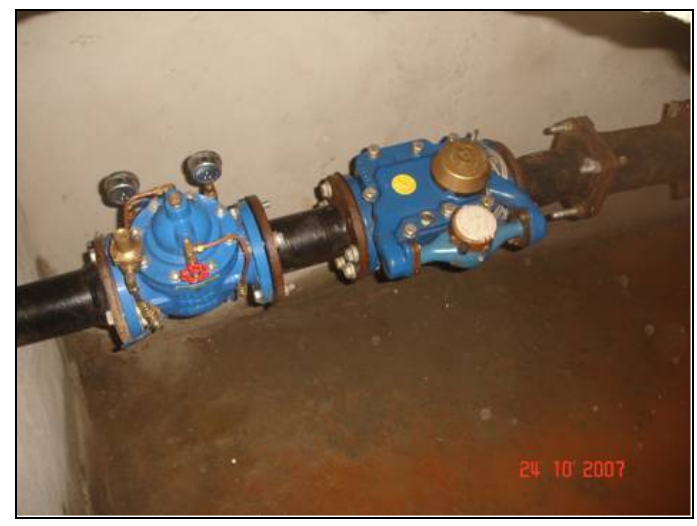

Figura 38 - VRP Instalada Fonte: Sabesp, 2009

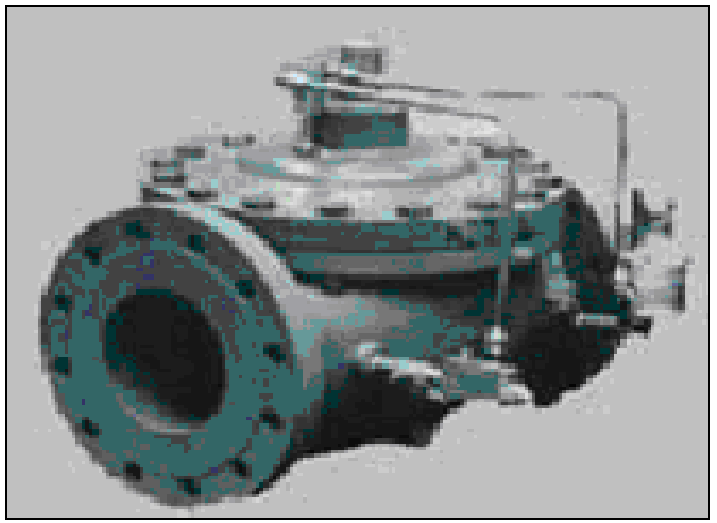

Figura 39 - Visão externa da VRP Fonte: Sabesp, 2009

Em locais já operados, a priorização de instalação de VRPs pode ser feita em função do histórico de incidência de vazamentos, alta pressão e índice de perdas elevado (BRASIL, 2004).

\subsubsection{As Redes Adutoras e as Redes de Distribuição}

Os sistemas de distribuição são compostos, de forma elementar, por reservatórios, estações elevatórias, redes adutoras e por toda a malha de distribuição. A malha, propriamente dita, é o conjunto de tubulações, conexões e acessórios de diversos diâmetros que se prolonga desde o reservatório até o cavalete de seu consumidor final. Tubulações fabricadas em materiais como aço, ferro, concreto e materiais plásticos que, de seção circular, revestidos ou não, servirão ao transporte de água, preservando sua qualidade e condições previstas em norma.

Os segmentos de redes de abastecimento dividem-se em: 
$\checkmark$ Redes adutoras: redes que se destinam ao suprimento da produção, de reservatórios e estações elevatórias. Grandes dutos, sifões e estações elevatórias servem à condução de água bruta da captação até as estações de tratamento e ao caminhamento de água tratada destas até os reservatórios de distribuição. São caracterizadas por grandes diâmetros e não admitem a alimentação de quaisquer outros tipos de rede ou de ligações residenciais (Yassuda \& Nogami apud AZEVEDO NETTO, 1973);

$\checkmark$ Redes primárias: conjunto de redes que serve ao suprimento de toda a malha de distribuição propriamente dita, ou seja, ao abastecimento exclusivo de redes secundárias. A conformação linear permite o controle de vazões nos trechos enquanto que circuitos fechados favorecem o controle sobre as variações de pressões no sistema. Não deve admitir ligações individuais.

$\checkmark$ Redes secundárias: conjunto de redes oriundas das redes primárias e que permite as tomadas de água por sua extensão (AZEVEDO NETTO et al, 1998; ITONAGA, 2005). Devem ser limitadas através de válvulas de bloqueio, permitindo assim seu isolamento em relação aos setores e subdivisões, de forma a garantir gestão independente dos setores circunvizinhos. Internamente, deve conter válvulas que permitam isolamentos menores para intervenções locais, mas que permaneçam constantemente abertas como meio de promover isolamento para intervenções locais com prejuízo mínimo aos demais moradores da área atendida. São as artérias propriamente ditas do Sistema de abastecimento (Adaptado de GOMES, 2004).

\subsubsection{Desgaste e a qualidade da rede de distribuição}

A rugosidade da tubulação é um fator crítico em razão das perdas de carga por ela provocadas e pelo material desprendido, calcário ou férrico, gerando reclamações por parte dos usuários motivadas por mudanças de coloração e de sabor e por possíveis danos estruturais a tubulação. Variam em função de padrões químicos, físicos e biológicos da água transportada, velocidade e pelos extremos de pressão e 
vazão a qual a tubulação fica submetida e pela qualidade do próprio material da qual são compostas, assim como de seus acessórios. Sua representação numérica é feita por coeficientes, os quais se destacam a equação de Hazen-Williams (1903), onde a rugosidade é representada pelo índice "C", reproduzindo matematicamente a natureza e o estado das paredes do tubo, e pela fórmula Universal ou de DarcyWeisbach (1850), representada pelo índice " $f$ ", representando o atrito em função de fatores como o número de Reynolds, rugosidade e dimensões da tubulação, sendo tais valores obtidos e reconhecidos em função de inúmeros estudos desenvolvidos. Tais formulações são utilizadas com boa eficiência na elaboração de dimensionamentos, estudos e, principalmente, de simulações hidráulicas (NOVAROSKI, 2005; ROSSMAN, 2000).

Conforme a NBR 12218/1994, norma atualmente em vigor no Brasil, a velocidade recomendada nas tubulações deve ser da ordem de 0,6 m/s (mínima) e 3,5 m/s (máxima). Entretanto, o limite máximo de $3,5 \mathrm{~m} / \mathrm{s}$ pode resultar em perda de carga relativamente alta, justificando cautela na sua adoção. Considera-se que uma velocidade máxima em torno de $2 \mathrm{~m} / \mathrm{s}$ possa ser admitida, o que permitirá operar o sistema com pressões mais estáveis.

A rugosidade da tubulação é um fator crítico com relação às perdas de carga distribuídas, merecendo um grande número de pesquisas devido a sua imprevisibilidade e as consequências que esta característica proporciona. A equação empírica de Hazen-Williams é reconhecidamente a mais utilizada na prática da engenharia sanitária, apesar de suas limitações quanto ao regime de escoamento laminar ou de transição a que esta é indicada, cabendo algumas reservas em cálculos de maior precisão. Para tanto, valores de coeficiente $\mathrm{C}$ de Hazen-Williams entre 90 e 140 são aceitáveis, conforme a idade e o material da tubulação. Por sua vez, a equação universal está também sujeita a limitações e, apesar de indicada a qualquer tipo de escoamento, requer cuidados poucas vezes considerados que acabam por repercutir em seus resultados. Sua pouca aplicação é decorrente de ordem operacional: variáveis como os defeitos de alinhamento, incrustações, tipo de acabamento, etc., que acabam por refletir na velocidade de escoamento (PORTO, 2001), fazendo-a complexa demais para muitas das aplicações a qual poderia ser utilizada. 
Tratando mais especificamente da equação de Hazen-Williams devido a sua ordem prática, a partir de amostragem de tubulações (como a da Figura 3.10), podem ser encontrados coeficientes de rugosidade " $\mathrm{C}$ " menores que 90. Isso ocorre com certa frequência em tubulações de ferro com idade superior a 40 anos ou em tubulações com grande aderência de sedimentos e que reduzem substancialmente seu diâmetro interno, comprometendo o fluxo a que antes estavam condicionadas. Valores baixos deste coeficiente levam à necessidade de reabilitação, ou seja, substituição desses trechos ou a técnicas de reconstituição, indicada especialmente para regiões de grande fluxo e de difícil intervenção, onde a interferência da obra cause grande perturbação nas atividades da cidade (trânsito, pedestres) - condição comum aos grandes centros urbanos. Tal reconstituição é ilustrada pela figura 3.10.

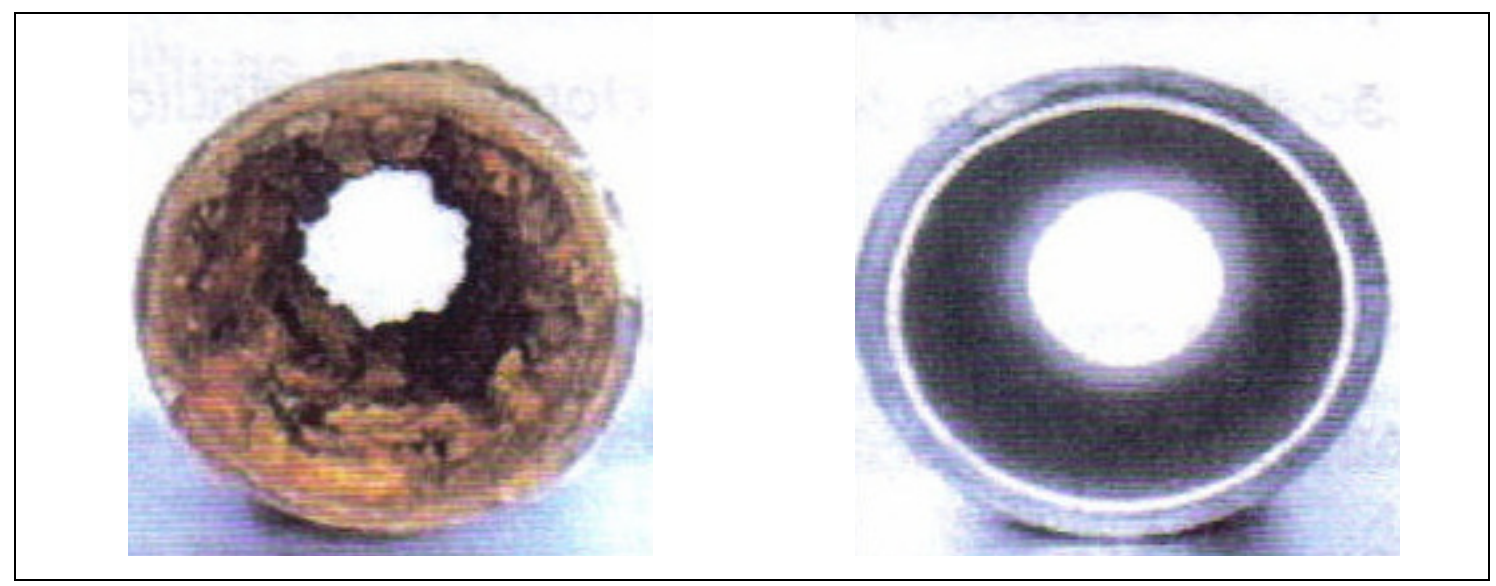

Figura 310 - Tubulação reabilitada com argamassa de Cimento

(A cor avermelhada caracteriza-se pelo arraste e aglomeração de material calcário e férrico e são de difícil previsibilidade de composição) Fonte: SABESP (2007)

A condição de rugosidade e a questão do revestimento interno da rede são cruciais quando o objetivo é a melhoria operacional do sistema de distribuição de água. No Brasil e por todo o mundo é muito comum o uso de redes de ferro fundido. O ferro só foi parcialmente substituído por razão da popularização do material plástico que, por minimizar os problemas com a rugosidade e qualidade, tornou-se muito disseminado a partir do final da década de 40 na Europa e somente a partir da década de 60 na América (SABESP, 2007; TSUTIYA, 2004).

As tubulações de materiais plásticos (PVC - Policloreto de Vinila, PE - Polietileno, PB - Polibutileno, etc.) têm sido largamente utilizadas pelas vantagens nos custos de aquisição e execução, além de não serem suscetíveis à corrosão e nem à 
formação de depósito de sedimentos com a mesma intensidade que tubulações de outros materiais. Têm sido largamente utilizadas em países como a República Tcheca, Reino Unido, Alemanha, França, Suíça e Lituânia, em porcentagem superior a $80 \%$ e, segundo relatório da IWSA - International Water Supply Association em 1995 (TSUTIYA, 2004), responsável pela elaboração de relatórios e divulgação de experiências de projeto e reabilitação em sistemas de distribuição, a maioria dos países que tem o ferro como principal material utilizado para a distribuição de água é porque ainda não reconheceu a praticidade do plástico. No Brasil, desde sua disseminação, quase a totalidade das redes de até $150 \mathrm{~mm}$ de diâmetro foram implantadas em PVC e, em municípios como Porto Alegre, mais de $500 \mathrm{~km}$ de redes com diâmetros de até $300 \mathrm{~mm}$ foram implantados (TSUTIYA, 2004), comprovando sua grande e progressiva aceitação e sua disseminação em relação aos seus antecessores metálicos.

As implicações decorrentes do assentamento e substituição das tubulações existentes significam a necessidade de abertura de trechos de vala aberta e todas as consequências desta forma de assentamento: desvios de tráfego, detecção de interferências ali instaladas anteriormente pelas demais concessionárias (telefonia, gás encanado e eletricidade), necessidade de recomposição de pisos especiais danificados e por questões de ordem burocrática, como a negociação de prazos e licenças por parte das autoridades envolvidas. Em casos extremos, justifica-se a aplicação de técnicas de intervenção não destrutiva que permite intervenções com proporcional praticidade e rapidez, mas que significa também proporcionalmente em maior custo para a obra.

A qualidade e durabilidade das tubulações podem ser afetadas por diversos fatores, tais como métodos incorretos de instalação (falta de mão de obra especializada), aplicação de material com qualidade inferior, ferramentas inadequadas, aquisição de tubulações com relação à classe de pressão não recomendada, risco de ocorrência de transientes e falta de garantias de efetivo controle do regime de pressão a que a tubulação será submetida (ARIKAWA, 2005; TARDELLI FILHO, 2004).

$\mathrm{Na}$ SABESP, principal operadora de serviços de saneamento na Região Metropolitana de São Paulo, grande parte das redes de distribuição sob sua 
responsabilidade foi assentada há mais de 50 anos e é constituída principalmente de ferro fundido. Tomando-se o exemplo do município de São Paulo, na região compreendida pela ilustração (figura 3.11), 30\% de um total de $5.800 \mathrm{~km}$ de redes de água que tem sua instalação datada em mais de meio século de idade, dentro de um total de $18.205 \mathrm{~km}$ do município e aproximadamente $28.000 \mathrm{~km}$ dentro da região por esta administrada na RMSP (SABESP, 2007). Apesar dos esforços aplicados para uma substituição gradual, a limitação de recursos para investimento cria uma disputa entre a reabilitação das redes antigas e a expansão de redes em novas áreas de atendimento. Neste contexto, cabe ao gestor avaliar as práticas que melhor permitam a otimização dos resultados.

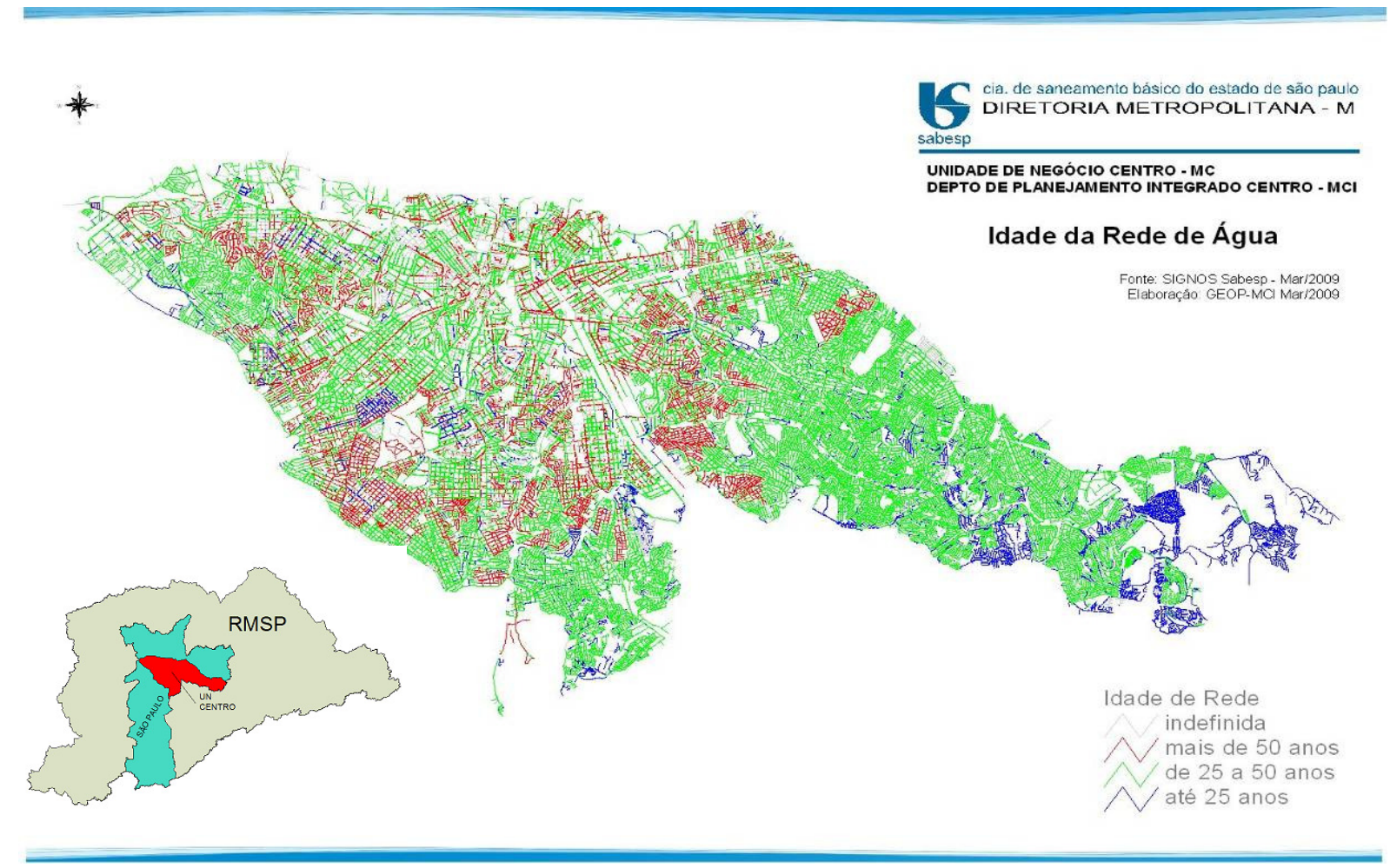

Figura 3 11- Faixa das idades de implantação das redes de distribuição de água Fonte: UN Centro - SABESP (atualização: dez/2008)

As redes mais antigas, geralmente, têm seus diâmetros reduzidos em função da agregação de sedimentos em seu interior, constituídos exclusivamente de material férrico. Para casos em que a intervenção seja complexa e que a solução mais viável seja a de raspagem interna da tubulação em razão das dificuldades de substituição, as tubulações necessitam possuir condições estruturais satisfatórias que permitam sua reabilitação com a retirada do material agregado à sua parede interna devido à 
tuberculização*, seguida do lançamento de um novo revestimento que deverá devolver à superfície interna da tubulação suas propriedades originais de rugosidade (TSUTIYA, 2004).

Em termos de custos, comparativamente, a Agência de Proteção ao Meio Ambiente dos Estados Unidos (USEPA) em estudo realizado, prevê um custo de 138 bilhões de dólares para a manutenção e substituição dos sistemas distribuidores existentes e, deste valor, uma estimativa de 77 bilhões de dólares voltada exclusivamente a técnicas de reabilitação e reparo das linhas de distribuição que são assentadas num total de $1.380 .800 \mathrm{~km}$ por todo o país, com expansão anual de aproximadamente 19.000 km (SELVAKUMAR et al., 2002). No município de São Paulo, a SABESP, através de seu Programa de Desenvolvimento Operacional prevê a troca e a recuperação de até $1 \%$ ao ano de todas as suas redes da Região Metropolitana, no horizonte dos próximos quinze anos, prevendo investimentos de cerca de 50 milhões de Reais ao ano, numa estimativa de $173 \mathrm{~km}$ de redes reabilitadas e $107 \mathrm{~km}$ de redes substituídas, dentro dos municípios por ela atendidos na RMSP (SABESP, 2008).

\subsection{Perdas em Sistemas de Distribuição}

Além das perdas em função do consumo extraordinário de energia elétrica nas estações de bombeamento e pela não geração de receita, como por conseqüência de fraude ou por submedição, considera-se como também como perda - real - todo o volume de água tratada disponibilizada através das redes de distribuição e que efetivamente não chega ao seu destino. Por razões técnicas e econômicas, não se deve esperar cálculos exatos do volume de perdas de cada área limítrofe, assim como a busca pela perda "zero" (MORAIS \& ALMEIDA, 2005). Se as o volume perdido for economicamente viável poderá ser tolerado em razão dos custos de recuperação do mesmo, o que infelizmente justifica um atraso tecnológico para muitos países em face de uma aparente autossuficiência.

$\left(^{*}\right)$ Tuberculização: provocada pela deposição de areia, silte, materiais orgânicos, alumínio, cal ou carbonato de cálcio quando sujeitas a baixas velocidades ou por fatores com alcalinidade, dureza, presença de sólidos em suspensão, temperatura e estado de superfície interna da própria tubulação, além dos elementos que produzem cor, tais como o ferro oxidado, o manganês e o cálcio). 
A quantificação das perdas é feita a partir da determinação de volumes perdidos e de índices comparativos adotados por todo o mundo. A disseminação da idéia de eficiência na gestão do sistema é obtida através de uma média móvel, de um período superior ao mensal, em razão dos efeitos das oscilações mensais e também a partir da vazão noturna, que permite uma análise mais precisa das perdas que efetivamente estão atuando na rede (GONÇALVES, 1998). Existem vários procedimentos de cálculos comparativos de perdas - o que permite hierarquizar 0 desempenho das empresas concessionárias. A mais conhecida é a que considera a diferença entre volumes macro e micromedidos, o que não retrata fielmente a razão de volumes em função, principalmente, da imprecisão dos hidrômetros utilizados e do efeito dos bolsões de ar.

Thornton (apud GALVÃO, 2007), trata o assunto da seguinte forma:

[...] A International Water Association (IWA) define duas categorias principais, sob as quais se classificam todos os tipos de perdas de água em sistemas de abastecimento:

- $\quad$ Perdas reais são as perdas físicas de água de um sistema de distribuição e incluem os vazamentos e extravasamentos, antes do ponto final de uso.

- $\quad$ Perdas aparentes são essencialmente perdas 'no papel' e se consistem em usos de consumidores que não são registrados devidos a erros de medição, avaliações incorretas dos usos não medidos, ou consumos não autorizados.

Segundo o PNCDA, a identificação e a segregação das perdas reais das aparentes são feitas mediante pesquisa de campo, utilizando uma metodologia para análise de registros contínuos e o consumo das vazões macromedidas. Nesse caso, a oferta noturna estabilizada durante a madrugada, subtraindo os consumos noturnos contínuos por parte de determinados usuários especiais (fábricas, hospitais e outros) representa, em sua quase totalidade, o volume de perdas físicas no período pesquisado, decorrente de vazamentos na rede ou ramais prediais. A perda não física será a diferença entre a perda total de água na distribuição (água não contabilizada) e a perda física levantada (BRASIL, 2004).

As perdas físicas podem ser divididas segundo sua visibilidade, conforme ilustra a Figura 3.12. A ilustração permite ainda avaliar os métodos mais comuns para a contenção e recuperação dos volumes de água perdidos. 


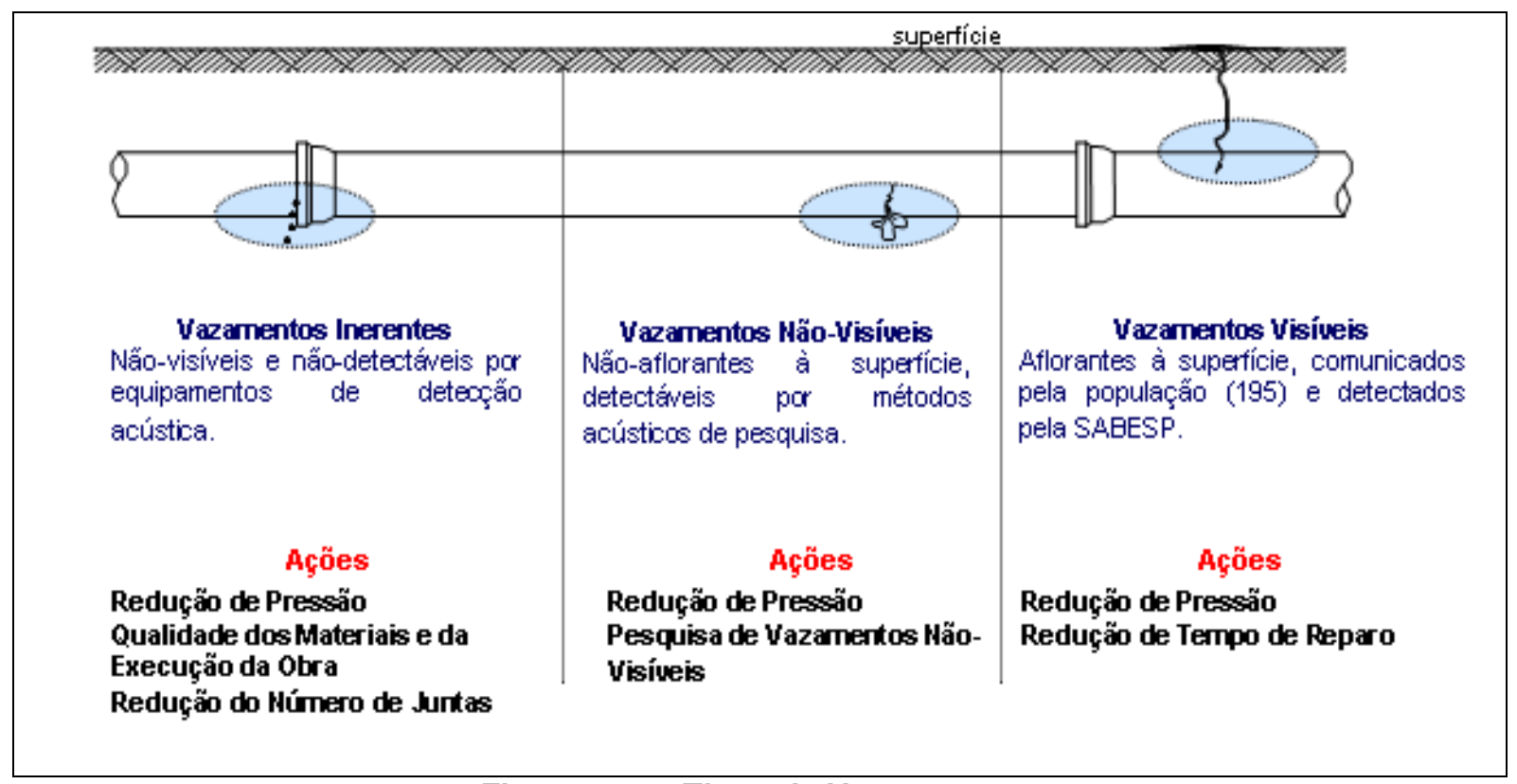

Figura 312 - Tipos de Vazamentos

Fonte: SABESP (2005)

Tratando-se especificamente de perdas reais, a questão a ser discutida é a estanqueidade do sistema e a ocorrência dos vazamentos ao longo do percurso, entre a produção e a disponibilização de água ao consumidor.

- Em geral, a principal ocorrência é a de vazamento através de ramais e cavaletes. É provocada especialmente por pressões elevadas e por grandes variações de pressão. Transientes hidráulicos, má qualidade dos materiais componentes do conjunto, má qualificação da mão-de-obra utilizada para sua instalação, inadequação de peças fundamentais como o ferrule (que servem como meio de conexão entre a rede e o cavalete da ligação, permitindo a entrega da água ao seu consumidor), intervenção de terceiros, intensidade de tráfego e deficiência de aterramento são razões que a influenciam o fenômeno dos vazamentos. É llustrada pela Figura 3.13.

- Vazamentos em redes e adutoras: Causadas pelo mesmo princípio, caracteriza-se por fissuras, rachaduras, arrebentados e deslocamento das conexões, sendo mais complexas e oriundas diretamente da tubulação. A necessidade de descobrir seus pontos exatos é condicionada ao uso de equipamentos de pesquisa como o geofone até que esta se permita visualizar, condição esta que pressupõe saturação da capacidade de 
drenagem do terreno e perdas substanciais dessas até o afloramento de águas, levando os usuários a solicitarem por manutenção. É ilustrada pela Figura 3.14.

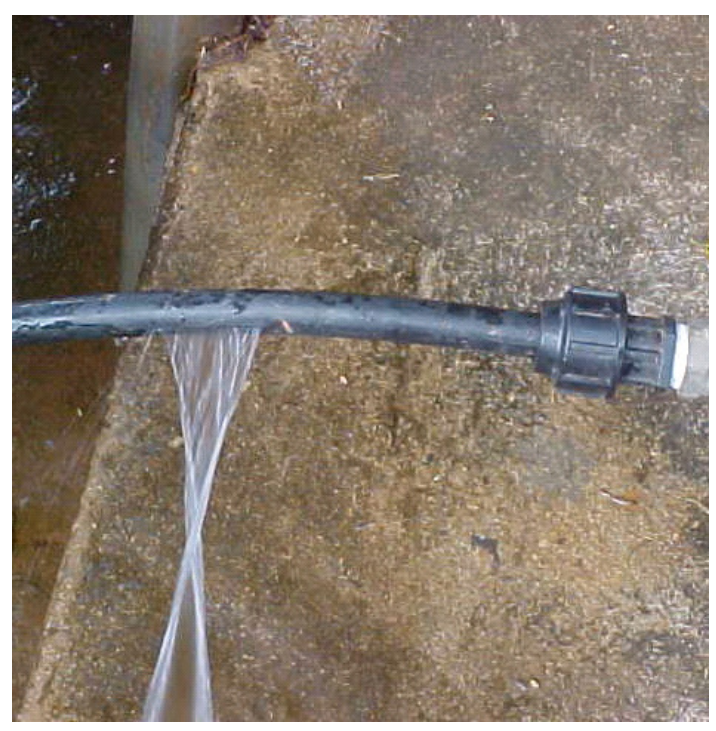

Figura 313 - Vazamento de ramal Fonte: SABESP

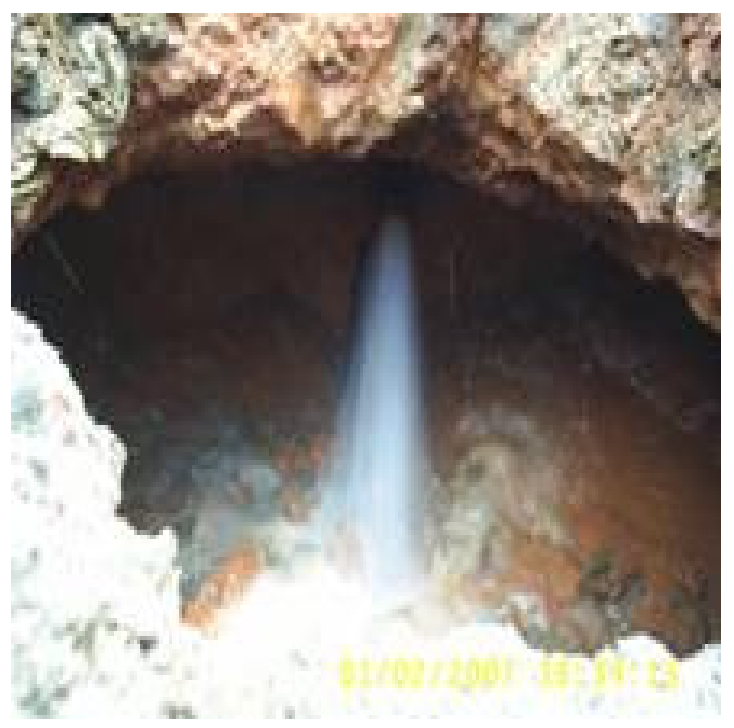

Figura 314 - Vazamento de Rede Fonte: SABESP

Vale ainda conceituar os denominados vazamentos inerentes que são quase que totalmente imperceptíveis: podem ser exemplificados pelo gotejamento decorrente de fissura de juntas de conexão ou por falha na estrutura da tubulação em região arenosa, reiterando assim a dificuldade da obtenção da perda-zero em condições comuns. A experiência profissional aloca este tipo de ocorrência na condição de inviável, tratando-se especificamente dos custos a serem aplicados para sua recuperação.

De fato, podem-se contabilizar perdas através da diferença entre vazões de entrada dos setores, as denominadas vazões macromedidas e as vazões micromedidas, contabilizadas através de hidrômetros, que permitem cobrança pelo volume consumido e, portanto, garantindo a sobrevivência da empresa concessionária, custeando a prestação dos serviços.

Para uma boa gestão dos volumes perdidos, é recomendada a instalação de medidores confiáveis nos reservatórios, válvulas reguladoras e em toda subdivisão do setor principal que mereça gerenciamento específico, permitindo o controle dos 
pontos críticos da rede, assim como o combate às fraudes. Políticas de controle sobre extravasamentos, transientes e demais perturbações que permitam fugas de maior âmbito e a execução rápida de reparos na rede de distribuição são a forma mais garantida de reduzir os índices de perdas a valores admissíveis (BRASIL, 2004).

As perdas não físicas ou aparentes apresentam um leque de variação bastante amplo, considerado o conceito de águas produzidas e consumidas que, porém, não são revertidas em faturamento. Com esta conceituação, as perdas não físicas podem ser decompostas nas seguintes causas:

- Ligações clandestinas / irregulares;

- Ausência de micromedição ou de quantitativo usado como volume operacional;

- Deficiências da macro e micromedição; e

- Gerenciamento ineficiente de consumidores.

Por não haver regra operacional além da efetiva fiscalização e gestão de volumes macro e micromedidos para a coibição deste tipo de ocorrência, obtém-se a mesma através da diferença das perdas totais e perdas reais (GOBBI, 2002). O desenvolvimento de novas tecnologias e maior precisão dos instrumentos de medição também permitirá avanços neste meio.

Estudos caracterizaram ainda o percentual de vazamentos segundo seu tipo. Vazamentos de ramal são responsáveis por $90 \%$ do total de ocorrências na RMSP (SABESP, 2004; ITONAGA, 2005):

\begin{tabular}{|c|c|c|c|}
\hline & $\begin{array}{c}\text { Vazamentos no tubo } \\
\text { do ramal }\end{array}$ & $\begin{array}{c}\text { Vazamentos nos } \\
\text { adaptadores }\end{array}$ & $\begin{array}{c}\text { Vazamentos nos } \\
\text { cavaletes }\end{array}$ \\
\hline Percentual (\%) & 40 & 20 & 40 \\
\hline
\end{tabular}

Tabela 31 - (Adaptado) Tipos de Vazamentos de Ramal.

Fonte: ITONAGA, 2005 


\begin{tabular}{|c|c|c|c|}
\hline & $\begin{array}{c}\text { Vazamentos não } \\
\text { visíveis e não } \\
\text { detectáveis }\end{array}$ & $\begin{array}{c}\text { Vazamentos não } \\
\text { visíveis e detectáveis } \\
\text { por métodos acústicos }\end{array}$ & $\begin{array}{c}\text { Vazamentos } \\
\text { visíveis }\end{array}$ \\
\hline Percentual (\%) & 25 & 30 & 45 \\
\hline
\end{tabular}

Tabela 32 - (Adaptado) Tipos de Vazamentos de Rede

Fonte: ITONAGA, 2005

\subsection{Os Modelos de Simulação}

Historicamente, a elaboração de um modelo reduzido, um projeto piloto ou testes de bancada eram, as melhores soluções para reproduzir condições naturais ou avaliar o comportamento diante de adversidades. Existiam até então grupos de profissionais cuja função era a de utilizar-se da experiência e das recomendações de um especialista, equações matemáticas disseminadas no meio hidráulico e amostras de dados, de forma manual, como a única forma de representar vantagens e desvantagens de uma determinada solução, convencer à tomadas de decisão e avaliar a expectativa de custos a serem empenhados. Alguns trabalhos mais complexos poderiam demorar anos e conduzir a contínuos gastos em função de adequações e ainda assim resultar em escolhas erradas. Com o advento da informática e o progresso da tecnologia da informação, foi possível transformar variáveis obtidas em bancada, adequar critérios e transformar uma gama de equações determinísticas da hidráulica em complexos algoritmos, permitindo infinitas interações e que em poucos segundos apontam resultados finais de boa qualidade, boa previsibilidade, ganho de tempo e economia de recursos.

A simulação pode ser definida como a técnica em que se fazem analogias, reproduzindo características físicas ou lógicas de um determinado conjunto, visando obter conclusões através do modelo, antecipando resultados e avaliando alternativas para solução. Tal ferramenta permite escolher a melhor destas, avaliando as consequências em todo o espaço simulado. No caso dos modelos de simulação para análise de sistemas de abastecimento de água, a analogia utilizada é a de atender ao maior número de variáveis ao algoritmo da programação, permitindo o comparativo de resultados das interações matemáticas do simulador com os dados obtidos em tomadas de amostragem em campo, corrigindo dispersões de forma a 
aproximar resultados, permitindo a investigação de causas e de possíveis consequências por intervenções, visando melhoria operacional.

Os modelos de simulação holística difere dos modelos de otimização por não apresentar natureza diretamente otimizante e sim descritiva. Tais modelos de simulação fazem a representação de um sistema para prever o seu comportamento, sob um dado conjunto de condições iniciais, de contorno e operativas (RIBEIRO, 2005), permitindo, entretanto, a otimização por meio indireto, pela avaliação da viabilidade de melhorias.

Os modelos matemáticos de simulação hidráulica, primariamente, podem ser assim classificados:

- Modelos de simulação estática: São algoritmos que efetuam o cálculo das pressões dos nós e vazões nos tubos, a partir de certa condição de carga fixa (por exemplo: nível do reservatório). São capazes de estimar uma só condição de carga, mediante a definição das características da rede e de certa condição de alimentação e demanda. Utilizam para a solução a Teoria Linear, Newton Raphson, etc. Sua utilização é geral e podem ser aplicados na análise de projeto de redes novas, ampliações e análises de condições de emergência;

- Modelos de simulação dinâmica (Período ou Tempo extensivo): Estes modelos assim como os estáticos, calculam as pressões nos nós e as vazões nos tubos, mas agora para diferentes condições de operação ao longo do tempo (por exemplo: variação do nível do reservatório ou de demandas nodais). São capazes de estimar a evolução de cargas nos nós, vazões nos tubos e níveis nos reservatórios de regularização durante um período definido. Mediante a definição das características da rede, das condições de adução e demanda de vazão para um dia (curva neutra de demanda), se determina a variação das condições hidráulicas na rede para o período de análise. Utilizam também a Teoria Linear, Newton Raphson, etc. Estes modelos podem ser aplicados a projetos de redes, determinação da 
capacidade dos reservatórios de alimentação e planejamento de políticas de bombeamento.

Cabrera \& Garcia e Luvizotto (apud GOBBI, 2002), em seus trabalhos, adicionam subdivisões aos modelos dinâmicos em função de variáveis de estado (carga e vazão), subdivididos entre inerciais e não Inerciais:

- Modelos Inerciais: Levam em consideração os efeitos inerciais da água e classificam-se em rígidos, quando não consideram os efeitos elásticos da água e da tubulação, sendo utilizados para descrever os fenômenos de oscilação de massa; e elásticos, quando os efeitos elásticos da água e da tubulação passam a ser considerados, sendo utilizados nas análises de transientes hidráulicos.

- Modelos não Inerciais: Nestes modelos a característica dinâmica não está associada aos efeitos de inércia e sim às variações temporais nas condições de contorno. São modelos usualmente utilizados nas simulações em período extensivo;

Winston (2004, apud GOBBI, 2002) complementou com mais duas subdivisões:

(a) Determinístico ou estocástico: Os modelos determinísticos, de resultados únicos, são os que, em suas formulações, não fazem uso de variáveis aleatórias em que os resultados obtidos são únicos. Os modelos estocásticos podem empregar uma ou mais variáveis aleatórias podendo obter resultados diversos;

(b) Discretos ou contínuos: São modelos discretos aqueles em que os avanços da contagem de tempo na simulação se dão na forma de incrementos, cujos valores podem ser definidos em função da ocorrência dos eventos ou pela determinação de um valor fixo. Nesses casos, só é possível determinar os valores das variáveis de estado do sistema nos instantes de atualização da contagem de tempo; enquanto para os modelos contínuos, o avanço da contagem de tempo na simulação dá-se de forma contínua, o que possibilita determinar os valores das variáveis de estado a qualquer instante. 
Ainda, segundo os procedimentos de cálculo e pesquisas utilizadas em suas rotinas, os modelos de simulação voltados à distribuição de água poderão ser classificados, segundo Bourguett, Fernandez e Tovar (apud GOBBI, 2002) como:

- Modelos de simulação de qualidade de água: A partir dos modelos de simulação estática ou dinâmica, efetuam concomitantemente o cálculo das pressões nos nós, vazões nos tubos e do decaimento (diminuição) da Concentração de uma Substância nas redes de distribuição, a partir de uma ou várias condições de carga. Geralmente se adicionam as equações que governam o comportamento de uma substância injetada no fluxo de água. São úteis para a análise da qualidade da água em todos os pontos da rede para estimar as concentrações, por exemplo, de cloro no tempo e no espaço, além de identificar zonas onde a qualidade da água se deteriora por estar parada ou com baixa velocidade. Também é possível analisar o efeito da mistura quando a rede é alimentada por duas ou mais fontes com qualidades distintas;

- Modelos de projetos e custo mínimo (com ou sem saída gráfica): Este tipo de modelo tem por objetivo calcular mediante algoritmos heurísticos, os diâmetros dos tubos, buscando cumprir certas restrições, como a pressão mínima de projeto, velocidade mínima e máxima, custos mínimos dos tubos, etc. São úteis em pequenas ampliações de redes ou em redes de tamanho pequeno. Utilizam como base de cálculo um modelo de simulação estática e economizam o tempo de trabalho do projetista, que normalmente faria por tentativa e erro;

- Modelos de projeto ótimo: Tem como objetivo o cálculo por meio de algoritmos de otimização, linear ou não, dos diâmetros dos tubos, buscando além de cumprir com certas restrições como, a pressão mínima de projeto, velocidade mínima ou máxima, custos das tubulações, etc. São úteis em ampliações da rede de qualquer tamanho. Utilizam como base de cálculo um modelo de simulação estática, e são, portanto, a segunda geração de modelos de otimização de custos; 
- Modelos de projeto ótimo custo - confiabilidade: Neste caso, o critério de projeto e análise não é só de custo mínimo; espera-se que a rede atenda além de custo mínimo, nível de confiabilidade na alimentação, tanto na vazão como na pressão, no tempo e no espaço. Estes modelos são de terceira geração dos modelos de projeto ótimo de redes;

- Modelos de calibração: Neste caso temos modelos que possibilitam uma mecanização dos processos de calibração de uma rede, a partir do modelo estático e de medições de campo. Dispõe-se também dos modelos com regras especializadas e de algoritmos lineares, não-lineares e de algoritmos genéticos nos processos de calibração;

- Modelos de reabilitação: Estes modelos possibilitam um sistema de suporte à decisão no processo de análise de substituição ou reabilitação de tubulações, a partir da análise de funcionamento da rede em simulação estática e análise de custos. Mediante uma função objetivo que é minimizar custos, se estabelecem restrições mediante a substituição ou reabilitação da tubulação, completando também as vazões e pressões de projeto. Existem algoritmos gerados com regras expressas e de algoritmos de otimização linear e não linear.

- Modelos para controle de vazamentos: Segundo Hindi \& Hamam (apud SOARES 2003), o controle de pressão no modelo tem a função de minimizar as perdas por vazamento, onde o objetivo do trabalho destes foi 0 de desenvolver modelos matemáticos e técnicas computacionais específicos para determinar a abertura de válvulas redutoras de pressão. Na primeira parte do trabalho, o problema é investigado para um conjunto conhecido de demandas e níveis de reservatório. Na segunda parte, um modelo é desenvolvido para minimizar as perdas quando diversos conjuntos de demandas são conhecidos. No trabalho apresentado pelos autores, os dois modelos desenvolvidos com sistemáticas de linearizações alternativas foram utilizados para a análise de diversos estudos de caso. Trabalhos com esta mesma iniciativa foram elaborados por GERMANOPOULOS e JOWITT (1989) e pelo próprio SOARES, em 2003. 
Muitos trabalhos foram desenvolvidos visando o planejamento e a antecipação de resultados, com foco na melhoria operacional. Para a localização ou para a definição de regras operacionais de VRPs em redes de distribuição. VAIRAVAMOORTHY \& LUMBERS (1998) trataram da otimização de abertura das válvulas para uma dada localização destas - sem considerar localizações ótimas - baseada em uma programação quadrática sequencial. SOARES (2003) aponta os trabalhos realizados por Gueli \& Pessinga, onde estes apresentaram trabalhos onde empregam Algoritmos Genéticos (AG), assim como Reis, Porto \& Chaudhry que desenvolveram, por sua vez, uma proposta de solucioção do problema de localização ótima de válvulas de controle de pressão em um sistema de distribuição de água, bem como o número de válvulas a adotar, via AG. O modelo de JOWITT \& XU (1990) foi utilizado para a avaliação hidráulica da rede e a determinação de aberturas otimizadas das válvulas, onde, partindo de um número máximo pré estabelecido de válvulas e demandas nos nós e níveis de reservatórios conhecidos, o algoritmo genético determina, simultaneamente a localização destas válvulas, maximizando a redução de vazamentos através de aberturas ótimas, considerando que os vazamentos são uma consequência direta dos defeitos da rede. Ainda, outra metodologia para a determinação dos parâmetros de vazamentos em redes de distribuição de água é apresentada também por LAMBERT \& HIRNER (2000) onde, utilizando dados extraídos das observações reais e aplicando análises estatísticas para o tratamento destes dados, os autores visam avaliar a eficiência hidráulica da rede, considerando nesta uma taxa mínima de vazamentos, já que sistemas estanques são considerados inexistentes. Os autores propõem ainda um estudo baseado em um balanço de massa envolvendo:

- O volume de água total que adentra o setor;

- Quanto ao faturamento: pago e o não pago;

- Perdas de água aparente (consumo não autorizado e medidores mal calibrados);

- Perdas de água reais (vazamento nas linhas de distribuição, conexões e medidores prediais e em reservatórios). 
Diversos autores são citados por SOARES, REIS e SILVA (2002) que, seguindo o exemplo de Fujiwara e Li, Tucciarelli, Tabesh e Karinzadeh e ainda Tanyimboh, reportam sobre o emprego de modelos de simulação hidráulica dirigidos pela pressão (MSHDP). Outros como Martinez e BARROSO (apud BARROSO, 2005) aplicaram os modelos pressão $\mathrm{x}$ demanda e pressão $\mathrm{x}$ vazamento internamente ao simulador hidráulico EPANET, intervindo no código-fonte do programa. Sem intervenção no código-fonte, autores como Hernandez construíram um procedimento iterativo com o auxílio do mesmo programa para avaliação e minimização de perdas por vazamentos, considerando demandas dirigidas pela pressão. O algoritmo utiliza técnicas de computação paralela, acarretando em uma diminuição expressiva do tempo computacional das simulações.

Focando a aplicação a sistemas de abastecimento, a programação é estruturada a partir da aplicação conjunta de métodos numéricos (Matrizes Esparsas, Equações Lineares, Eliminação Gaussiana e Newton-Raphson), formulações hidráulicas (fórmulas de Darcy-Weisbach e Hazen-Williams) de forma a permitir a reprodução de condições realísticas por meio de programas que, se devidamente condicionados a partir de técnicas de calibração, poderá representar fielmente o comportamento deste conjunto, diante da existência de uma nova rede ou da supressão de alguma destas ou mesmo impondo ao sistema um bombeamento que possa se mostrar mais eficiente, fornecendo assim subsídio à decisão. A ferramenta pode servir também à solução de problemas operacionais que eventualmente surjam para avaliar o comportamento hidráulico dentro de um contexto maior.

Em suas pesquisas, CESÁRIO, em 1995, já afirmava que aproximadamente 86\% das concessionárias de água no mundo já eram usuárias desse instrumento de planejamento, antevendo uma progressiva disseminação - o que provavelmente se confirmou, assim como adaptada a ferramenta a outros fins dentro, em especial, da análise de sistemas de abastecimento, exemplificada pelos estudos sobre previsão de transientes e monitoramento de qualidade da água, que a sucederam.

Os modelos de simulação hidráulica têm sido aplicados para analise de complexos sistemas de distribuição, com caráter de expansão, planos de manutenção e para estimar custos operacionais, bem como têm sido utilizados em muitos trabalhos 
acadêmicos com diversas finalidades de teste e avaliação de eficiência. Autores como GOBBI (2002), VIEGAS et al. (2002), AL-ZAHRANI \& MOIED (2003), SOARES (2003), CARRIJO (2004), GOMES (2004), RIBEIRO (2005), CHEUNG (2005), ITONAGA (2005), AKDOGAN (2004), BARROSO (2005) e GALVÃO (2007) são apenas alguns dos autores com trabalhos publicados que se utilizaram essa ferramenta.

Atualmente, com a evolução computacional e a capacidade de geração de resultados em segundos, este tipo de trabalho passou a ser muito mais simples e barato, tornando-se amplamente disseminado como instrumento de avaliação técnica.

\subsubsection{A calibração dos modelos}

Segundo WALSKY (2001), por mais cuidadoso que seja o levantamento de dados e o seu lançamento no simulador, o modelo jamais poderá representar completamente um sistema real em razão de tratar da reprodução do resultado das principais e equações matemáticas utilizando dados recebidos que podem ser tratados ou não, da onde a precisão dependerá do número de variáveis estudada.

A maior parte das informações é passível de falhas e não garante $100 \%$ de confiabilidade. Existe a necessidade de se verificar a consistência do modelo e observar o comportamento do todo sob algumas condições impostas, admitindo um aceitável percentual de erro em razão de fatores oriundos de pesos estabelecidos, rigor ou falta deste na coleta de dados, incerteza de variáveis e adequação a condições aquém das experimentais ou originárias de estudos anteriores (MORAIS e ALMEIDA, 2005).

As principais fontes de erro, segundo MORAIS e ALMEIDA (2005) são:

- Adoção de curvas de bomba inapropriadas em função do desgaste natural pelo uso ou substituição de componente;

- Perdas de carga a jusante das bombas; 
- Coeficientes de rugosidade dos condutos;

- Configuração e modo de funcionamento dos reservatórios;

- Vazões dos reservatórios;

- Erros na introdução de dados;

- Adequação das hipóteses significativas consideradas;

- Incerteza nas demandas.

A consulta a informações mais específicas que, à primeira vista, podem parecer fora de contexto, terminam por garantir a qualidade de resultados. No caso da distribuição de água, a oportunidade de aproximação na obtenção de dados com boa precisão, assim como visitas ao local, levantamento de histórico operacional e demais informações relevantes.

ORMSBEE e LINGIREDDY (1997) afirmam que a aplicabilidade dos modelos de redes hidráulicas depende da precisão de seus dados de entrada. Assim, o emprego de modelos de simulação de redes, por sua vez, requer que os parâmetros relevantes do ponto de vista hidráulico sejam identificados com vistas à reprodução (previsão) realística do comportamento do sistema, sob diferentes condições operacionais.

A técnica de calibração, segundo WALSKY (2001), consiste no processo de comparação do modelo com os dados reais observados e o seu ajuste até que este represente 0 desempenho esperado. $O$ processo pode conter correção das demandas de consumo, ajuste fino de rugosidade das tubulações, características de operação dos conjuntos motor-bomba, assim como o ajuste de outros atributos de forma a representar o mais fielmente possível a características reais da área estudada. O processo de calibração é necessário, pois:

- Os resultados simulados são frequentemente utilizados como regra de decisão e, portanto, há necessidade de garantir que o modelo se adapte a todas as condições esperadas; 
- Reproduzindo o desempenho da área estudada, permite-se através de uma análise mais cuidadosa reconhecer pontos vulneráveis do sistema de forma a corrigir fragilidade e melhorar seu desempenho, propondo adequações antes das mesmas tornarem-se críticas.

A calibração, segundo AKDOGAN (2004), consiste no ajuste de parâmetros (como os coeficientes de rugosidade ou demandas diferenciadas em razão da flexibilidade da solicitação por parte do consumidor) comparando-se com os valores obtidos em casos reais. Desta forma, o número de funções-objetivo fica reduzido a condições ainda mais satisfatórias e condizentes com a realidade.

Fatores como a imprecisão de coeficientes de rugosidade das tubulações, coerência de diâmetros e demandas de aplicação, pressão em locais determinados e de perdas geradas por vazamentos na rede justificam no mais completo dos modelos a necessidade da calibração. Os diversos autores pesquisados trabalham na elaboração de formas de calibração do sistema com boa aplicabilidade e desvios mínimos, utilizando-se de algoritmos genéticos e não-lineares, matrizes inversas, matriz de sensibilidade ou mesmo de métodos híbridos para soluções cada vez mais realísticas.

Num processo de calibração, são relacionadas por WALSKY (2001) as principais inconsistências correntes que merecem investigação:

1. Diâmetros nominais $x$ Diâmetros reais da tubulação;

2. Problemas com a rugosidade interna da tubulação;

3. Distribuição incorreta de demandas nos nós;

4. Erros cadastrais;

5. Variação de consumo durante o dia;

6. Simplificação demasiada do modelo;

7. Curvas características das bombas. 
O ponto chave da boa utilização de modelos matemáticos é a sua calibração. A verificação para que o modelo espelhe o sistema real, necessita da definição de quais e quantos pontos de medição de pressão e vazão são necessários e suficientes para essa análise.

Os pontos básicos que necessitam de medição são:

- $\quad$ Nível e vazão de reservatórios;

- V Vazão de "Booster" e VRPs;

- $\quad$ Pressões a montante e a jusante de "Booster" e VRPs; e

- $\quad$ Pressões nos pontos críticos.

Verifica-se que quanto maiores são as perdas de carga no sistema em estudo, maior será a quantidade de pontos de medição necessários para a calibração do modelo.

Somente após a certificação de calibração do modelo é possível utilizá-lo para simulações. Caso o modelo seja utilizado sem ter sido calibrado, as simulações decorrentes poderão levar a resultados completamente irreais.

Em seus trabalhos, SOARES, REIS e SILVA (2003b), investigaram a técnica denominada de problema inverso, onde dados de campo são inseridos na simulação e forçosamente obrigam o alinhamento dos demais dados onde, matematicamente, resultados de maior probabilidade duvidosa convergem de forma a adequar-se ao maior número de restrições impostas. Eles e muitos outros autores trataram de avaliar o uso do AG em suas pesquisas, o que permitiu processamento rápido e sua disseminação a uma grande variabilidade de usos em razão dos bons resultados obtidos em processos de calibração.

\section{Eficiência da Calibração}

O Water Research Center apresenta critérios para a avaliação dos resultados em tempo estendido (COLOMBO, 2007), segundo critérios estabelecidos na publicação 
da Hydraulic Research "Tables of Hydraulic Design of Pipes and Sewers" de 1983 (WALSKI, 2001) no Reino Unido, relacionada à diferença dos valores simulados ou observados:

Baseada nas demandas:

(1) As demandas iguais ou superiores a $10 \%$ da demanda total devem ter, no máximo, uma discrepância de até $5 \%$ da medida em campo;

(2) As demandas menores que os $10 \%$ da demanda devem ter uma discrepância de até $10 \%$ das medidas em campo;

Baseada nas pressões:

(1) $\pm 0,5$ mca em $85 \%$ das pressões medidas ou $\pm 5 \%$ da perda de carga máxima de todo o sistema, o que for maior;

(2) $\pm 0,75$ mca em $95 \%$ das pressões medidas ou $\pm 7,5 \%$ da perda de carga máxima de todo o sistema, o que for maior;

(3) $\pm 2,0$ mca em $100 \%$ das pressões medidas ou $\pm 15,0 \%$ da perda de carga máxima de todo o sistema, o que for maior.

Entretanto, a AWWA Engineering Computer Applications Committee, em 1999 (WALSKI, 2001), retrata que cada simulação requer medidas independentes, se referindo aos critérios de eficiência apenas como exemplos e não como padrões. $\mathrm{O}$ modelo será considerado calibrado se atender as necessidades de desenho, operação, manutenção e custos que o justificaram. Como observação, cabe ainda mencionar que tais quantitativos são recomendáveis em termos de redes adutoras e redes primárias, mas redes secundárias de distribuição não possuem critérios oficiais devido a pouca exploração dos seus meios de calibração, o que, em termos, viabiliza a concepção deste trabalho.

\subsubsection{Análise da simulação hidráulica}

Ao utilizar a equação de continuidade, estabelece-se uma condição de equilíbrio entre as redes de água e o suprimento solicitado. Sendo nula a soma algébrica das 
vazões em cada nó da rede e a vazão solicitada pelo reservatório ou derivação em marcha, se pode analisar os diversos trechos e as condições de resistência.

Para o cálculo das perdas de carga distribuída, geralmente são adotadas a equação de Hazen-Williams (de 1903) e a fórmula Universal (ou de Darcy-Weisbach, de 1857), apresentadas pelas fórmulas (1) e (2), respectivamente:

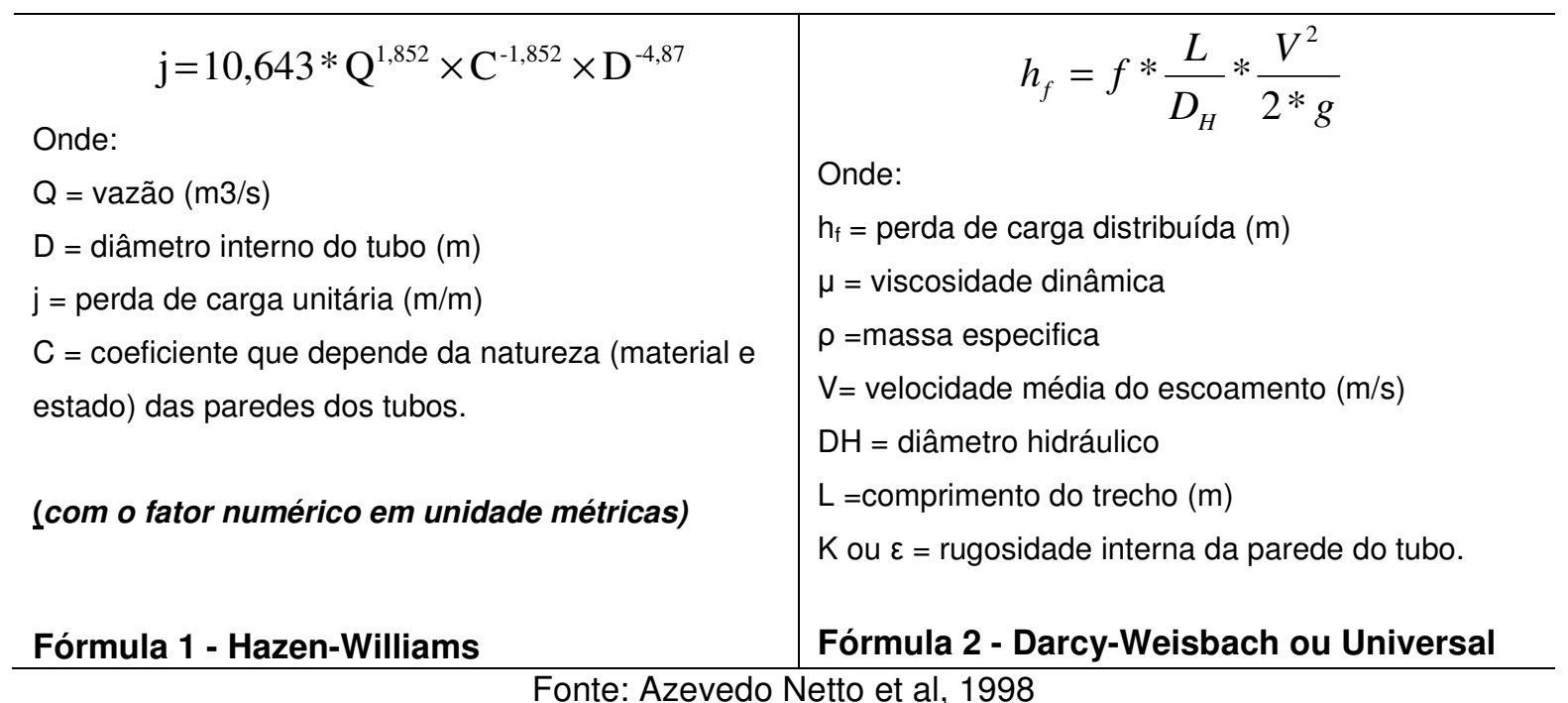
Fonte: Azevedo Netto et al, 1998

A norma que rege o uso da fórmula universal nos sistemas de distribuição de água, no Brasil, é a NBR 12218. Autores como AZEVEDO NETTO et al (1998) divergem do uso da mesma, justificando que o assunto transcende aos objetivos de uma normatização, devendo ficar a critério do projetista a escolha da fórmula a ser utilizada, relacionando o problema prático das imprecisões ao uso de fórmulas empíricas que não alterariam a ordem de grandeza dos resultados. PORTO (2001) por sua vez, reitera o uso da fórmula universal pelos projetistas devido a limitações da fórmula de Hazen-Williams que inviabilizam seu o uso, tais como temperatura, diâmetro e tipo de escoamento, parâmetros considerados pela fórmula universal e que, tratando-se especialmente das perdas de carga da condução de água, merece rigor máximo.

Assim, dois tipos de problema podem ser analisados (Orsini apud TSUTIYA, 2004):

1. Verificação da capacidade máxima da rede existente: consiste em determinar as vazões nos trechos e as cotas piezométricas nos nós, para uma rede com 
diâmetros e comprimentos conhecidos. Este problema é determinado e possui solução única;

2. Dimensionamento de rede: neste caso, devem-se determinar os diâmetros, vazões nos trechos e cotas piezométricas nos nós, com condicionamento nas velocidades e pressões. Este problema admite várias soluções, podendo procurar-se a solução de mínimo custo. Tal problema pode ser normalmente solucionado por tentativas de acordo com a seguinte sequência:

- Fixação de limites de pressão e de velocidade de escoamento para o bom funcionamento da rede;

- Admitem-se os valores para os diâmetros dos vários trechos em função das velocidades limites (as vazões são conhecidas)

- Calculam-se os valores das pressões nos pontos de interesse da rede;

- Verificar se as condições impostas de pressão estão sendo atendidas. Em caso contrário, alteram-se diâmetros admitidos e repetem-se os cálculos, até que as pressões resultantes estejam satisfatórias.

Condições especiais devem ser observadas e colocadas como condição de processamento para a análise, tais como limites estabelecidos de pressão nos domicílios, diâmetros comerciais ou especiais, velocidades máximas e sensibilidade da rede a efeitos de transientes e perdas singulares relevantes ao sistema.

Com a simulação em mãos, observados todos os fatores relevantes ao condicionamento do sistema, pode-se observar no relatório o comportamento do sistema, apontando pressões ou vazões negativas (impossíveis num sistema real, mas notadamente um alvo para adequação e correção no sistema daquele trecho ou nó) e os limites estabelecidos como condição. Através da simulação e das correções para atendimento destes fatores e com a visão de futuro do projeto, sabe-se se esta formulação de sistema atende às necessidades. Caso contrário, ainda em fase de 
estudo de concepção, pode-se avaliar formas de correção, tais como adequação de redes, instalação de válvulas especiais, "Boosters” ou novos reservatórios.

A modelagem é uma ferramenta muito útil para simulação do comportamento hidráulico de redes de distribuição. Para a utilização apenas nesse sentido (restringindo seu uso para controle da qualidade da água) pode-se trabalhar com um sistema de rede esboçado, onde só são introduzidas no modelo as suas tubulações principais. A prática de esboçar a rede requer certa experiência do usuário para não haver uma distorção com relação ao sistema real (BRASIL, 2004).

Já existem muitos programas no mercado internacional que podem muito bem ser utilizados no Brasil. Sua utilização pode auxiliar no dimensionamento e na escolha do sistema de controle de pressões (implantação de VRPs e "boosters", novo reservatório, reforço de rede, etc.), pois permite visualizar o comportamento da rede com suas variações de pressão em todos os pontos do sistema por períodos de 24 horas ou durante dias. O mesmo modelo pode ser usado posteriormente para simulações de condições operacionais excepcionais, decorrentes de necessidades de racionamento ou direcionamento da água para utilização num combate a um incêndio, por exemplo.

A Agência de Proteção ao Meio Ambiente dos Estados Unidos (U.S.EPA) disponibiliza, através da Internet, um modelo denominado EPANET, que embora possua ainda um sistema de entrada de dados não muito amigável, possibilita resultados gráficos satisfatórios para análise de pressões em pontos da rede, velocidade nas tubulações e qualidade de água, sendo recomendado como o programa ideal para um primeiro conhecimento da modelagem hidráulica. Em 2002 foi desenvolvida a primeira edição em Português pelo Laboratório Nacional de Engenharia Civil de Portugal e, em 2007, os professores do Laboratório de Eficiência Energética e Hidráulica em Saneamento da Universidade Federal da Paraíba (UFPB) desenvolveram sua versão traduzida e adaptada em português para o Brasil.

A escolha de um programa comercial de modelagem, com mais recursos que 0 EPANET, deve levar em conta as necessidades e as ferramentas já disponíveis, pois 
no mercado internacional existe uma gama desses programas, cada qual com suas peculiaridades.

Geralmente, quanto maior o número de recursos maior é a complexidade para o seu manuseio.

Os programas mais sofisticados permitem a alimentação de dados através do sistema SCADA - Supervisor Control And Data Acquisition, úteis quando o sistema de distribuição for complexo e dotado de controle à distância, além da utilização de bases georeferenciadas.

\subsubsection{Condições para uma modelagem eficiente}

\section{Confiabilidade das informações}

É fundamental o armazenamento de informações de toda a estrutura do sistema e sobre todas as redes de água e a pronta atualização de quaisquer alterações ou substituições a que estas estejam sujeitas. Dados operacionais como os volumes distribuídos, comportamento dos reservatórios, vazamentos e o controle de funcionamento das bombas nas estações elevatórias e "boosters", que permitem o gerenciamento do conjunto e garante meios para cobrir suas deficiências é da mesma forma importante quando da elaboração de uma simulação hidráulica. Regras minuciosamente reproduzidas serão determinantes à atuação do modelo.

Autores como CARRIJO (2004) e SOARES (2003) reconhecem a questão, expressando em seus trabalhos a questão da falta de confiabilidade e as dificuldades encontradas na elaboração de seus estudos de caso. Juntamente com a falta de garantia das previsões realizadas em cenários de ocupação populacional que não possuem regras e rotinas definidas, tais condições são de difícil controle efetivo, tornando-se dificultadores e criando descrédito da ferramenta por muitos dos técnicos envolvidos. 
II. A variação da demanda pelo fator noite-dia

É notório que residências típicas tenham um comportamento parecido, com picos de consumo nos horários das refeições, onde há um pico de consumo que tende a se reduzir, progressivamente, até a madrugada, reduzindo-se a um consumo mínimo. Nestes horários, por não haver consumo expressivo e nem a necessidade de bombeamento devido à flexibilidade proporcionada pelos reservatórios e caixas d'água, é fundamental a redução proporcional de volumes bombeados e a atuação de válvulas reguladoras de pressão, em razão deste aumento de pressão interna que promove e maximiza vazamentos nestes horários.

Dotados de comportamento diferenciado, os "não residenciais" (indústrias e comércios), em sua maior parte, desenvolvem um consumo regular em um horário próximo das $8 \mathrm{~h}$ e às $18 \mathrm{~h}$, quando grande parte da equipe e seus clientes provocam o fenômeno conhecido por população flutuante - muito comum em regiões turísticas e litorâneas, onde é necessária uma demanda de suprimento extraordinária em determinadas épocas do ano, feriados e em finais de semana - e atendimento a regimes especiais de abastecimento, como o de hospitais, delegacias e o corpo de bombeiros, que demandam, inclusive, de alternativas que permitam a continuidade do abastecimento ininterruptamente. Fenômenos como este geram curvas de consumo em função da hora do dia diferenciadas a cada setor de abastecimento, conforme suas características e as redes de água devem estar adequadas a sustentar tais demandas. Por sua vez, o projetista não pode simplesmente adotar a demanda máxima diária do sistema, pois tal procedimento acarreta num superdimensionamento das instalações, inviabilizando investimentos.

\subsubsection{Avanços nos estudos de otimização}

A pesquisa voltada à otimização por meio indireto, através do uso de simuladores de cunho heurístico para a operação de sistemas de abastecimento de água está sendo muito explorada pelos hidráulicos pela sua capacidade de fornecimento de um diagnóstico e os resultados dos trabalhos até este momento apresentados têm atendido cada vez às expectativas esperadas. Trabalhos de pós-graduação e 
congressos tem este tema amplamente retratado por grande parte dos autores já citados, contribuindo cada um destes com o desenvolvimento de novas tecnologias, contando alguns com simuladores e otimizadores desenvolvidos pelas universidades e outros com programas disponibilizados no mercado. Muitas destas pesquisas potencializaram as ferramentas mais disseminadas, assim como permitiram o desenvolvimento de novos algoritmos auxiliares, como os utilizados para facilitar a calibração ou a aplicação dos modelos de simulação em tempo real.

CARRIJO, em 2004, considerou que, em razão das condições topográficas das redes, são necessárias, algumas vezes, com o objetivo principal de corrigir falhas decorrentes de equívocos e simplificações feitas em demasia na fase do planejamento e projetos de redes de distribuição, recorrer-se às chamadas VCAs Válvulas de Controle Automático. Voltadas especialmente ao sustento, controle e a redução da carga de pressão, autores como Prescott e Ulanick, Poll, Brunone e Morelli e o próprio RIGHETTO (apud RIGHETTO, 2002) propõem-se a adequar tais válvulas ao modelo computacional utilizando o Método das Características, a partir de equações formais em condições transitórias de escoamento. Simpson (apud RIGHETTO, 2002) testou a eficiência de alguns programas comerciais no trato com tais válvulas e sustenta que, para alguns casos, os modelos não convergiam para solução adequada.

Outro fator importante constatado por CARRIJO em suas pesquisas é a questão da adequabilidade das simulações não só ao projeto e planejamento, mas também a fase de operação. Este ainda relata que autores como Zahed Filho e Souza trabalharam na aplicação de simulações na operação de sistemas de abastecimento em tempo real e sobre a pronta resposta do sistema ao realizar uma dada manobra. Relata sobre a simulação em períodos estendidos e sua aplicabilidade na operação, verificando se as pressões nos nós e nos pontos de reservação apresentam-se coerentes com a realidade, permitindo assim seu pronto uso como orientador de regras operacionais. Assim, vários modelos foram desenvolvidos com a finalidade de estudar a operação em tempo real nas etapas de projeto e planejamento, podendose citar os trabalhos feitos por Ral e Bref, Sousa e Silva, Simonovic, Rahal, Dandy e Kritpiphat. No mesmo contexto, porém utilizando-se uma combinação de um modelo de simulação e um modelo de riscos que incorpora a previsão de demanda, Zongxue 
desenvolveu um modelo aplicado ao sistema de abastecimento de Fukuoka, no Japão.

Fatores como a confiabilidade na operação do sistema foram retratados por autores como Tanyinboh, Ostfeld e Shistine tiveram a oportunidade de estudar, oportunamente, as formas de avaliar tal confiabilidade com pleno atendimento às demandas dos consumidores e na disponibilidade hídrica e operacional do sistema.

A complexidade do sistema e a necessidade de metodologia para simplificação dos sistemas mais complicados foram objeto de pesquisa de Anderson e Al-Jamal, em 1995 (CARRIJO 2004).

DIAS e GOMES propuseram regra de otimização para redes dotadas de estações de bombeamento, através de uma adaptação do algoritmo de Hansen, Medsen e Nielsen (apud DIAS e GOMES, 2002), quando um problema não-linear inteiro original é aproximado a cada interação de um problema de programação linear convertido em soluções inteiras adjacentes, e, através do método de Kessler e Shamir (apud DIAS e GOMES, 2002), para a indução de diâmetros comerciais da tubulação, são apontados os custos gerais de bombeamento e de operação das estações de recalque, permitindo soluções com custos mais baixos e tão eficientes quanto o método de algoritmos genéticos, porém com tempo de processamento consideravelmente menor.

\subsection{O Geoprocessamento como ferramenta de gestão de Sistemas de Distribuição de Água}

A topologia real das redes de distribuição de água nem sempre termina por ser a inicialmente projetada em razão, na maioria das vezes, de interferências não previstas num primeiro levantamento. Por esta razão, é exigido na entrega da obra o fornecimento das plantas que apontam as correções em relação a esta primeira versão do projeto - os denominados "As Builts" - plantas que mostram o que foi efetivamente implantado e que permitirá a médio e longo prazo a programação de reparos preventivos e adequações (LUVIZOTTO e RODRIGUES, 2002). 
Infelizmente, o cadastro sofre alterações que não são devidamente registradas por inúmeras razões - em especial por razões burocráticas - gerando dúvidas quanto à veracidade das informações que podem vir a ser essenciais para a operação do sistema e para a elaboração de simulações hidráulicas. Mudanças tais como a alteração no sentido original de escoamento, válvulas ora inexistentes ou limites de setor indefinidos que permitam a influência de um segundo setor em termos de vazão e pressão são dúvidas constantes e de difícil rastreabilidade, em visto ao objetivo de buscar um controle efetivo o e equilíbrio das pressões médias em todos os setores de abastecimento, do centro para as regiões periféricas, aproximando o comportamento piezométrico em ambas as faces das válvulas e permitindo por ali a passagem de água de um setor para o outro - inviabilizando a gestão sobre vazões e pressões dentro de um setor que, a princípio, deveria estar estanque (adaptado de SOARES, 2002).

O diagnóstico de rede pressupõe que se tenha como base um cadastro técnico confiável, dotado de todos os registros e informações úteis à caracterização do sistema de abastecimento e com todo o detalhamento necessário, assim como sugere CONEJO (1999):

- Detalhamentos como a indicação de cotas e redes componentes (adutoras e redes de distribuição);

- Informações de extensões, diâmetros, material e data da instalação da rede;

- Localização de conexões, peças especiais, válvulas, registros de manobra, "boosters", dispositivos para redução de pressão, etc.

Para facilitar a localização espacial das instalações e equipamentos do sistema de abastecimento e a consulta a suas propriedades, utiliza-se o Geoprocessamento, uma técnica muito disseminada internacionalmente, especialmente entre as companhias de saneamento, que demandam de velocidade e iteratividade entre informações e usuários dos serviços. 
$\mathrm{Na}$ literatura são encontradas várias definições para o Geoprocessamento (ou Geographical Information System - GIS), cada uma delas privilegiando um conceito ou um aspecto da tecnologia, uma vez que, por envolver várias áreas do conhecimento, é percebida de maneira diferente pelos especialistas de cada uma destas.

O instrumento pode ser resumido, conceitualmente, num conjunto de técnicas cumulativas, utilizando-se de programas computacionais, funcionando em um ambiente único e em equipamentos adequados à aplicação de determinada organização e que, utilizando recursos de computação gráfica, associa dados geográficos a bancos de dados convencionais (fig. 3.15). Esta tecnologia possibilita a recuperação de informações, baseadas na localização espacial de dados, trazendo ao gestor uma visão privilegiada da situação de sua organização e interrelacionando várias condições comuns como à cartografia e a topografia (informações geográficas) até então só disponibilizadas em outros recursos, como plantas em papel ou ferramentas digitais específicas de difícil adequação e correção das informações (FRANCO, 2000).

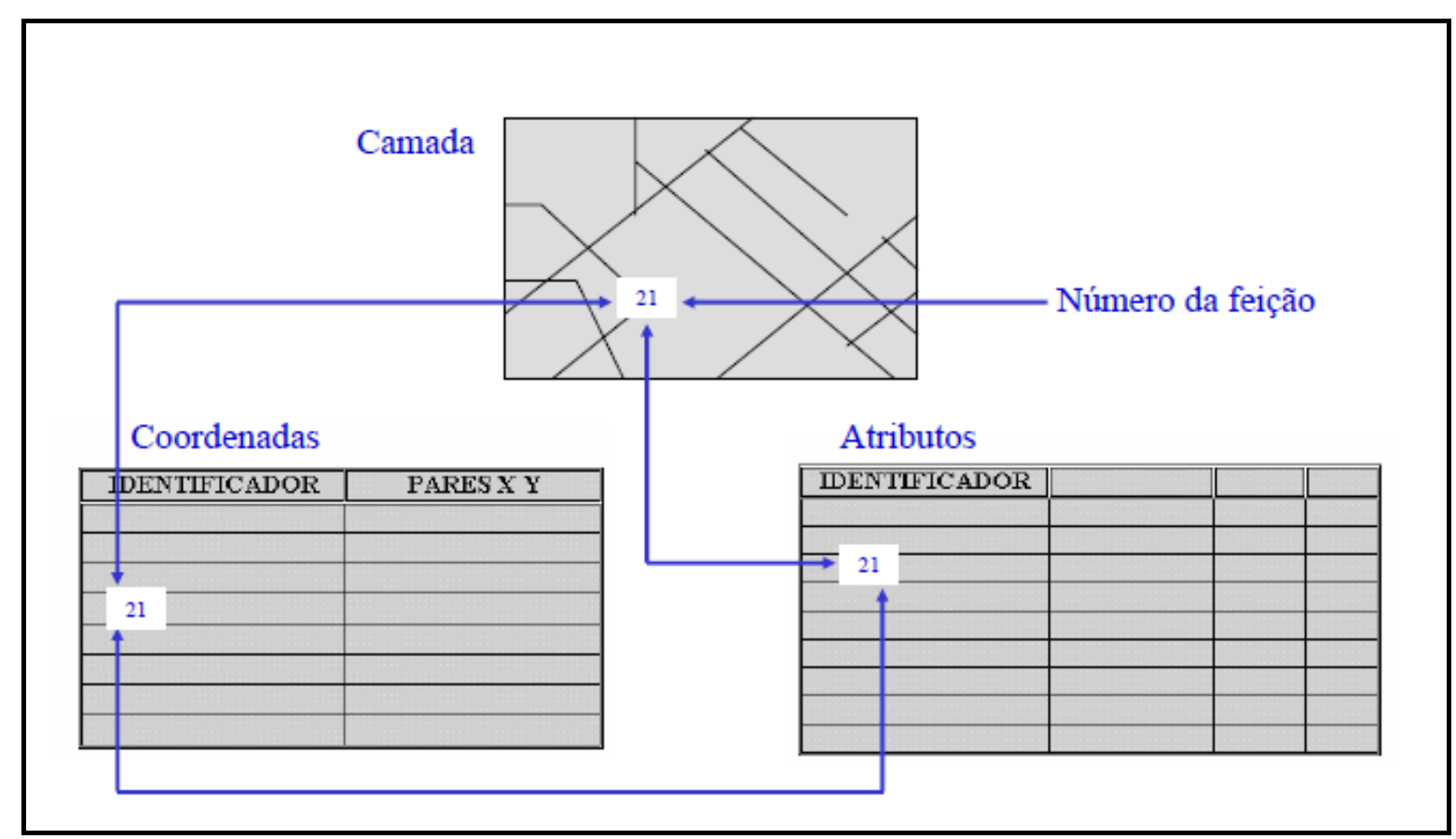

Figura 315 - Ligação entre feições (camada), coordenadas e atributos (dados). Fonte: PROVARZEA, 2ำ Sem/2004 
Essa tecnologia tem sido largamente aplicada em ramos como a do meio ambiente, agronegócios e transportes, possuindo aplicação reconhecida nas especialidades que envolvam, principalmente, a função territorial e geográfica, permitindo a troca de informações entre as empresas que trabalham numa área comum. Problemas relacionados às interferências entre concessionárias constantemente atrasam e dificultam tarefas que poderiam ser rapidamente executadas e incidindo em maiores custos em se tratando de reparos a propriedade da empresa prejudicada (TAVARES, 2001).

A principal aplicação da ferramenta é justamente como instrumento de gestão, conferência remota das informações prestadas e levantamentos, dividindo as responsabilidades pela atualização entre todos os envolvidos em cada etapa, ou seja, da estrutura operacional diretamente pelas equipes que realizam serviços de reparo, das equipes da área comercial, de planejamento e de projeto. Além das técnicas estatísticas espaciais, há também muitas outras ferramentas analíticas espaciais incorporadas aos SIGs, que incluem análises de padrão, interpolação, transformação de coordenadas e algoritmos de classificação.

Para os SIGs, conceitos como os de escala gráfica, projeções, projeção UTM, legenda, mapas digitais e temáticos, entre outros, são bastante utilizados e confirmam o papel vital da cartografia nestes sistemas, pois fornecem princípios de desenho/produção de mapas, leitura e interpretação dos mesmos.

Segundo SIMÃO \& RODRIGUES (2003), a importância dos SIGs em sistemas de abastecimento podem ser resumidos por:

1. Possibilitar a identificação dos condutos sujeitos à intervenção e suas características (diâmetro, material, classes de pressão, tipo de juntas, etc.);

2. Facilitar a imediata identificação de registros para fechamento no isolamento de zona de abastecimento e, simultaneamente, de descargas a abrir; 
3. Conhecendo-se a rede secundária sujeita à interrupção no abastecimento, é possível identificar o número de clientes afetados que poderão ser comunicados previamente da intervenção;

4. Permitir incorrer em várias economias: redução do desperdício de água caso a intervenção seja de natureza corretiva, otimização de recursos (humanos, financeiros e energéticos) e minimização do desgaste da imagem da concessionária, enquanto serviço essencial à comunidade. A otimização de recursos é promovida, por exemplo, pela redução do número de visitas ao local de intervenção, redução do tempo da manutenção, etc.

O SIG é, a mais de uma década, reconhecidamente como uma das ferramentas preferenciais para a criação de um cadastro único informatizado (Cubillo et al., 1997; Gonçalves, 1996). A capacidade de armazenar simultaneamente informações alfanuméricas e cartográficas e de relacioná-las, permitindo a visualização e análise integrada (Goodchild, 1988; Maguire, 1991), ainda que limitadas no entender de autores como Openshaw (1991) e Simão (2000) são as razões determinantes de sua importância (SIMÃO \& RODRIGUES, 2003).

\subsubsection{Aplicações dos SIGs}

Segundo Rodrigues (apud FRANCO, 2000) áreas como Geologia, Hidrologia, Agricultura, Urbanismo e das engenharias Civil, de Transportes e de Minas estão ligadas à atuação do homem sobre o meio físico, em atividades cuja análise combina manipulação de mapas e dados, como por exemplo:

- Projeto de vias (rodovias, ferrovias, canais, etc.) de irrigação, de loteamentos, drenagem, etc.;

- Operação de redes de utilidades (água, esgoto, gás, telefone, eletricidade,,.. );

- Planejamento urbano, regional, agrícola ou de transporte;

- Análise espacial ambiental, geológica, urbana, regional e de transportes; 
- Gerenciamento de processos agrícolas e de variados processos de distribuição e alocação;

- Monitoramento de processos ambientais, urbanos e regionais;

- Gerenciamento de redes de utilidade, equipamentos, etc.

A abordagem conceitual e básica de todas as aplicações tem em comum a estrutura da tecnologia dos SIGs. Além disso, um Sistema de Informações Geográficas é muito mais do que um conjunto de programas computacionais, exigindo um conhecimento da área de aplicação, da organização, da teoria de modelagem das informações e das várias fases, componentes e modelagens.

Ao longo do desenvolvimento da presente pesquisa, considerou-se importante aprofundar um pouco mais sobre estes conceitos, não para implantar um SIG, mas para tê-lo como referência no desenvolvimento de produtos cartográficos digitais para análise visual. 


\section{DESENVOLVIMENTO E METODOLOGIA}

Através da integração das bases de dados de um sistema de distribuição de água propõe-se criar uma metodologia de elaboração e análise de dados para a montagem de uma simulação hidráulica das redes primárias e secundárias para avaliação e melhoria do desempenho operacional de setores de abastecimento de água. Os consumos utilizados na simulação hidráulica serão obtidos a partir de uma base comercial, apontadas ali seus consumos micromedidos, de onde será tomada uma média de 12 meses. Será acrescida uma vazão média de perdas, determinada através da diferença entre os valores macro e micromedidos.

Serão utilizados o programa de simulação hidráulica Bentley / Haestad - WaterCAD 8i 500 tubos e o programa ESRI, Inc.- ArcView 3.1.1 para Geoprocessamento, de propriedade e sob licença da companhia concessionária. A base SIG contratada pela empresa está na plataforma Smallworld (GE), permitindo assim a integração e a disponibilização de suas bases de dados remotamente atualizadas para a realização de suas atividades de alimentação de dados, consulta e processamento de informações.

O programa de simulação hidráulica deverá receber os dados previamente selecionados, excetuando-se instalações, redes e ligações que não façam parte do setor, mesmo que fisicamente dentro de sua área de abrangência. Tais informações serão oriundas do SIG, Cadastro Comercial e do Cadastro Técnico que deverão ser organizadas e na ferramenta de Geoprocessamento, de forma a permitir sua integração:

1. Será produzido um modelo do tipo EPS (simulação em tempo estendido) que compreenda um comportamento dinâmico. Para tanto, adotou-se a curva de modulação de consumo, composta por fatores de multiplicação com padrão temporal proposta por TSUTIYA (2004), de forma a representar a variação de demanda de abastecimento no setor durante 24 horas, conforme ilustra a Figura 4.1: 


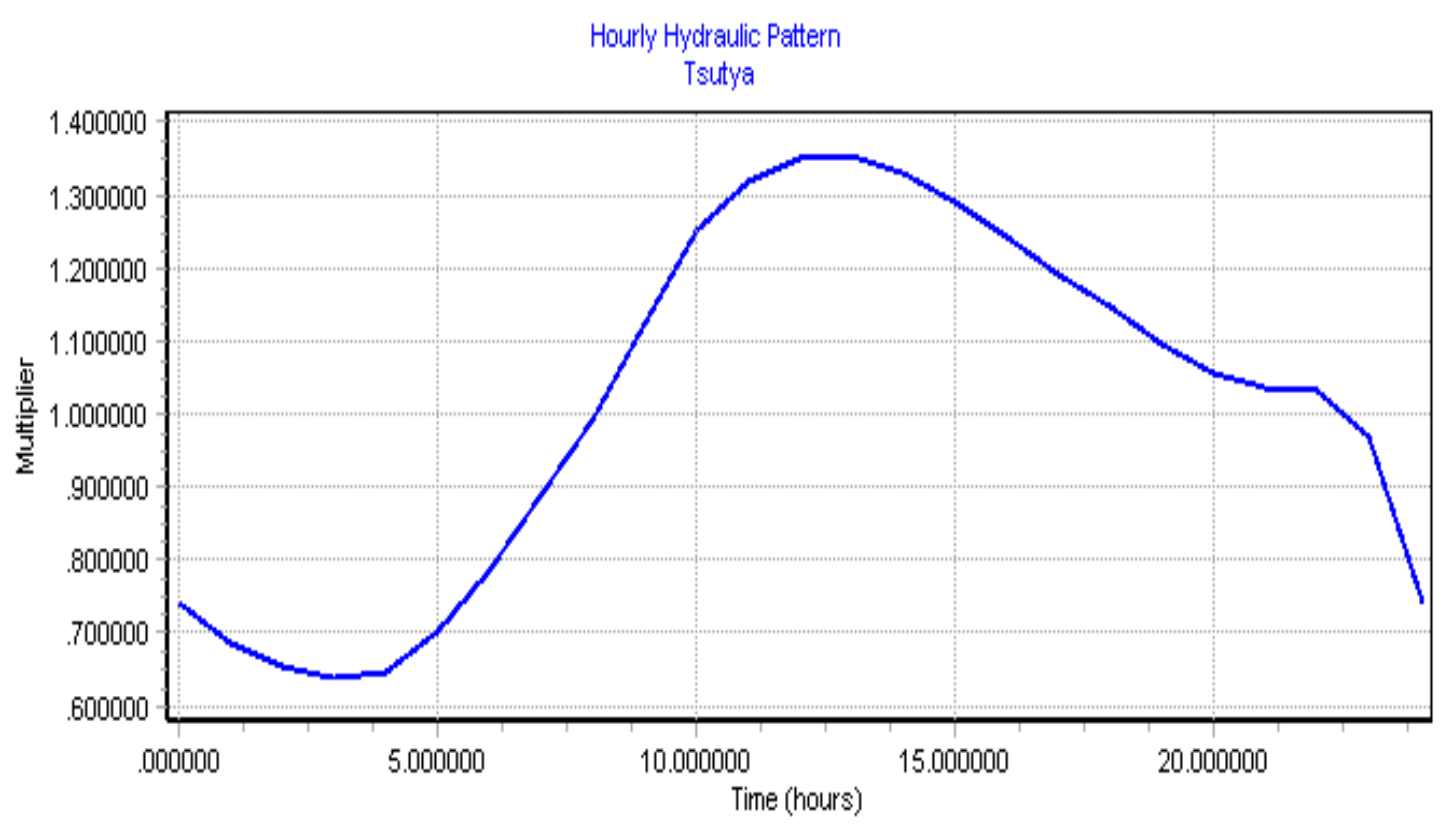

Figura 41 - Curva neutra para modulação temporal de consumo nos nós Fonte: TSUTIYA, 2009

2. TUBULAÇÔES:

- Informações relevantes às tubulações (extensão, diâmetro e material), para a proporcional reprodução de seu segmento;

- Os tubos estarão ligados através de nós, onde estará concentrada toda a demanda que suprirá as subdivisões do setor, assim como suas extremidades;

- A data de instalação da tubulação corresponderá a um determinado coeficiente que represente a sua rugosidade, segundo seu diâmetro e material;

- Para seu equacionamento, foi adotada a equação de Hazen-Williams;

- Excepcionalmente, redes implantadas com idade desconhecida deverão admitir a caracterização de idade da mais velha existente no conjunto como critério de segurança;

3. NÓS

- Os nós serão definidos a partir uma somatória de ligações definidas pelo critério de proximidade. Os volumes (ou demandas de consumo) serão calculados a partir da média de consumo mensal destas ligações durante 
12 meses. Estes deverão ser somados, definindo a demanda do respectivo nó e posteriormente deverão ser somados a um percentual de perdas a ser definido;

- A cota geométrica será definida pela maior das cotas das ligações, obtidas segundo curvas de nível;

\section{SISTEMAS MECÂNICOS}

- O modelo será alimentado com informações obtidas dos equipamentos já instalados de forma a reproduzir seu funcionamento. Será utilizada a curva de bombas para a Estação Elevatória definida no ensaio de bombas em razão desta representar a condição atual dos conjuntos motor-bomba, reproduzindo proporcionalmente a condição de desgaste das mesmas oriundas dos seus anos de uso.

5. Não serão consideradas as perdas singulares dos tubos;

6. Admite-se que a área adotada esteja totalmente estanque, ou seja, os únicos volumes admitidos de água no setor são originários de seu reservatório principal;

7. Serão tomadas informações de campo, medidas e horários, para que estas sejam comparadas aos resultados da simulação, permitindo a sua calibração com dados reais;

8. Será reproduzida a vazão de um ponto comum de forma a avaliar a curva demanda $x$ tempo utilizada.

A ferramenta de geoprocessamento permitirá, através da organização das bases operacionais históricas, a concepção de mapas temáticos. Serão elaborados mapas que reproduzirão o número de ocorrências do mesmo tipo (reclamações dos usuários e de serviços de manutenção, como vazamentos). As informações serão agrupadas em quadras, segundo a base da Prefeitura de São Paulo, de forma a representar, através de cores, as faixas e locais de maior e menor incidência. 


\section{PROPOSTA:}

a. Desenvolver o exercício do desenvolvimento da simulação hidráulica e de calibração em redes secundárias, utilizando EPS, deixando a mesma em condições de permitir simulações reais para adequação das instalações e equipamentos, de forma a otimizar o comportamento de setor com a redução de perdas por vazamentos e custo com instalações civis, mecânicas e elétricas;

b. Produzir um comparativo analítico dos pontos onde a simulação hidráulica aponta maiores incidências de pressão com um acréscimo do número de vazamentos através do uso de mapas temáticos concebidos com o histórico de informações corretivas de forma a correlacioná-los, permitindo assim uma segunda forma de calibração do modelo.

\section{ANÁLISE DE FALHAS:}

Para a análise de falhas, definiu-se avaliar os itens mais relevantes disponibilizados pelo programa utilizado através de duas das ferramentas disponibilizadas para tanto:

\section{* Pressão nos nós}

Com este instrumento, espera-se reconhecer o comportamento piezométrico de toda a rede modelada e, como análise preliminar, reconhecer grandes incompatibilidades com a realidade do setor de abastecimento. Utilizando tal informação, é possível avaliar seus valores extremos, reconhecendo pontos baixos, sujeitos a um número maior de vazamentos, e pontos altos, passíveis de falta de água. 
* Perda de Carga na rede de distribuição

Grandes perdas de carga indicadas pelo gradiente da linha piezométrica permitem ao analista avaliar, em primeiro plano, demandas incompatíveis com a dimensão das redes propostas. Confirmados gradientes altos, pode investigar reais problemas através da substituição ou de reabilitação de redes de água, reduzindo desta forma rugosidades extremas que comprometam volumes e pressões, assim como corrigir possíveis erros de lançamento.

Avaliando-se uma primeira versão da simulação, será possível detectar resultados pouco prováveis, apontando espaços para investigações e adequações cadastrais, da onde podemos exemplificar:

- Detecção de trechos de redes não cadastradas ou já abandonadas, assim como permitir a correção de diâmetros, extensões ou áreas inadequadamente lançadas;

- Atuar em válvulas equivocadamente fechadas ou abertas - interferindo diretamente nos limites e, portanto, sobre os volumes entregues no setor;

- Exclusão de ligações atendidas por redes primárias ou independentes que atravesse o limite estudado com o propósito de servir ao abastecimento de setores circunvizinhos:

- Estimativa de porcentagem de perdas muito aquém da real. 


\section{ESTUDO DE CASO: O SETOR SACOMÃ}

Historicamente, o Setor Sacomã sofreu, desde sua primeira setorização em 2002, uma redução significativa de seus limites originais de atendimento em razão de adequação dos limites dos setores vizinhos, cabendo a este apenas um terço da sua área original, conforme ilustra a Figura 5.1. Seu sistema de bombeamento, por ter sido dimensionado para uma área proporcionalmente maior, encontra-se superdimensionado apesar do desgaste natural em função de sua vida útil e ainda por conta de sua tarifação de energia elétrica, justificando assim sua escolha entre os demais setores da RMSP.

O setor localiza-se no centro da Região Metropolitana e no município de São Paulo, junto à divisa dos municípios de São Caetano do Sul e São Bernardo do Campo, do lado esquerdo do Rio Tamanduateí, compreendendo uma área de aproximadamente 291 ha.
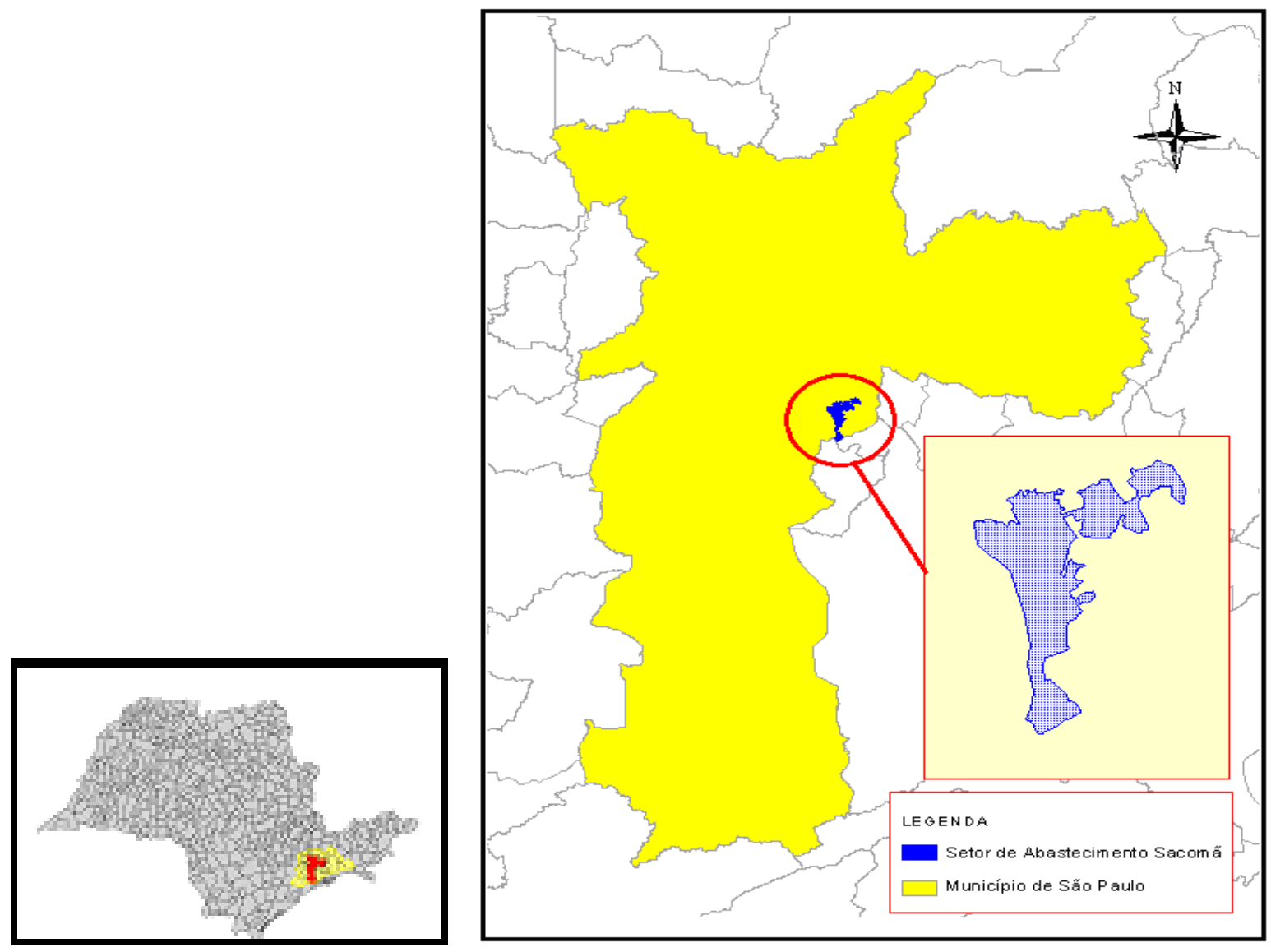

Figura 51 - Limites do Setor de Abastecimento Sacomã 
A amplitude altimétrica é da ordem de 70 m, com cotas entre 755 e 834 m. Os limites físicos principais do setor são:

- Nordeste: Avenida marginal direita da Rodovia Anchieta

- Sul: divisa com o município de São Bernardo do Campo

- Oeste: Parque do Estado

O setor apresenta uma população da ordem de 40.300 habitantes, segundo o último censo do IBGE, em 2000.

O setor conta com $60 \mathrm{~km}$ de redes de distribuição e 8890 ligações ativas contemplando 15.739 residências, 787 pontos comerciais, 143 indústrias e 14 economias públicas, com um consumo micromedido de aproximadamente 230.000 $\mathrm{m}^{3} / \mathrm{mês}$ (abr./2009).

Apresenta características heterogêneas em termos de ocupação e uso do solo, com predominância residencial de todas as classes sociais, com forte tendência ao processo de verticalização. Existem favelas situadas na região. A região, potencialmente, se sobressai pela boa infra-estrutura, com serviços de telefonia, rede elétrica, drenagem etc. e ainda possui oportunidades de lazer, como o Zoológico e o Parque do Estado.

\subsection{Aspectos hidráulicos do Setor}

A reservação do setor Sacomã recebe água do Sistema Cantareira a partir do reservatório Jabaquara através de uma linha de DN 900 e com aproximadamente 5.900m de extensão. Conta com uma estação elevatória localizada na saída do reservatório Sacomã que atende a Zona Alta do setor. Existe uma torre que serve como atualmente como controlador de atuação. 
O reservatório semi enterrado Sacomã possui duas câmaras com valores nominais de $6.000 \mathrm{~m}^{3}$, possibilitando reservação útil de até $9.298 \mathrm{~m}^{3}$ (77\% de rendimento).

A elevatória está localizada junto ao reservatório principal, responsável pelo abastecimento da zona alta. Possui instalações para três conjuntos motor-bomba com vazão de $250 \mathrm{l} / \mathrm{s}$, altura manométrica de 65 mca e 1780 RPM cada unidade e apenas dois deles, conjuntos 1 e 3 , em atividade, conforme ilustra a Figura 5.2:

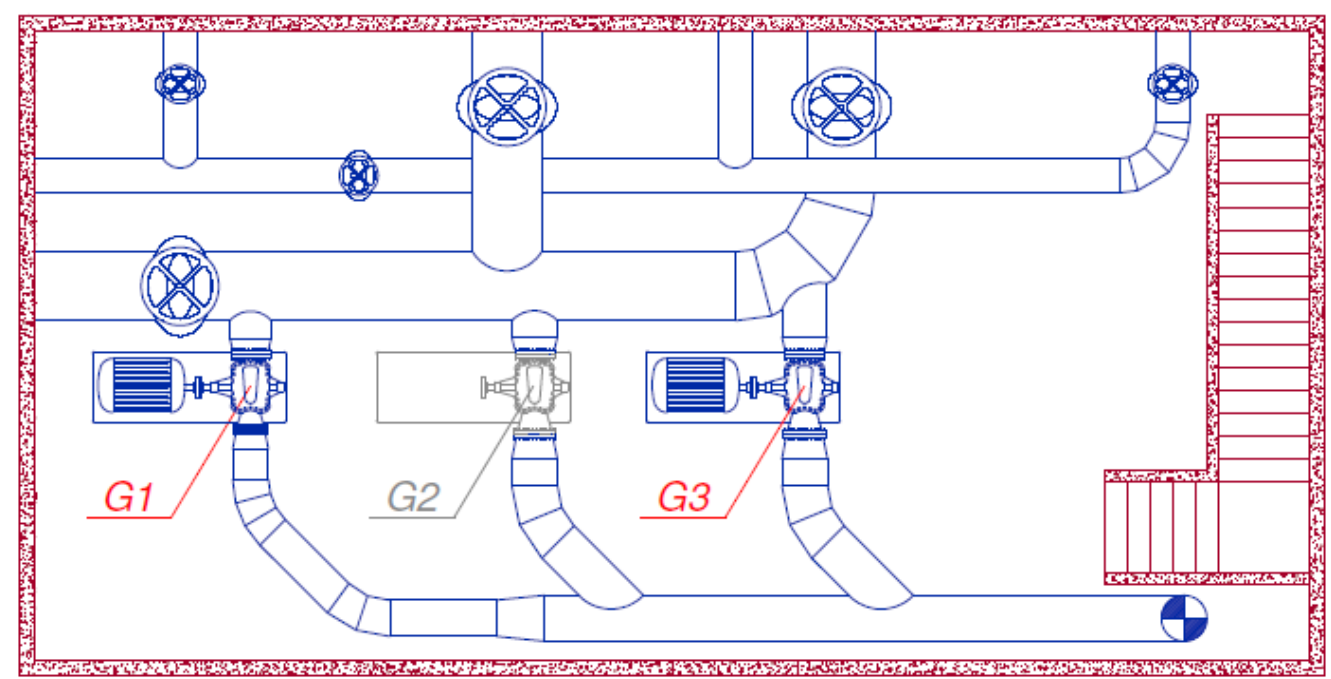

Figura 52 - Instalações hidráulicas da EEA Sacomã Fonte: Sabesp, 2009

Em 2002, foram concluídas as obras que resultaram numa nova setorização dos limites originais do setor, segundo projetos analisados e aprovadas durante o ano de 1997 (SEREC, 1997; PROENGE, 1995; PROESA, 1987). Depois de grande parte das obras realizadas, houve necessidade de readequar o abastecimento dos setores vizinhos, cabendo mudanças em razão da inviabilidade de execução de algumas das propostas então aprovadas no projeto original (travessias através de método não destrutivo, intervenções que representavam paralisação em vias de grande movimentação ou que mereceram reestudo ou adequação) que se mostraram inviáveis. Reavaliações técnicas e os custos operacionais oriundos da necessidade de reforma do reservatório elevado fizeram com que o setor, originalmente destinado ao suprimento de uma zona alta de grandes proporções, fosse reduzido a uma zona de coroa com menos de um terço da sua área original. Por curiosidade, vale justificar 
que o projeto original permitiria o abastecimento de toda a zona baixa através unicamente do reservatório enterrado e, a partir deste, ainda houvesse o recalque através de estação elevatória que garantiria o suprimento de toda a zona alta, amortizada pelo reservatório elevado. A região extraída da então zona alta que, somada a outra da então zona baixa, foi depois denominada por zona média (e agora como Setor Cursino), que seria abastecida por uma reservação independente, o que acabou por concretizar-se conforme as expectativas. Hoje, a área atendida pela zona baixa é hoje conhecida por "Derivação Sacomã", abastecida através de uma derivação em marcha, sobrando toda a antiga reservação existente unicamente ao suprimento da área de coroa, o agora denominado Setor Sacomã, objeto deste estudo de caso, conforme sugere a Figura 5.3:

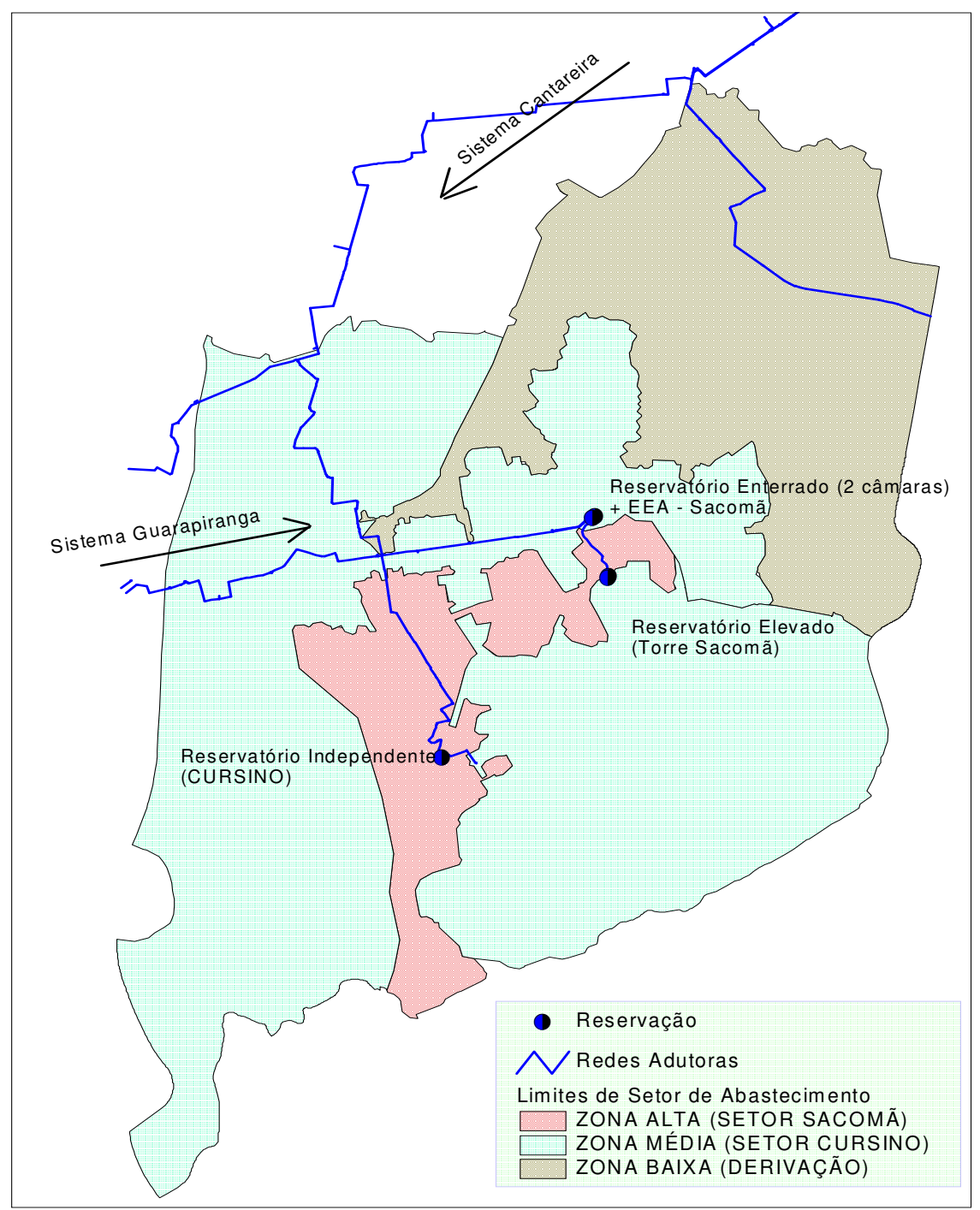

Figura 53 - Limites do Antigo Setor de Abastecimento Sacomã 
Devido aos seus novos limites, os grupos dos conjuntos motor-bomba do setor encontram-se subutilizados, permitindo um ciclo de bombeamento que se repete em intervalos curtos de 20 a 30 minutos, utilizando apenas um de seus conjuntos motorbomba e servindo um segundo grupo apenas como reserva. Tais conjuntos motores, devido ao desgaste natural, já apresentam proporcional perda de rendimento, mas a maior justificativa para intervenção vem do consumo de energia elétrica em razão destes curtos intervalos entre os ciclos de bombeamento, o que vem incidindo em altos custos a concessionária. A torre, por sua vez, em função de necessidade de reforma, hoje faz o papel de um piezômetro que, de acordo com seu nível, dá o comando de acionamento ao conjunto motor-bomba, conforme ilustra a Figura 5.4, desligando-o assim que estabelecido o abastecimento.

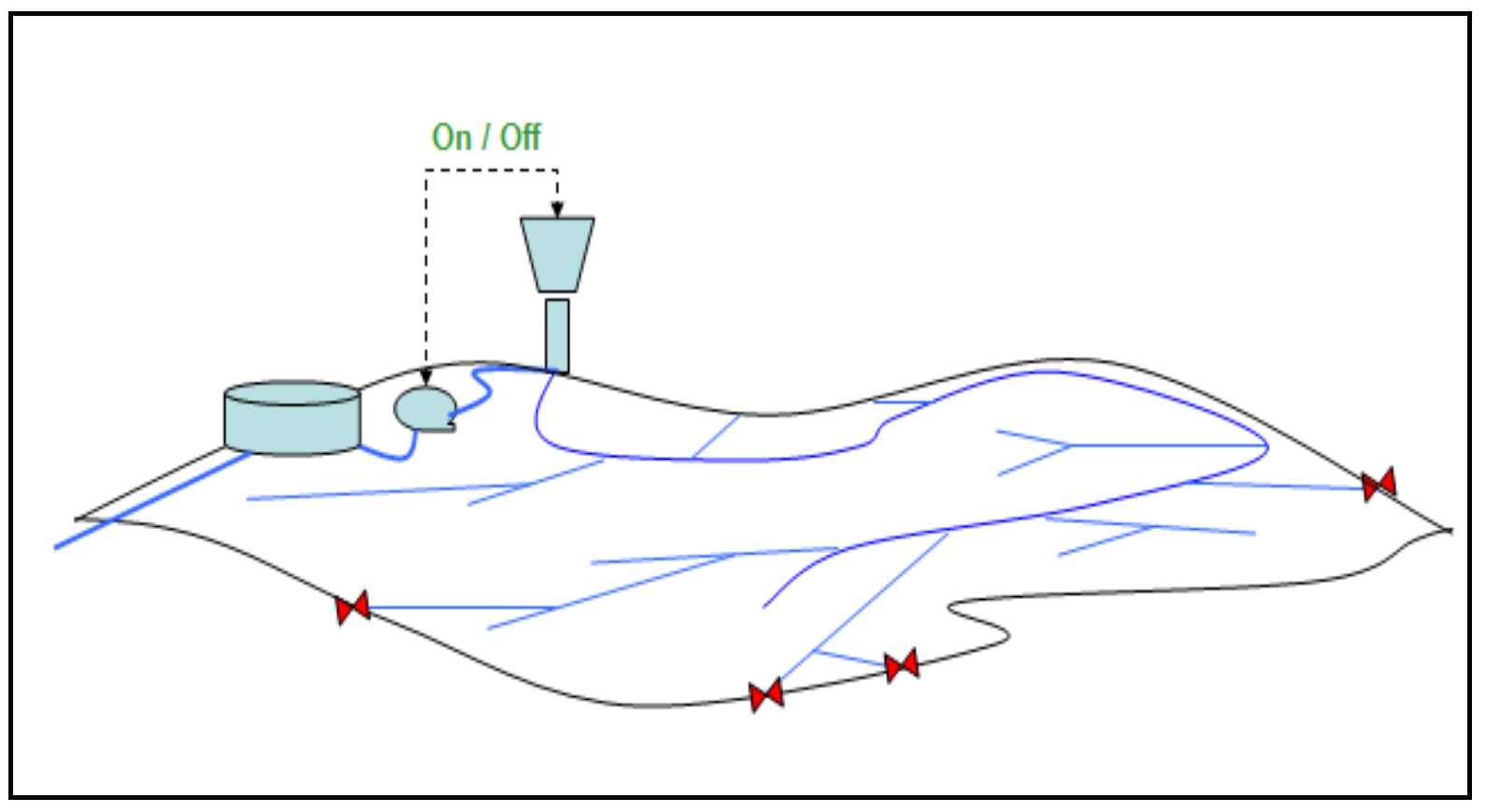

Figura 54 - Esquema operacional do setor Sacomã

São apresentadas pelas Figuras 5.5 e 5.6, respectivamente, a vista geral do sistema de distribuição do objeto deste estudo de caso, assim como uma ortofoto do local. 


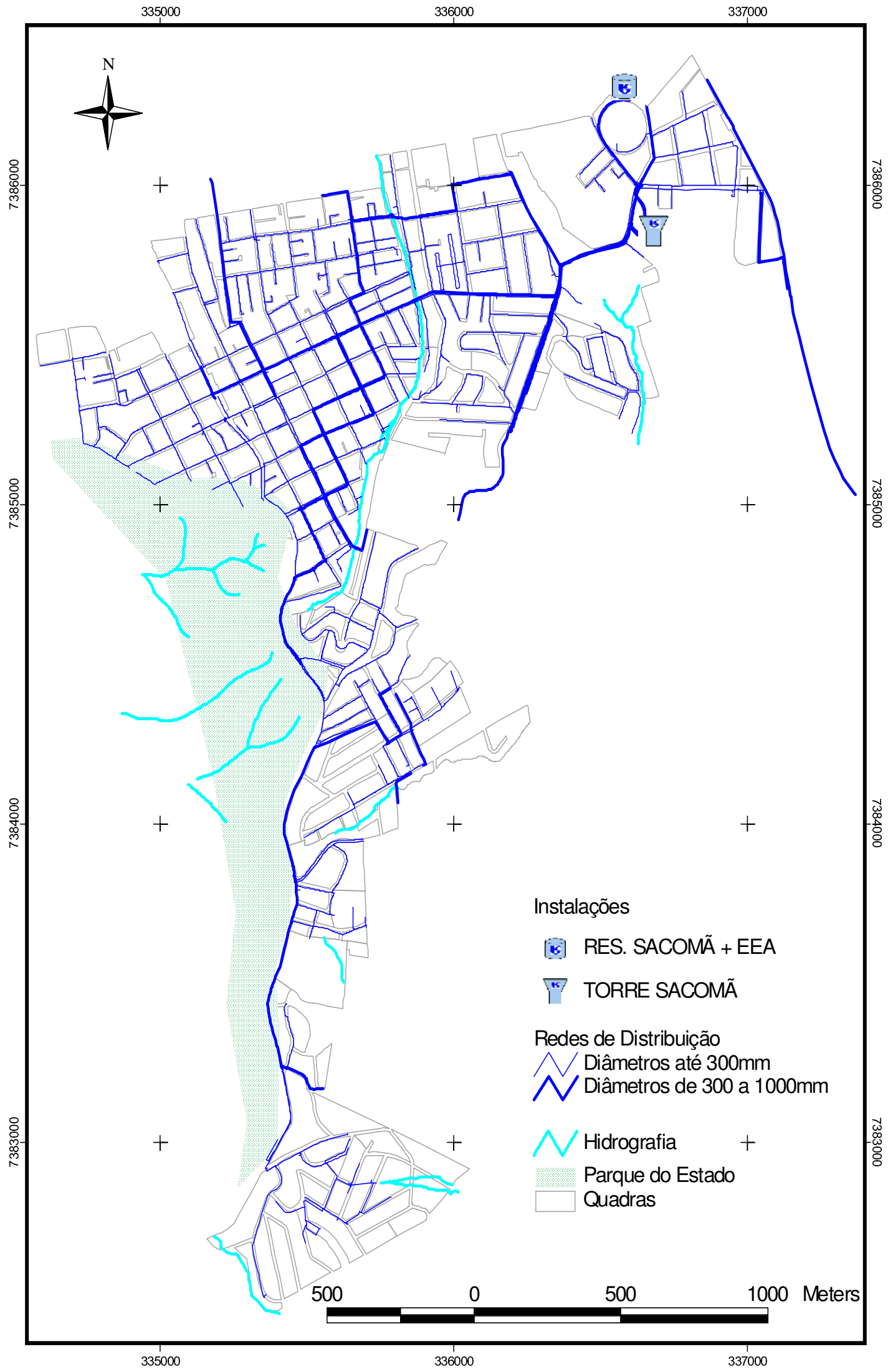

Figura 55 - Vista Geral do Sistema de Distribuição de Água - Setor Sacomã Fonte: Sabesp 2009 


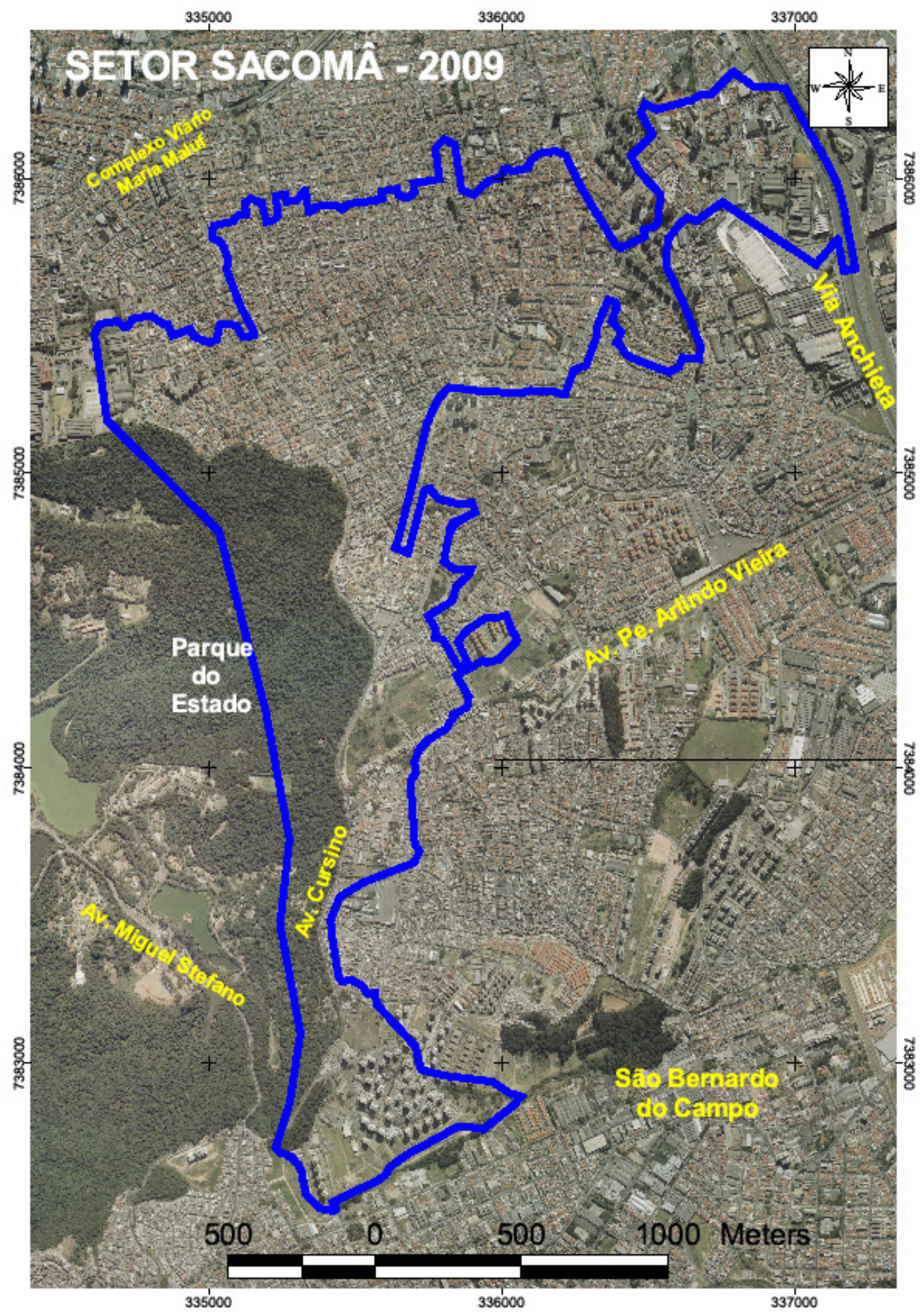

Figura 56 - Ortofoto dos limites do Setor de Abastecimento Sacomã Fonte: Sabesp 2009 


\subsection{Aspectos operacionais do Setor}

Em razão da primeira intervenção de 2002, o Setor teve reduzidos os seus índices de reclamações referentes à falta d'água e por falta de pressão na rede, notando-se claramente a baixa incidência de reclamações em razão de problemas operacionais. Nas Figuras 5.7 e 5.8, são exibidos os mapas temáticos oriundos de reclamações entre o ano de 2006 e o segundo semestre de 2009, mostrando a boa atuação do setor.

Nesta oportunidade, vale também destacar a questão da confiabilidade do banco de reclamações. Em alguns casos, o usuário dos serviços, ao notar qualquer irregularidade no abastecimento, antes de avaliar quaisquer problemas internos, contata a concessionária para que ações sejam tomadas. Assim, muitas destas reclamações acabam por não serem procedentes, não resultando propriamente em manutenção, mas em orientação ao cliente, induzindo a falhas no banco de dados. Por sua vez, tais manifestações por parte dos usuários são muito importantes, cabendo atenção a cada uma delas visto que grande parte destas acaba por gerar providências e reparos.

Tratando mais exatamente da manutenção dos sistemas de água e do georeferenciamento destas, cabe conhecer que tipo de serviços retrata cada um dos mapas temáticos que ilustram este trabalho:

- Vazamento de Rede: Reparos simples na tubulação, conexões ou juntas, acessórios, hidrantes, válvulas e arrebentados de maior porte;

- Vazamentos de Ramal: Conserto ou trocas de ramal ou do ferrule e a supressão de ramais abandonados;

- Vazamento de Cavalete: Reparo de cavalete ou troca de registro do mesmo.

O objetivo da elaboração de mapas temáticos é o de quantificar, por quadras, o número de ocorrências de mesmo padrão, para que sejam investigadas e que sejam tomadas ações preventivas, reduzindo o número de incidências ou que seja solucionada a causa do que as provoca. 


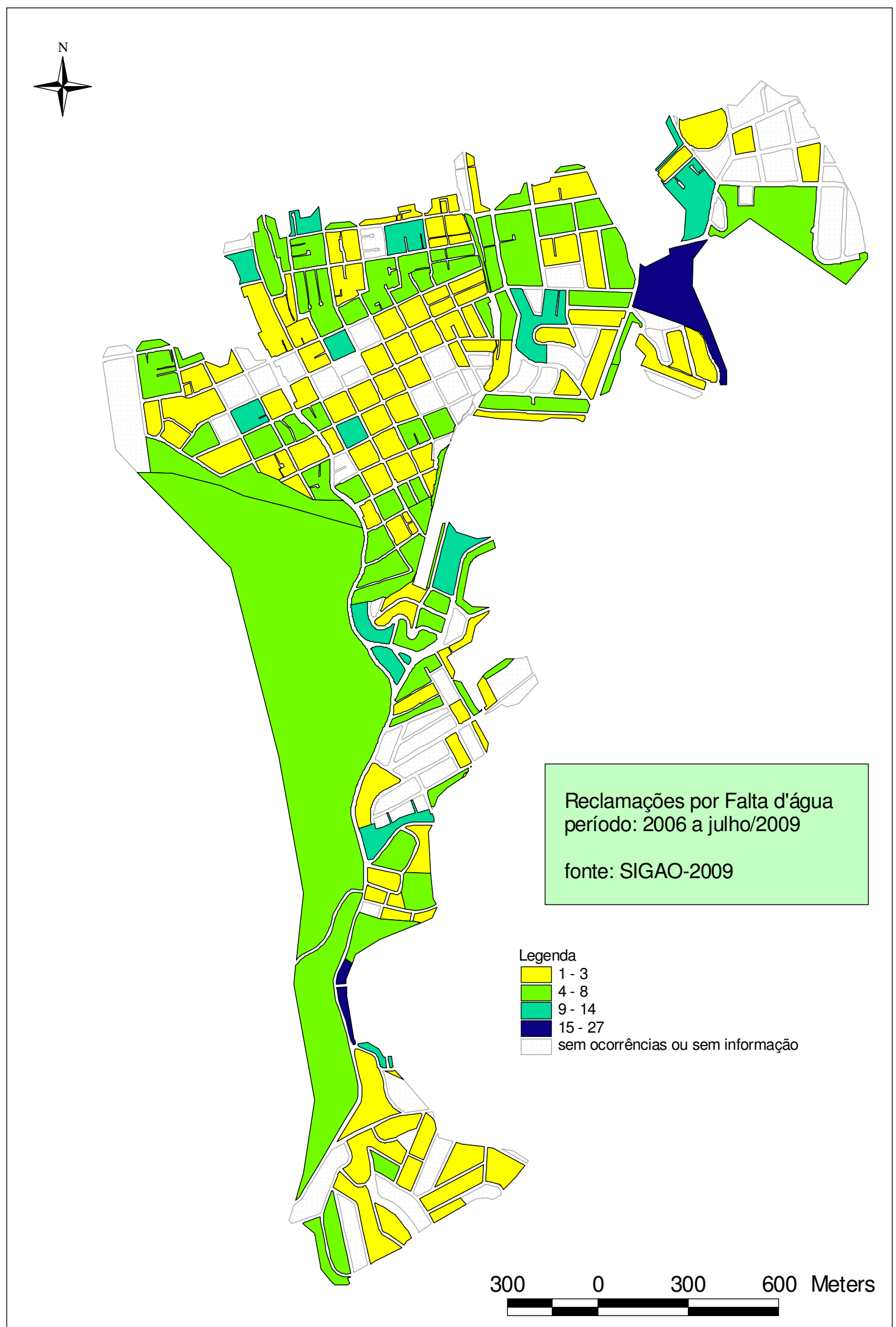

Figura 57 - Reclamações por Falta d'água

Fonte: SABESP, 2009 


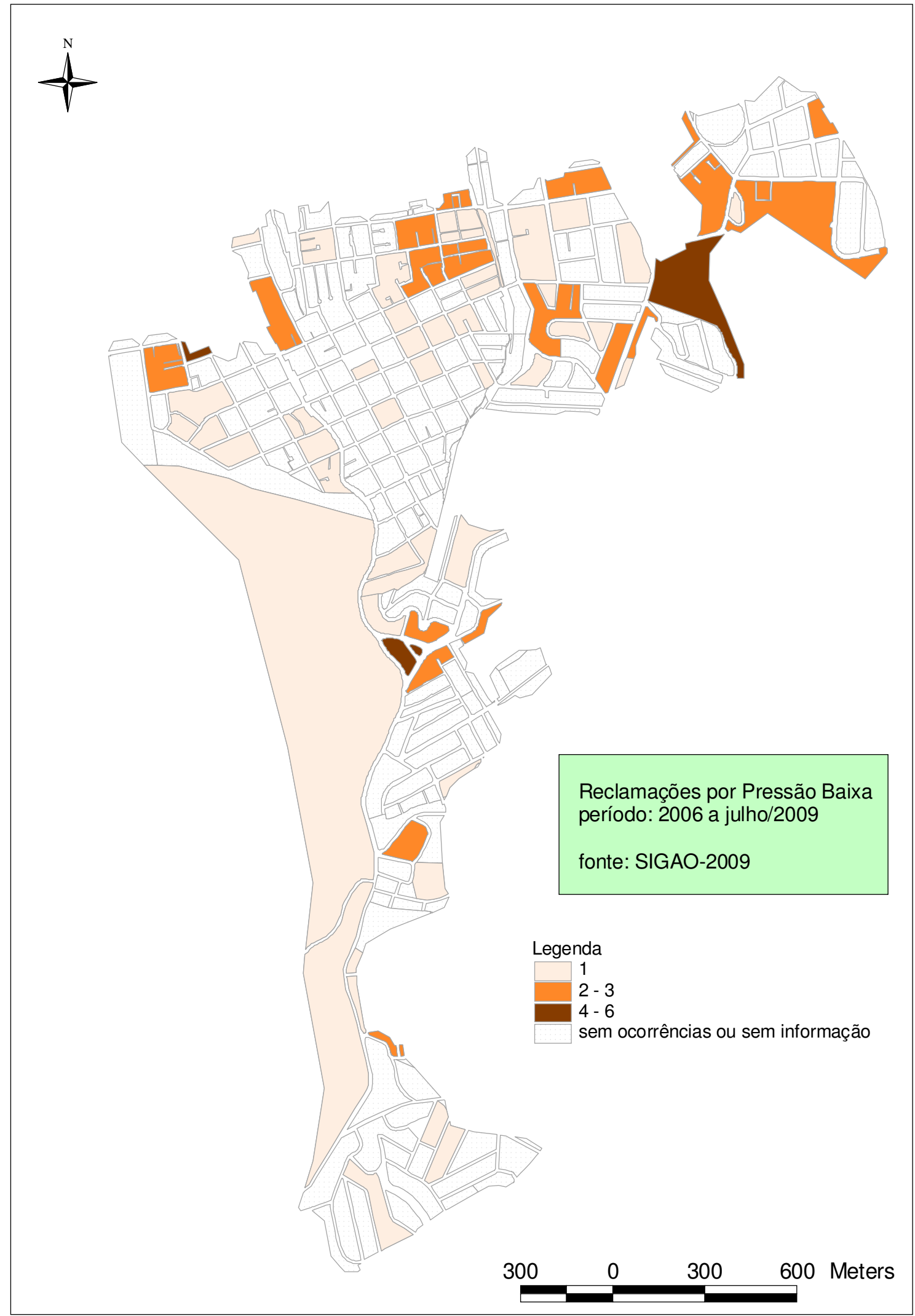

Figura 58 - Reclamações por Pressão Baixa

Fonte: SABESP, 2009 
Através de uma escala de cores, é possível, de forma visual, avaliar os locais com maior número de ocorrências e, por este, começar a investigação dos principais problemas que o provocaram.

\subsection{Modelagem hidráulica do Setor}

Um estudo específico como o que demanda das redes de distribuição, caberá um trabalho minucioso que não permite simplesmente ignorar diâmetros ou extensões, mas avaliar a que o mesmo se presta e a função deste no conjunto.

De forma a tornar o modelo simplificado, optou-se por limitar o número de trechos originais do setor, avaliando e descartando trechos de pequena extensão que não representassem posição comprometedora ao modelo e, definindo nós (agrupamento de trechos de rede de comportamento similar e de suas ligações onde estarão concentrados os consumos que deverão estar a estes subordinados), partindo da idéia de que toda a rede possui válvulas abertas, permitindo escoamento regular, com válvulas fechadas apenas em seus limites, tornando este setor similar a uma ilha. Contornando ainda quanto a perdas singulares, provocadas por curvas e acessórios, que não serão consideradas senão por parte de imprecisão do trabalho, conforme ilustra as Figuras 5.9 (mapeamento original) e 5.10 (mapeamento tratado). 


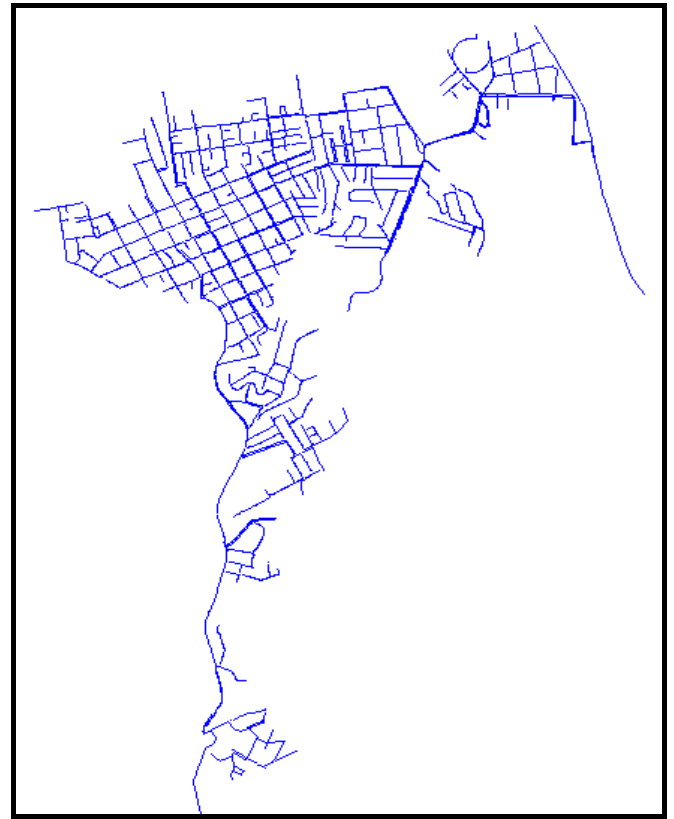

Figura 59 - Setor Sacomã original: 1512 trechos

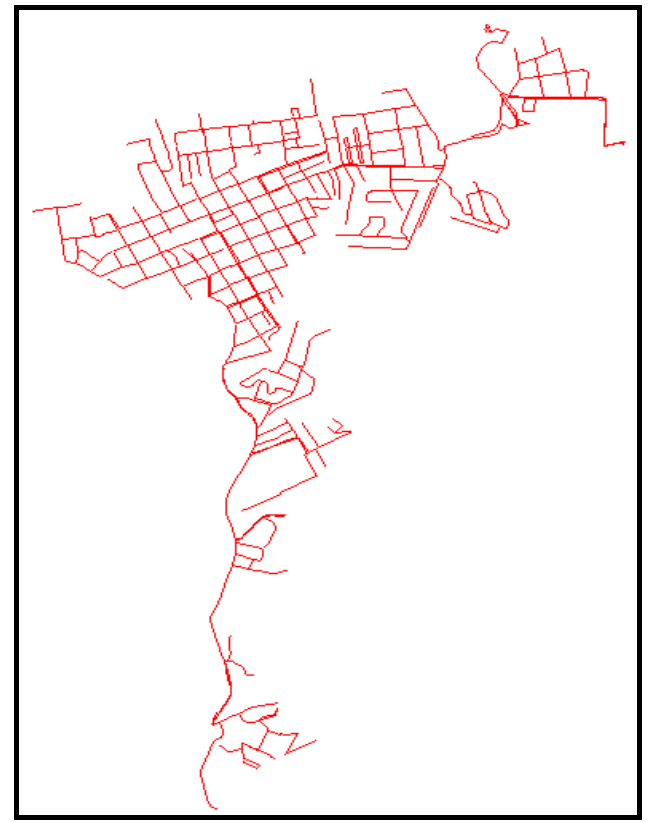

Figura 510 - Setor Sacomã tratado: 452 trechos

Infelizmente, como o sistema dispõe de registros prontos à abertura e fechamento entre um setor e outro, foi necessário averiguar in loco o fechamento de cada uma das válvulas, garantindo assim a estanqueidade do setor a outras entradas de água.

Foram então obtidas todas as ligações georeferenciadas no GIS. Vale lembrar que o sistema disponibiliza, inclusive, o histórico das ligações excluídas - o que se mostrará útil a alguns estudos posteriores. O consumo de cada ligação foi agrupado por critério de proximidade a um nó ligado a rede do modelo e uma cota geométrica como ilustra a Figura 5.11: 


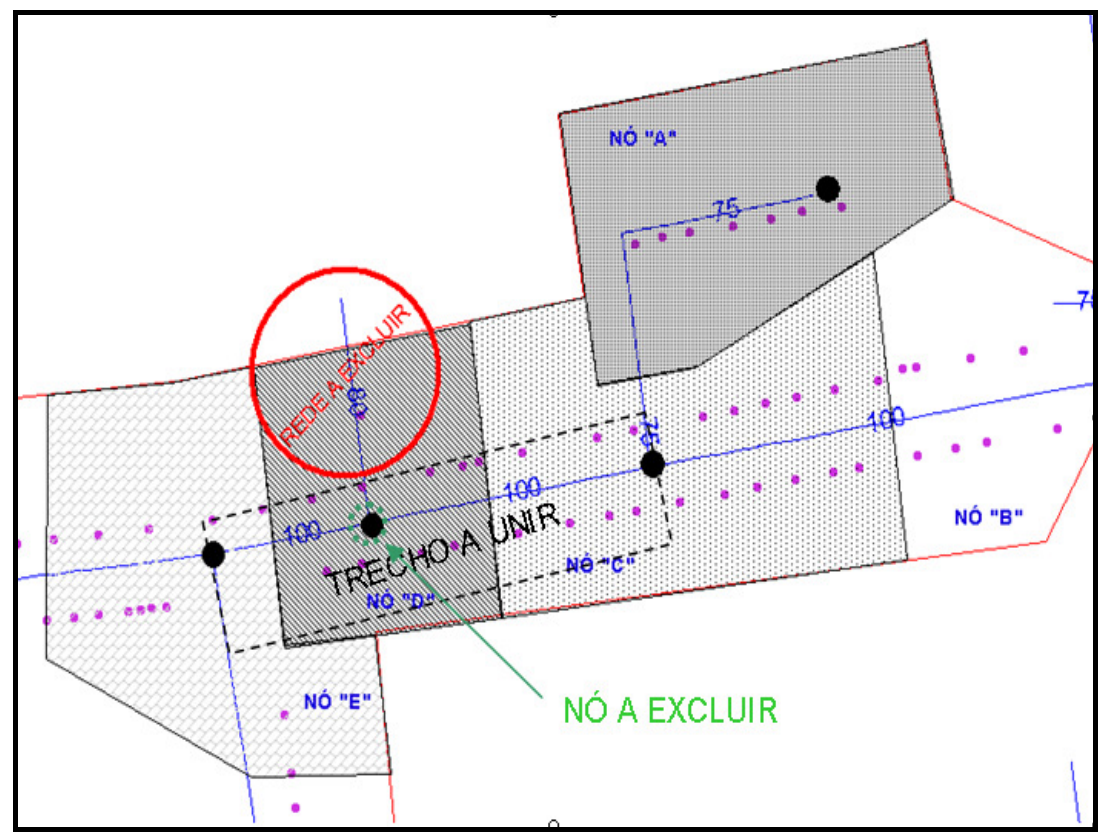

Figura 511 - Exemplo de filtro

(Definição dos nós e exclusão de redes desnecessárias)

O sistema de reservação foi assim modelado:

- O Reservatório enterrado, com a única função de abastecer o sistema de bombeamento quando assim solicitado, com cota constante (supondo-o sempre cheio), e com seu nível d'água correspondente a cota definida para o conjunto motor-bomba de forma a não refletir em altura piezométrica que influa no desempenho das bombas.

- O Reservatório elevado, por sua vez, receberá dados tais como cota do terreno, cota mínima e máxima do nível de água. No estudo de caso, o reservatório elevado tem a função de, a partir da redução do nível de água (representando assim a demanda solicitada), disparando um comando que, por meio de telemetria, permita a operação das bombas até que o nível da água atinja seu máximo. A partir daí, outro comando para desligamento parte por telemetria, reproduzindo a condição de funcionamento.

Informações como a da curva da bomba foram obtidas através do ensaio de bombas de forma a reproduzir o estado real das mesmas, observando que o uso da curva original, disponível no catálogo do fabricante, não retrata mais a instalação, 
em função de desgaste natural e redução de seu rendimento original (fig. 5.12). Só será avaliada neste exemplo a bomba ํํ 01.

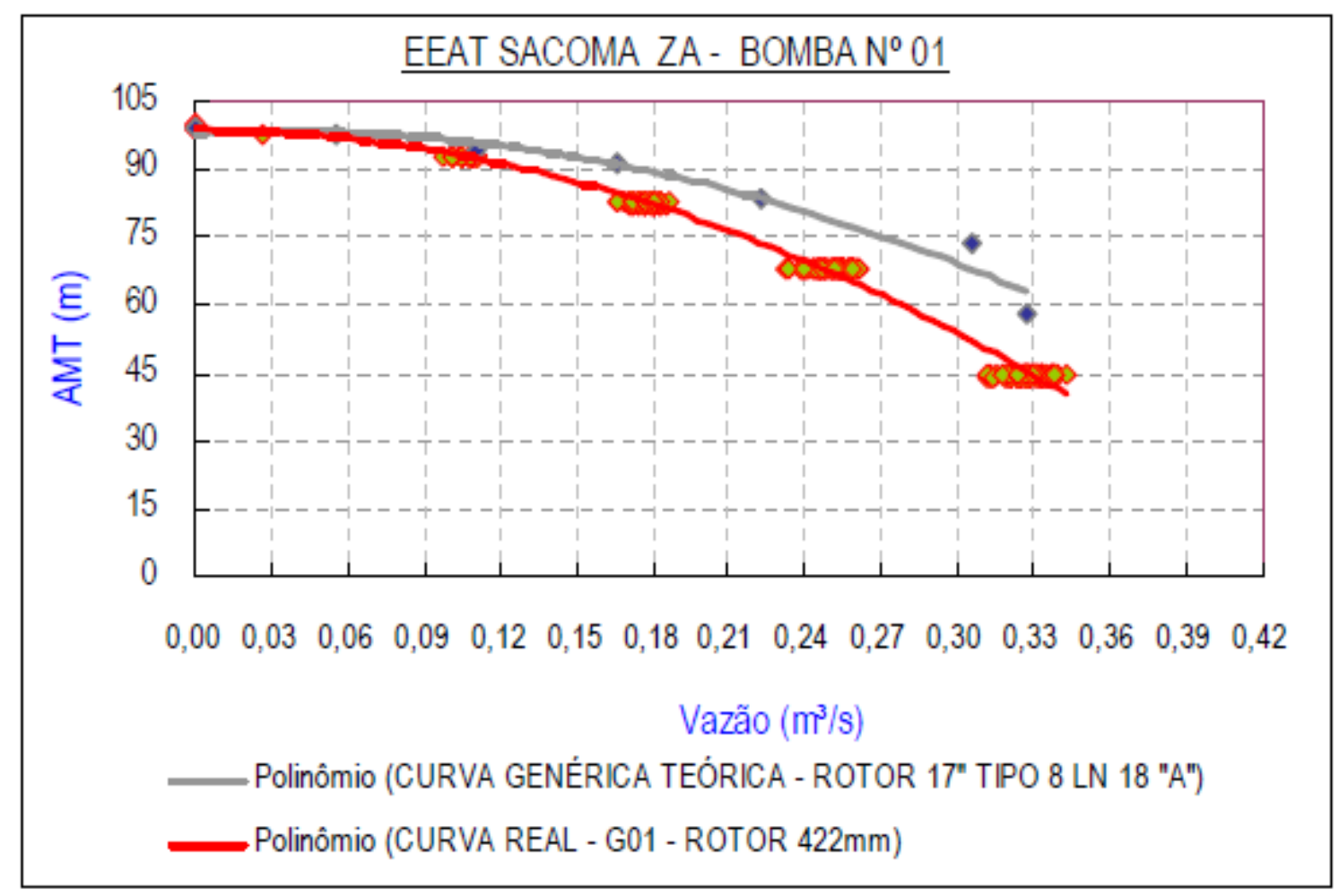

Figura 512 - Curva de bombas adotada na EEA Sacomã Fonte: Ensaio de bombas SABESP, mar/09

As redes foram reproduzidas fielmente no modelo, inserindo-se a variação dos diâmetros, extensões e adotando-se inicialmente uma rugosidade padrão $\mathrm{C}=90$ (adotada) para todos os tubos. Através do ArcView, foi possível garantir que a relação nós e tubos e ligações e nós, por proximidade, fosse sempre a mesma sem o risco de se reagruparem senão por necessidade de correção.

Será apresentada a configuração adotada, montadas em cinco ilustrações nas Figuras de 5.13 a 5.17, reproduzindo as áreas de influência de cada nó, onde estão inseridas as ligações, e a interligação com o trecho de rede que permite seu suprimento. 


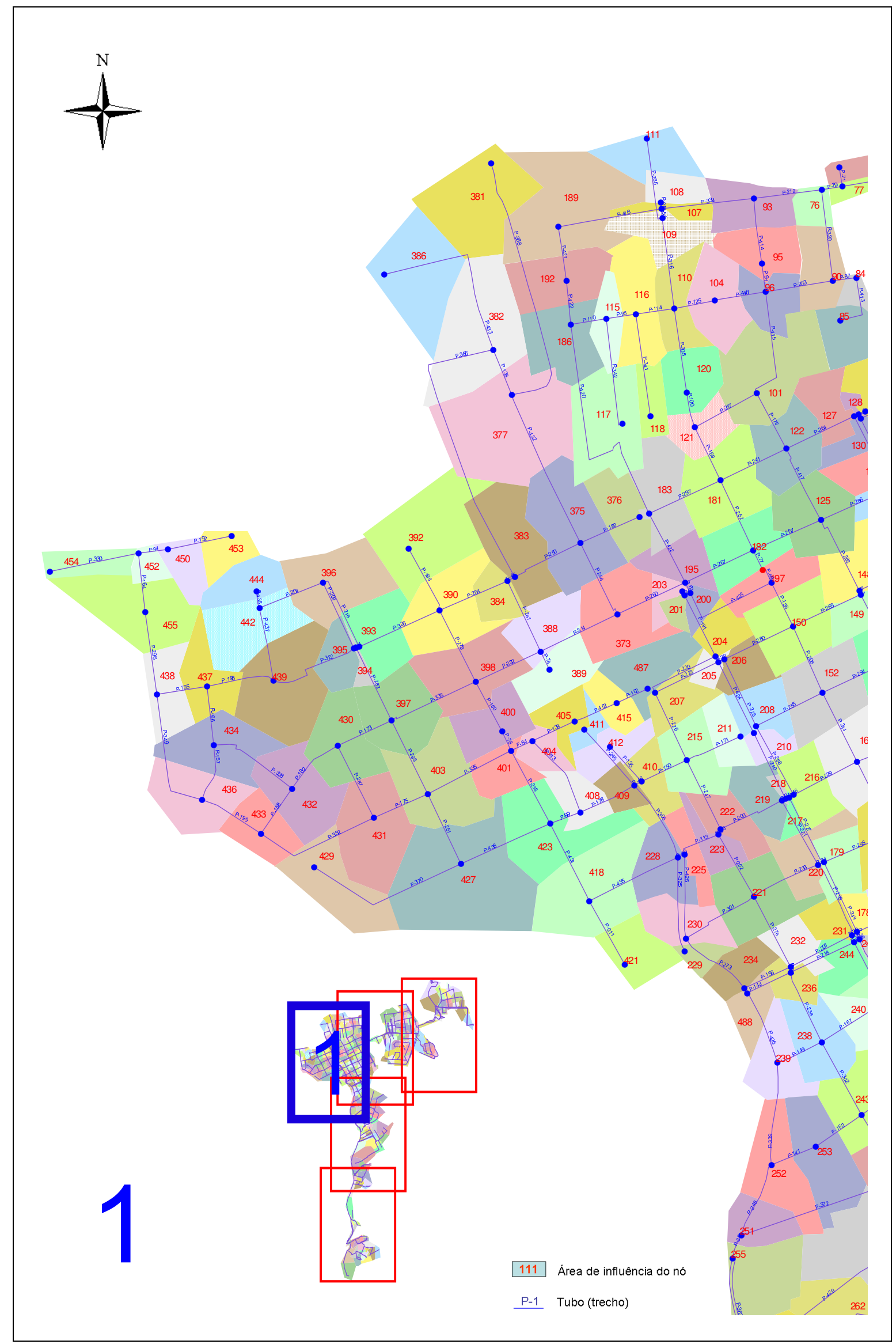

Figura 513 - Limites dos nós e posicionamento das redes de distribuição (1/5)

Sem escala - fonte Sabesp, 2009 


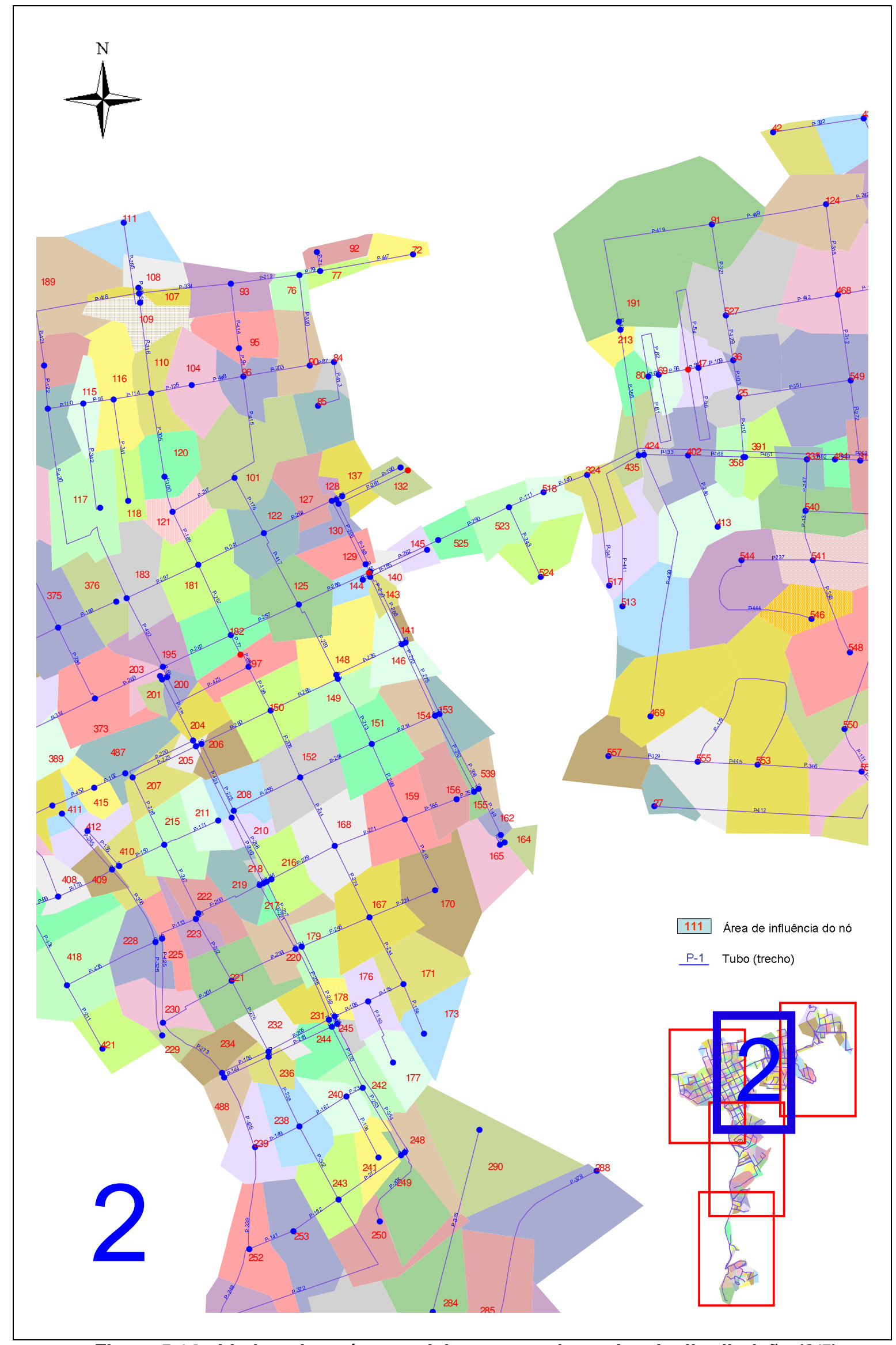

Figura 514 - Limites dos nós e posicionamento das redes de distribuição (2/5)

Sem escala - fonte Sabesp, 2009 


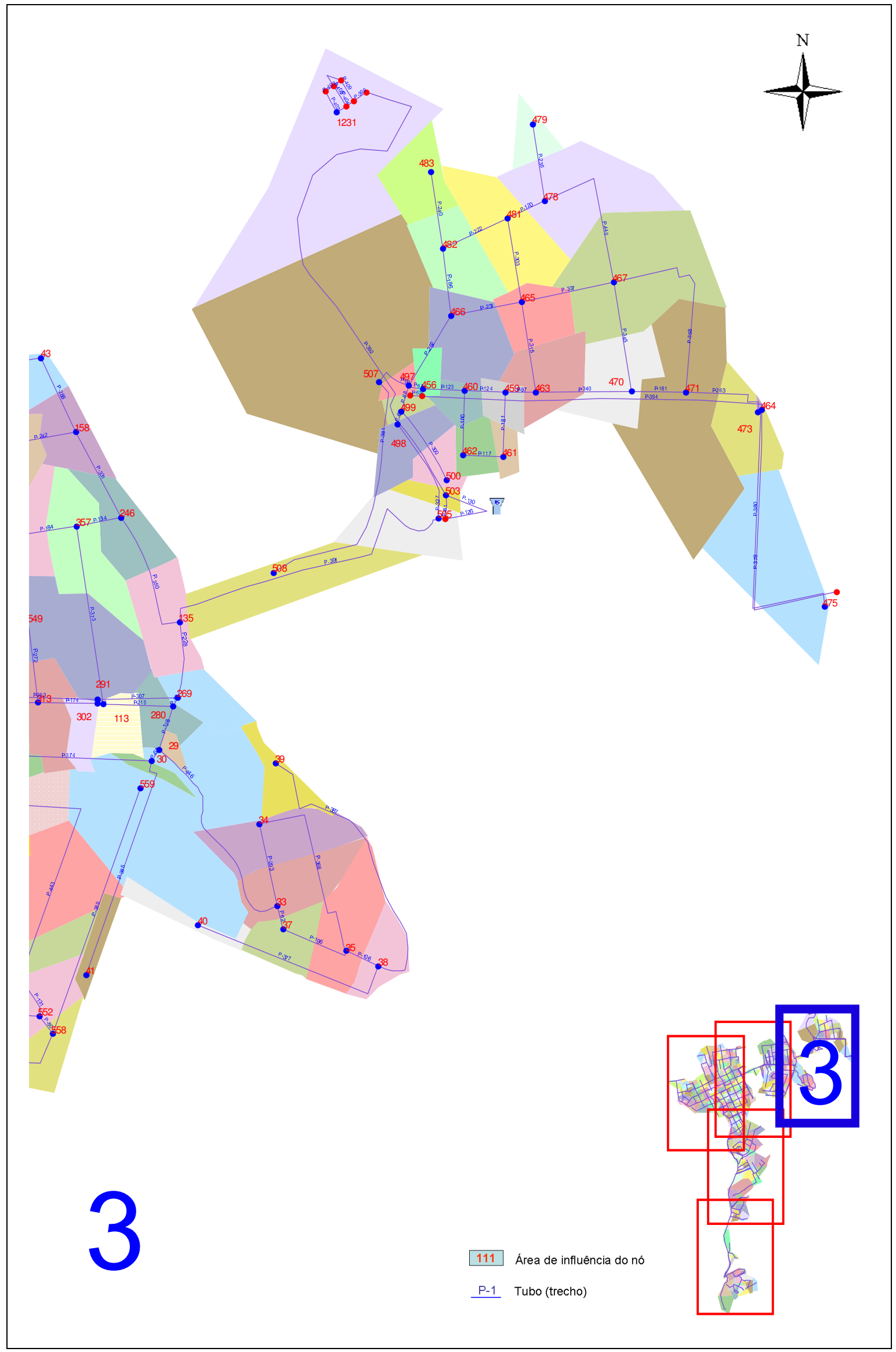

Figura 515 - Limites dos nós e posicionamento das redes de distribuição (3/5)

Sem escala - fonte Sabesp, 2009 


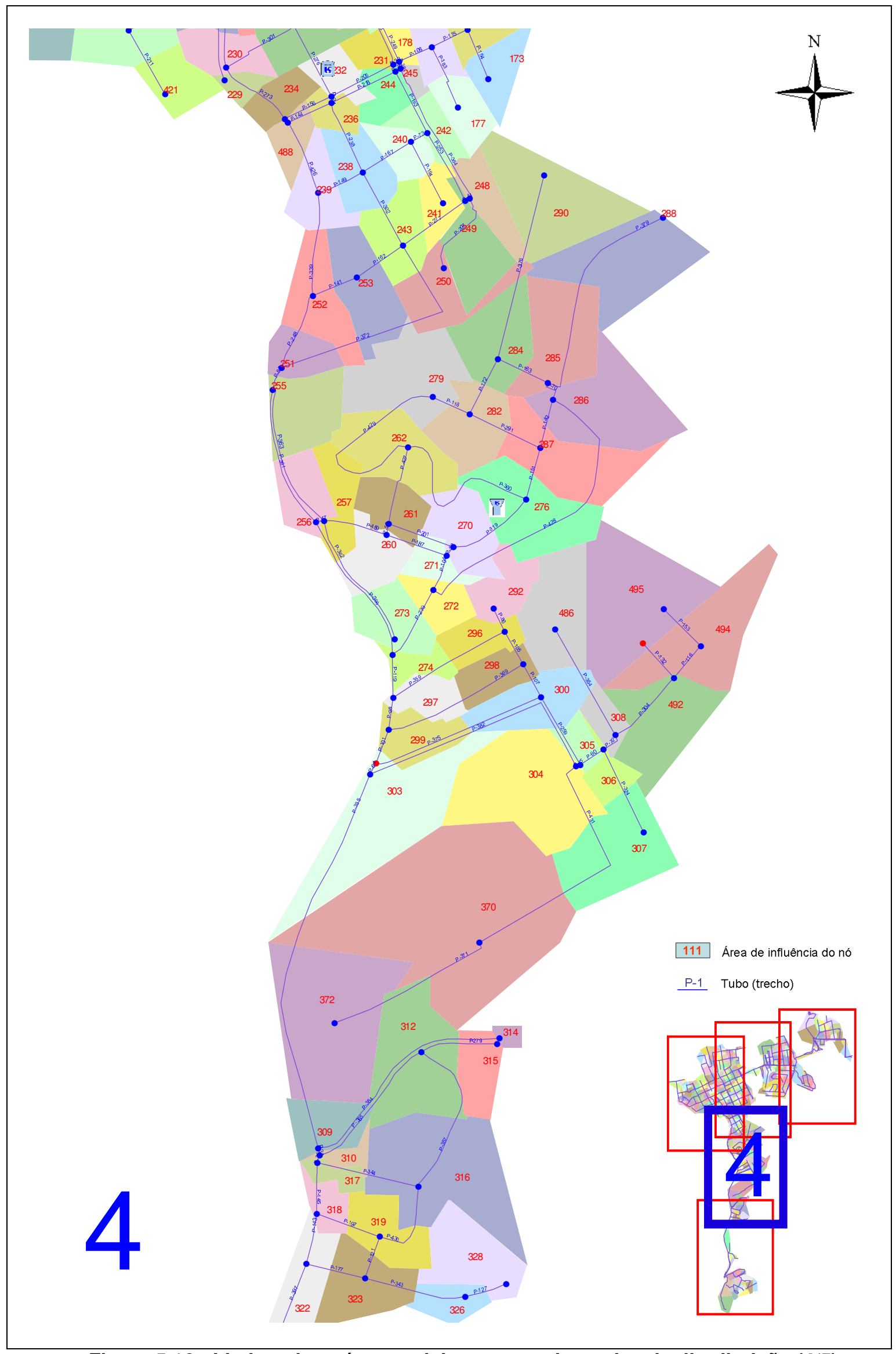

Figura 516 - Limites dos nós e posicionamento das redes de distribuição (4/5)

Sem escala - fonte Sabesp, 2009 


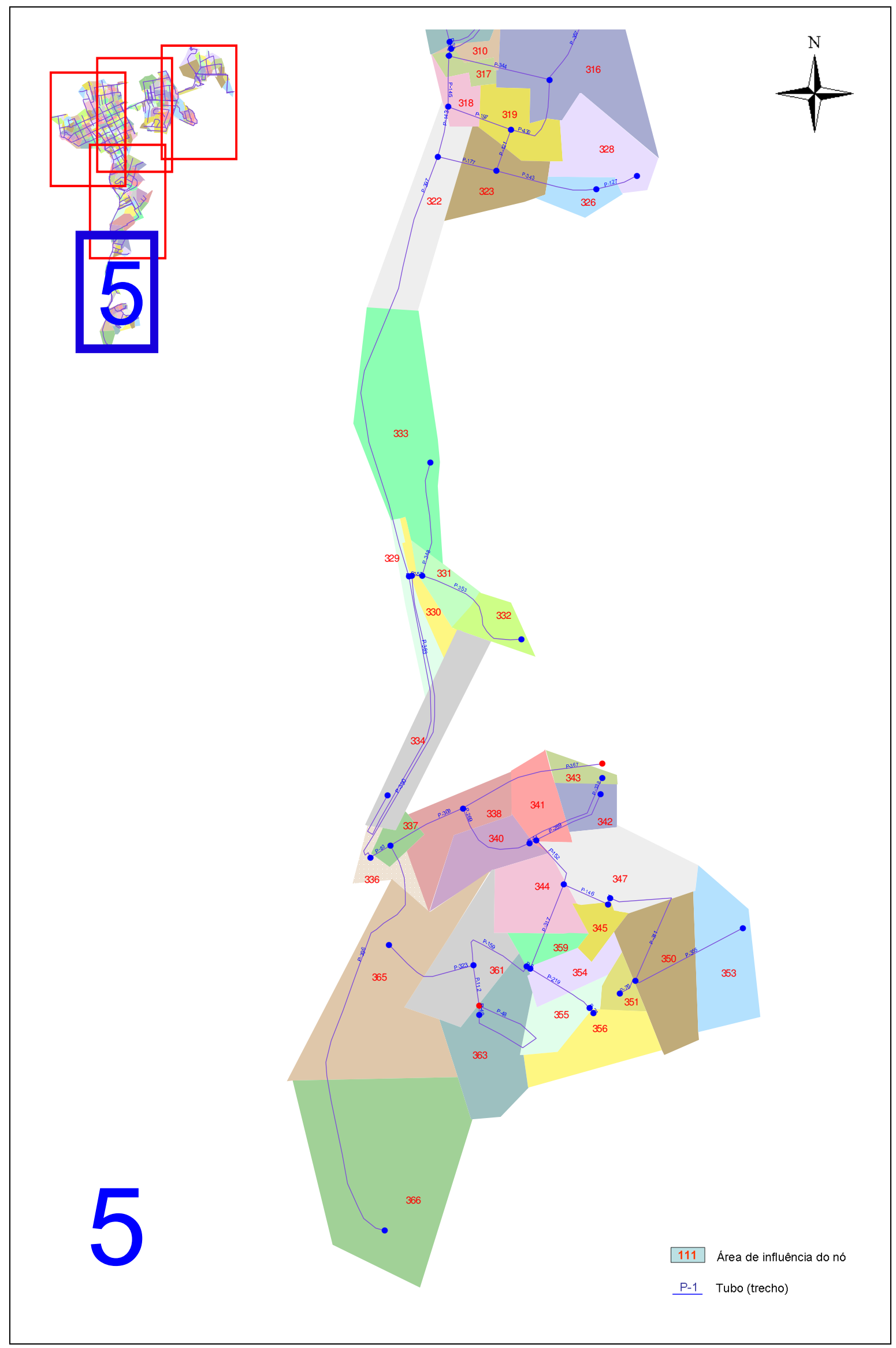

Figura 517 - Limites dos nós e posicionamento das redes de distribuição (5/5) Sem escala - fonte Sabesp, 2009 


\subsubsection{Determinação das demandas de consumo}

O estudo da demanda a ser utilizada é outra importante variável a ser definida. $O$ consumo de cada uma das ligações - um total de 8.561 unidades dentro do Setor em 2009 (segundo o GIS SABESP) foi definido como a média de consumo anual. Caso fosse utilizado um mês frio como referência, certamente iria haver falta d'água nos dias de verão e, com o inverso, projetado durante um mês quente, haveria o risco de superdimensionamento das instalações em dias frios.

Dispondo da base comercial da Concessionária, foram avaliados os últimos anos e o regime de progressão de consumo no setor para atentar a grandes variações de comportamento que pudessem comprometer o dimensionamento. Para este fim, utilizou-se o número de ligações existentes no mês de julho de 2009 (última base de dados disponível no momento), permitindo assim avaliar as demandas entregues em função do número de ligações existentes atentando para que fossem também contemplados os volumes das ligações hoje inativas, facilitando a avaliação quanto ao crescimento e decréscimo populacional ou de demanda que pudesse interferir nos volumes a serem distribuídos aos nós.

\begin{tabular}{|c|c|c|}
\hline Ano Ref. & Ligações ativas & Volume médio (I/s) \\
\hline 2004 & 7391 & 71,17 \\
\hline 2005 & 7530 & 74,91 \\
\hline 2006 & 7594 & 77,80 \\
\hline 2007 & 7727 & 81,80 \\
\hline 2008 & 7844 & 82,68 \\
\hline 2009 & 7988 & 83,11 \\
\hline \multicolumn{3}{|c|}{ Tabela 5 1- Relação Ligações x Demanda } \\
Fonte CSI SABESP - jul/09
\end{tabular}

A relação "volume / ligação ativa" (tab. 5.1), aponta variações coerentes, garantindo estabilidade dos volumes a serem aplicados. Com esta informação, seguramente, pode-se adotar a média entre os meses de agosto de 2008 e julho de 2009, para este exercício de simulação hidráulica.

A ferramenta WaterCAD permite que o analista elabore trabalhos não apenas estáticos, mas também dinâmicos, adotando-se para tanto uma curva de consumo 
que permita reproduzir sua variação durante o dia. Cada setor de abastecimento tem curvas muito particulares em razão do abastecimento simultâneo de residências, indústrias, comércio e de população flutuante (aquela que não mora, mas trabalha, estuda ou faz compras em outras regiões, utilizando toda sua infraestrutura). Por esta razão, adotou-se a curva proposta como média por TSUTIYA (2004) em sua obra, permitindo assim o equacionamento de máximas e mínimas demandas exigidas da rede e de sua reservação durante o dia, preservando a curva típica, oriunda dos levantamentos de campo, para a calibração e avaliação da curva padrão proposta por este em sua obra.

\section{I. Índice de Perdas}

O índice de perdas é um fator crucial nas modelagens baseadas em dados de micromedição, visto que o volume considerado para dimensionamento das redes é o macromedido, ou seja, tratando-se exclusivamente do processo de distribuição, todo aquele volume de água medido na saída da reservação principal e que se perde durante seu transporte até a nova contagem, por hidrômetros, no momento da pronta disponibilização ao cliente.

- O volume atribuído às perdas efetivas é de difícil caracterização, visto a existência das perdas aparentes, permitindo quantificá-los apenas por diferencial probabilístico e, portanto, não exato. Por oportunidade da simulação, devem-se distribuir aos volumes micromedidos, em cada um dos nós, os volumes referentes às perdas, de forma a permitir o equilíbrio entre volumes disponibilizados e entregues. Utilizando-se desta regra, na aplicação no estudo de caso, deverá ser acrescida à demanda de volumes micromedidos uma porcentagem que represente suas perdas, independentes de serem reais ou aparentes, garantindo ao modelo a análise matemática da carga transportada a cada trecho.

O índice de perdas adotado será definido pela fórmula relacionada na tabela 5.2: 


\begin{tabular}{|l|c|}
\hline Volume Macromedido (mar/2009) & $7015,25 \mathrm{m3} / \mathrm{dia}(81,20 \mathrm{l} / \mathrm{s})$ \\
\hline Volume Micromedido (mar/2009) & $5199,7 \mathrm{m3} / \mathrm{dia}(60,18 \mathrm{l} / \mathrm{s})$ \\
\hline Formulação adotada: & $I P=\frac{\text { Vol.Macro }- \text { Vol.Micro }}{\text { Vol.Macro }}$ \\
\hline Índice de Perdas adotado: & $26 \%(0,26)$ \\
\hline $\begin{array}{l}\text { Cálculo do Volume de cada nó } \\
\text { acrescido da porcentagem de perdas: }\end{array}$ & Demanda $(2)=\frac{\text { Demanda }(1)}{1-I P}$ \\
\hline
\end{tabular}

Tabela 52 - Fórmula de demandas de cada nó a partir do Índice de Perdas 


\section{RESULTADOS}

\section{1. $1^{\mathrm{a}}$ Versão}

Utilizando os conceitos, elaborou-se a primeira versão da simulação. Para uma primeira análise, foram trazidas duas faces de consumo distintas: uma retratando um consumo quase nulo sujeito a picos de pressão durante a madrugada, às $3 \mathrm{~h}$ da manhã, e o segundo, mostrando o horário de maior consumo durante o dia, ou seja, o intervalo das 12 às 13 horas. Nas Figuras 5.3 .8 e 5.3 .9 foram obtidas 6 observações, sinalizadas diretamente no mapeamento e agora descritas:

Detalhe "A": Pressões de até 15 mca: São comuns pressões baixas em cotas geométricas altas, mas às $3 \mathrm{~h}$ da manhã, com demandas relativamente baixas e pressões máximas, é esperado que num setor sem VRPs, nenhum nó tenha pressão inferior a 15 mca;

Detalhe "B" e "E": Pressões acima de 60 mca são consideradas altas em quaisquer condições e merecem intervenção em função do número de vazamentos e perdas de água que esta provoca;

Detalhe "C": Ao meio dia, é possível notar um mapeamento incondizente com a realidade. Pressões de até -84 mca seriam, em teoria, impossíveis e representadas em razão da total incapacidade de sistema de viabilizar qualquer abastecimento neste horário. Se observado o mapeamento de reclamações (fig. 5.5 e 5.6), deveria ser refletido ali o alto grau de insatisfação do cliente;

Detalhe "D" e "F": Perdas de carga altas, acima de 0,06 m / m de tubulação.

O ponto considerado crítico pela sua extensão é o detalhe "C", onde é notório um erro de lançamento que pode, inclusive, ter provocado os demais. 


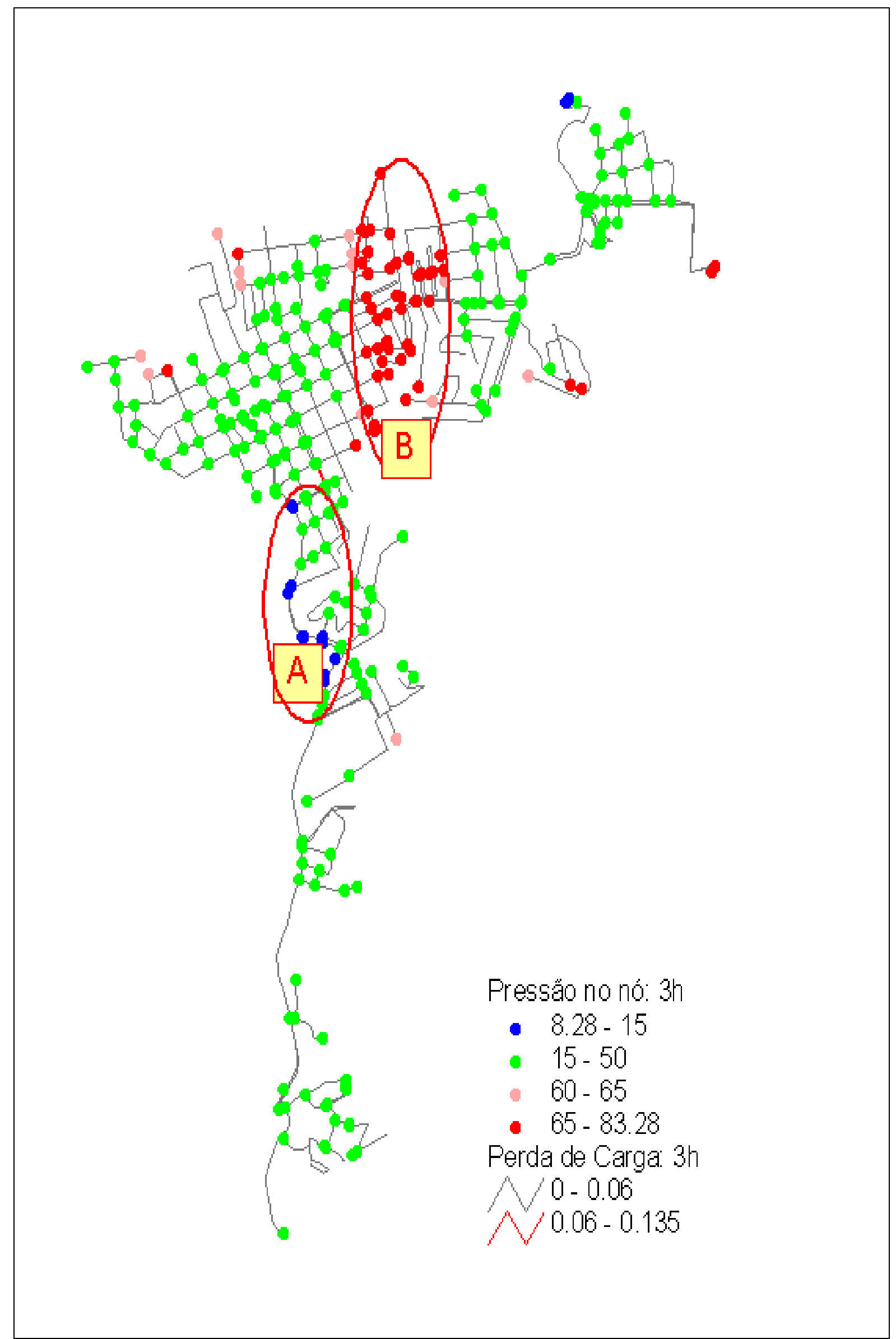

Figura 61 - 1a Versão da simulação trabalhada em ArcView 3.2- momento: 3h 


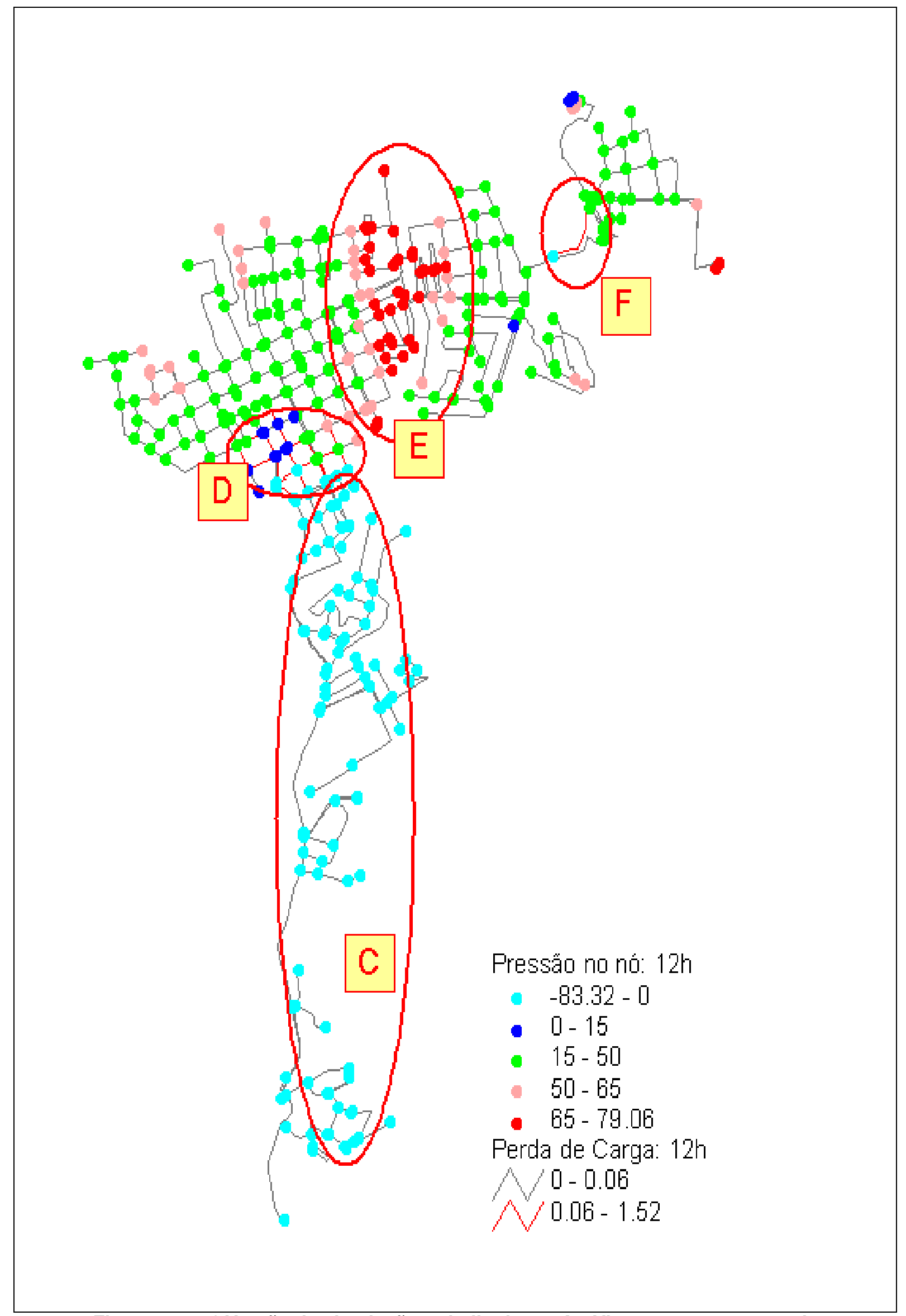

Figura 62 - 1ª Versão da simulação trabalhada em ArcView 3.2- momento: 12h 
Analisando tais observações, mostram-se claramente grandes incoerências que mereceram investigação.

Avaliados os pontos onde foram localizadas grandes perdas de carga e pontos críticos de pressão a partir de revisão das informações lançadas nos trechos considerados críticos ("A" a "E"), foram constatadas pequenas falhas ocasionadas por problemas de cadastro e que provocaram resultados que não condiziam com a realidade apresentada:

- Um condomínio localizado nas proximidades do reservatório elevado estava sendo abastecido originalmente por uma rede de DN 600 que servia unicamente ao setor Cursino, representando uma redução de mais de $2 \mathrm{l} / \mathrm{s}$ ao volume até então transportado pela rede de DN 75 local, o que gerou a perda de carga no erro "F".

- Um dos diâmetros foi erroneamente lançado como DN 75 sendo que na realidade tratava-se de uma tubulação de DN 400, provocando considerável perda de carga, visto que a primeira suporta uma média de $3 \mathrm{l} / \mathrm{s}$ enquanto a segunda admite um valor, ao menos, dez vezes maior. Tal erro teve como consequência direta ao erro "D"

- Uma ligação pública de $2,75 \mathrm{l} / \mathrm{s}$ por problemas cadastrais estava ligada erroneamente numa rede de DN 75, deslocada em mais de um quilômetro da posição real. Tal erro foi constatado em visita ao local e, devidamente posicionada, constatou-se que a mesma estava ligada a uma rede de DN 300 , corrigindo, portanto, a perda de carga mais crítica apresentada no modelo e que refletiu como consequência em grande parte do setor, ou seja, na falha " $C$ ", repercutindo em grande parte do setor, assim como na falha " $A$ ";

- Os erros "B" e "E" são toleráveis em razão das condições operacionais do setor. Altas pressões locais são consequência da grande vazão que passa naquela região, visando a atender aos extremos do setor.

Corrigidos os potenciais desvios, foram então produzidos os resultados ilustrados pelas figuras 6.3 e 6.4 : 


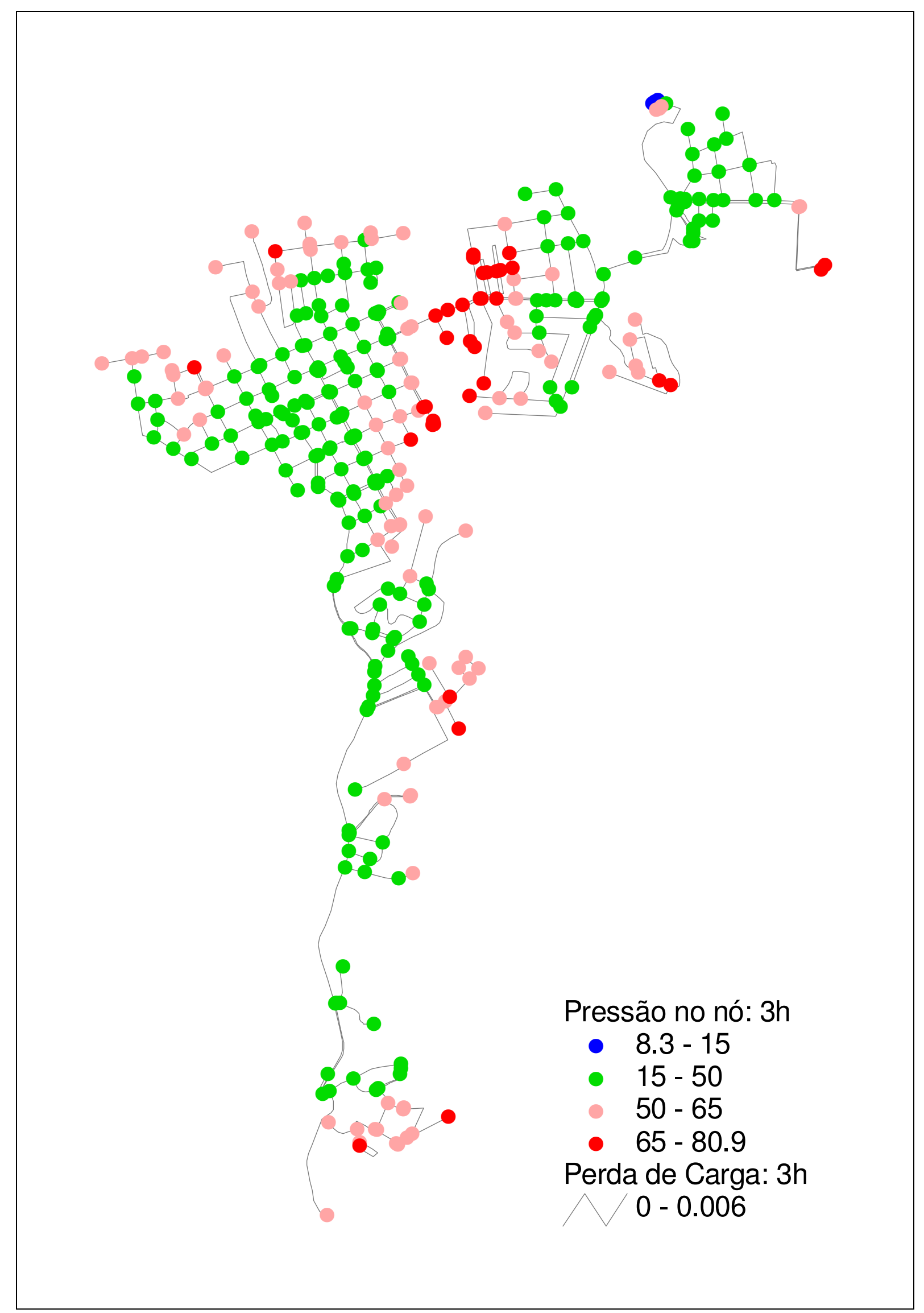

Figura 63 - 2ª Versão da simulação trabalhada em ArcView - momento: 3h 


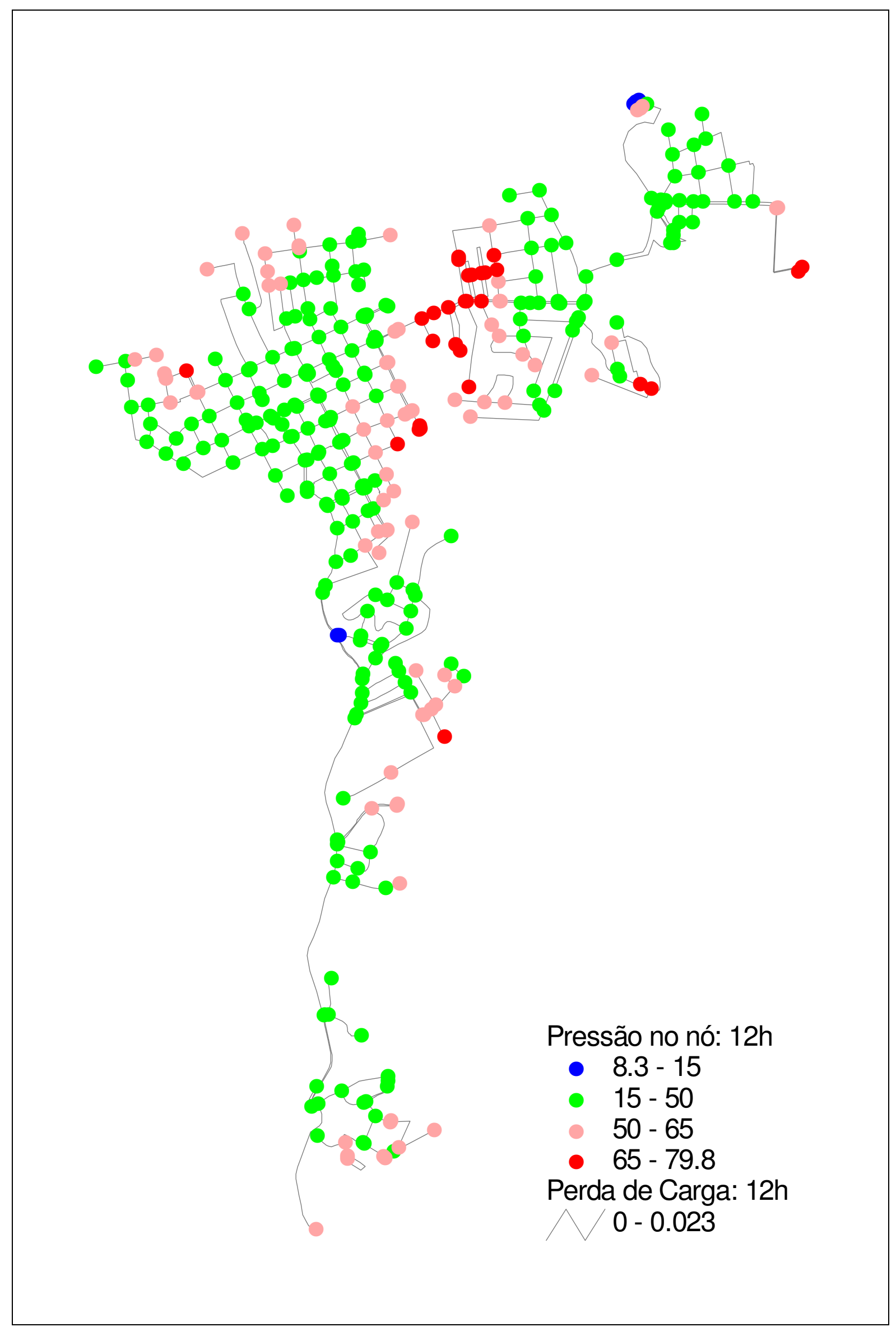

Figura 64 - 2 Versão da simulação trabalhada em ArcView- momento: 12h 


\section{2. $2^{\mathrm{a}}$ Versão}

Com esta segunda versão da rede modelada, a simulação representa resultados que estão consideravelmente coerentes com a realidade. O comportamento em ambos os horários, às $3 \mathrm{~h}$ e às $12 \mathrm{~h}$ mostra-se regular, com boa parte do setor apresentando pressão na faixa entre 15 e 50 mca conforme sugere a norma, com um ponto único, na cota mais alta do terreno na faixa entre 8,3 a $15 \mathrm{mca}$ - pressão esta que define o nó 256 como ponto crítico. As perdas de carga apresentam-se proporcionais, sem grandes distorções ou perdas acentuadas sem razão aparente. O sistema de bombas modelado representa o comportamento operacional da estação elevatória, ligando e desligando em intervalos regulares a partir do comando pela baixa do nível da torre, conforme sugerem as Figuras 6.5 e 6.6 :

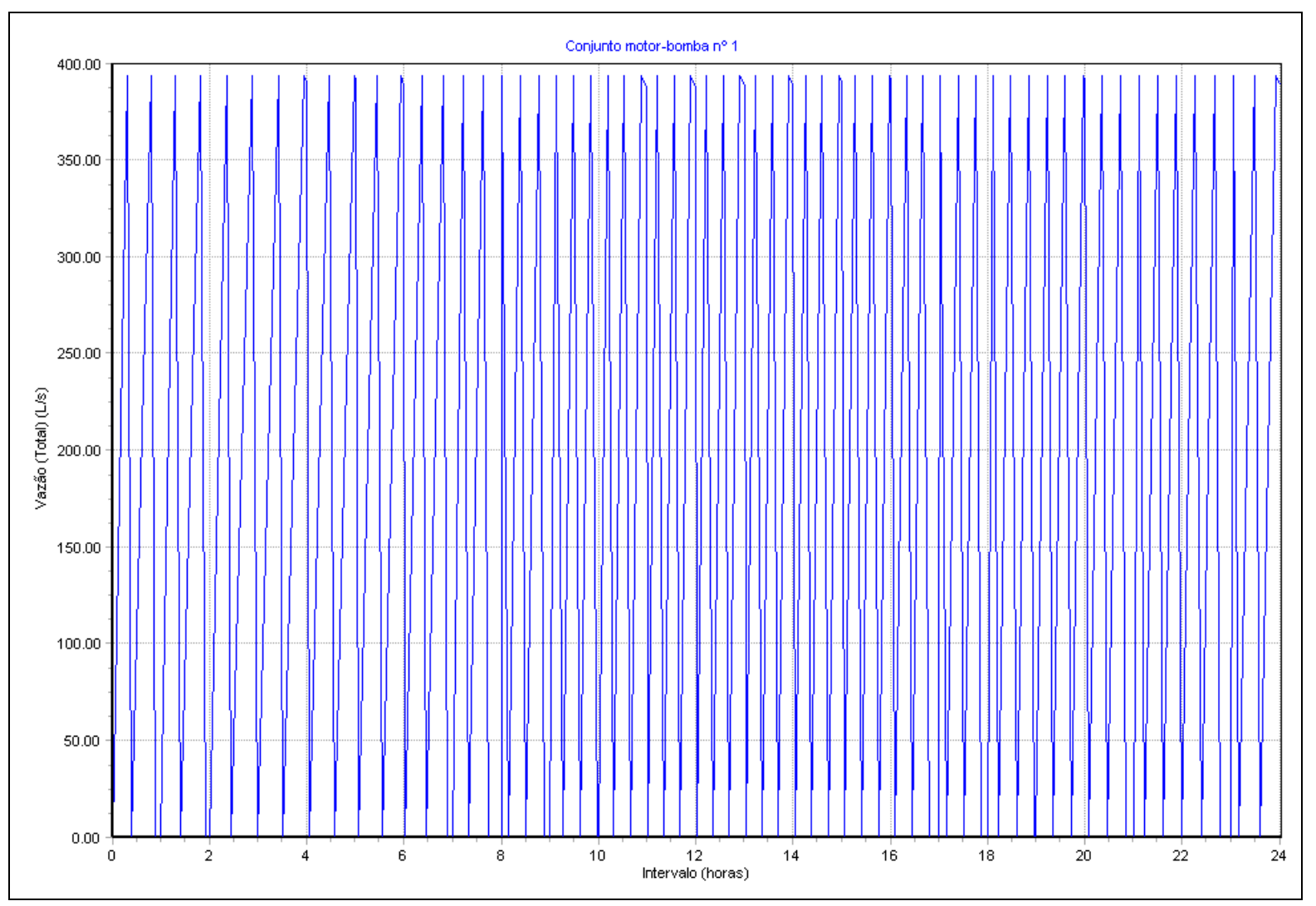

Figura 65 - Gráfico de funcionamento: Conjunto motor-bomba no 1 da EEA Sacomã 


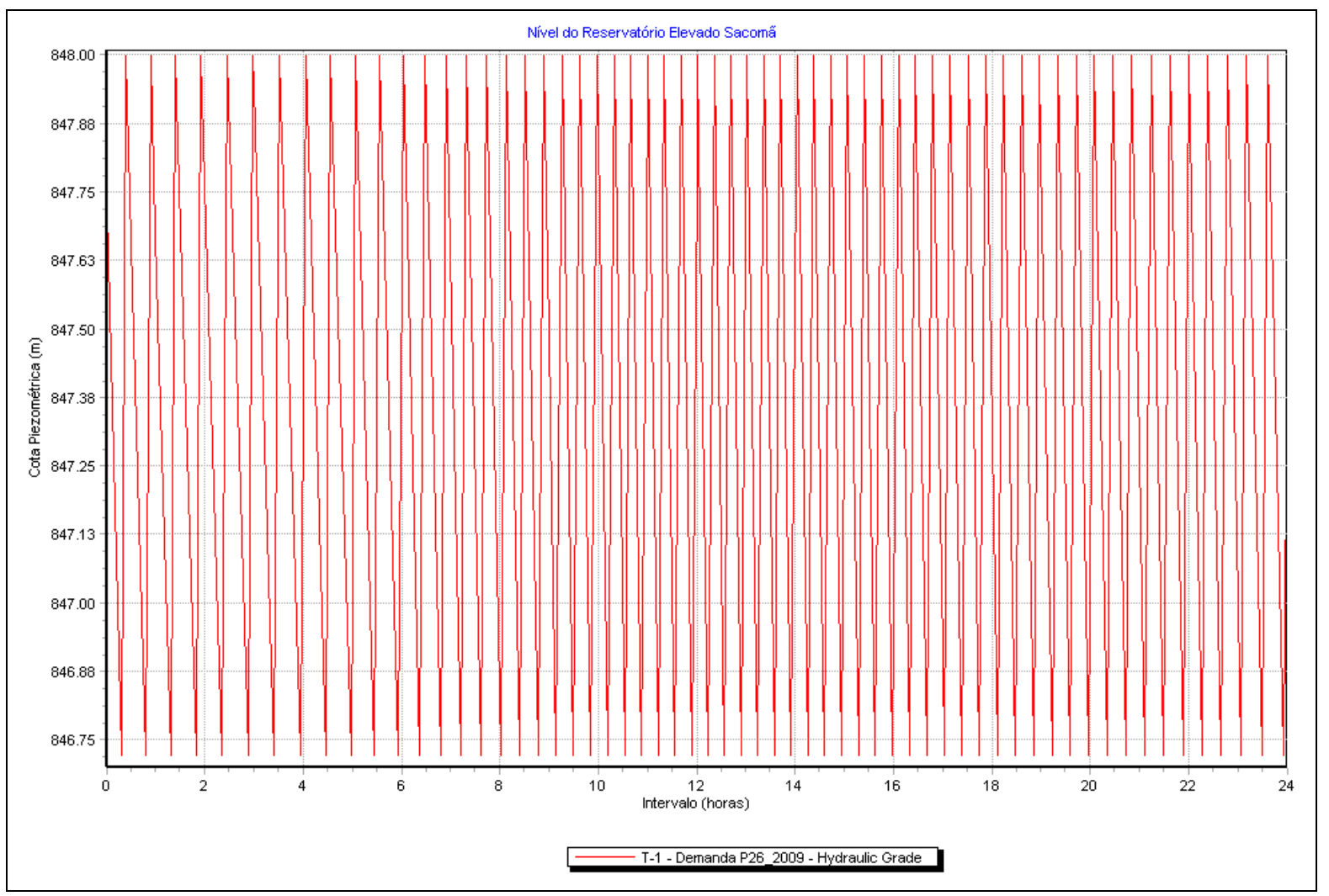

Figura 66 - Gráfico de funcionamento: Reservatório elevado (torre) Sacomã.

\subsection{3ㅁ Versão}

Como comparativo, uma simulação foi elaborada em função de avaliação da rugosidade das redes de distribuição. Cale lembrar que a primeira e a segunda versão foram elaboradas com uma rugosidade padrão - técnica regularmente utilizada principalmente por consultorias com a função de planejar melhorias para o setor - e que definem um coeficiente de rugosidade de Hazen-Williams igual a 90 ou 100 como um valor médio a ser aplicado em razão dos problemas encontrados para a definição de coeficientes mais precisos. Os novos coeficientes foram elaborados segundo a tabela 6.1, produzida através da interpolação de resultados propostos nos trabalhos dos autores (AZEVEDO NETTO et al, 1998) e, as redes sem data definida de instalação foram lançadas com a idade de rede mais antiga presente na simulação. Foram produzidos, então, os resultados ilustrados pelas figuras 6.7 e 6.8 , conforme segue: 


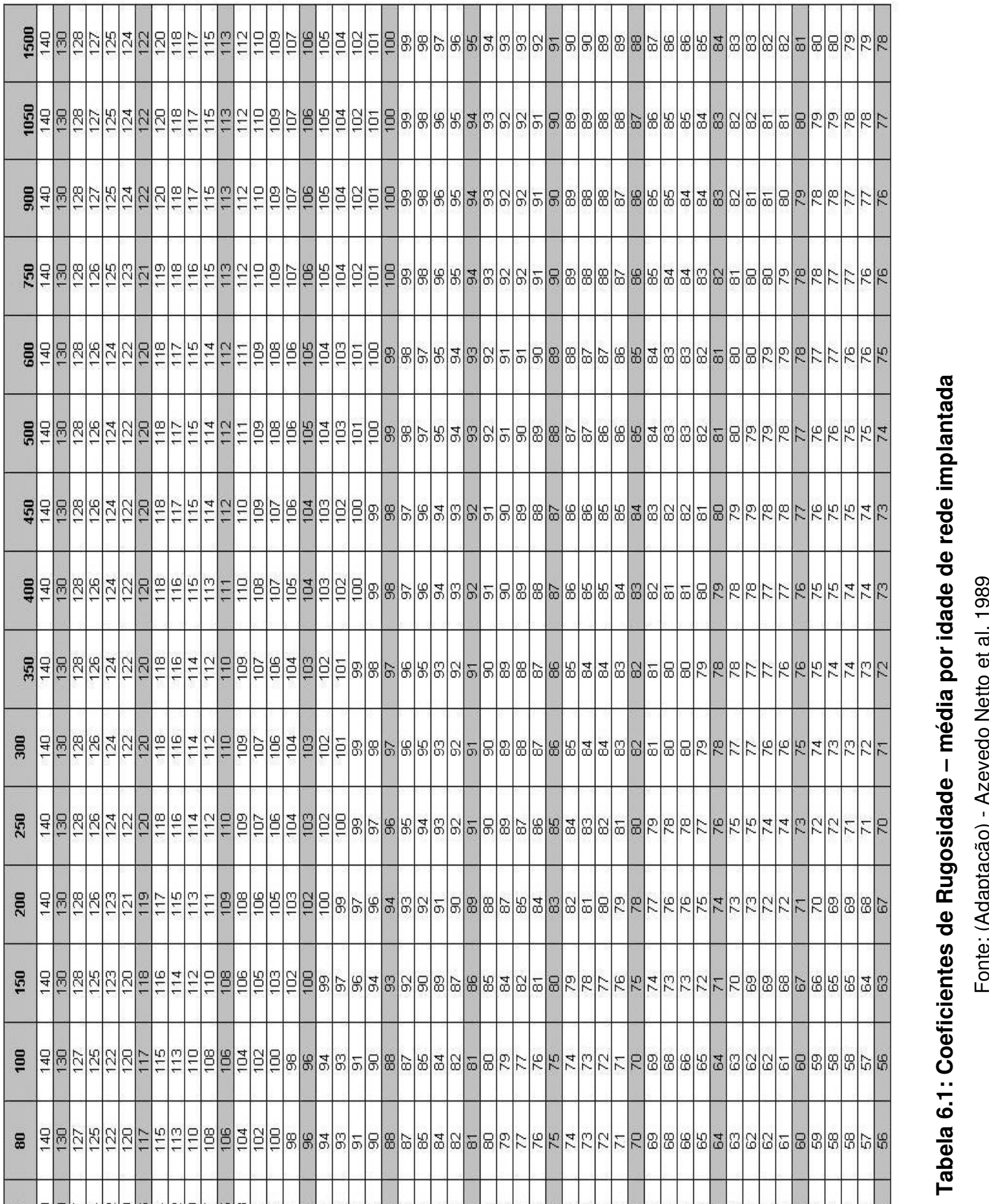

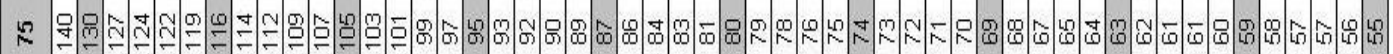

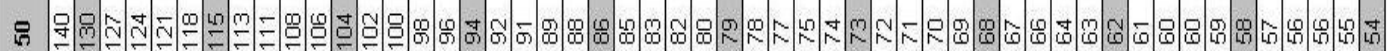

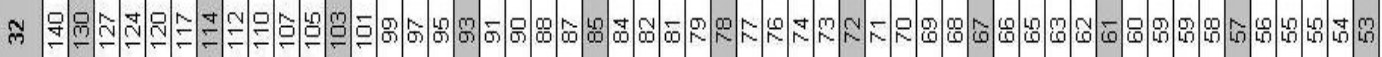

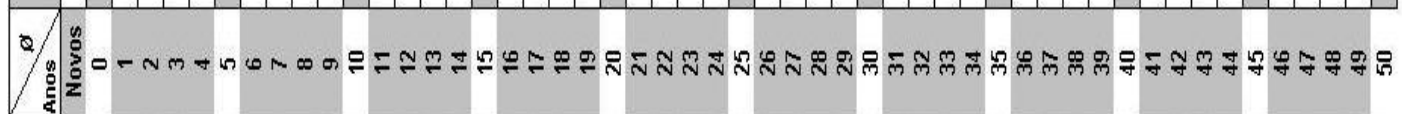

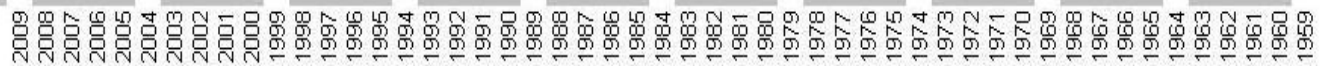




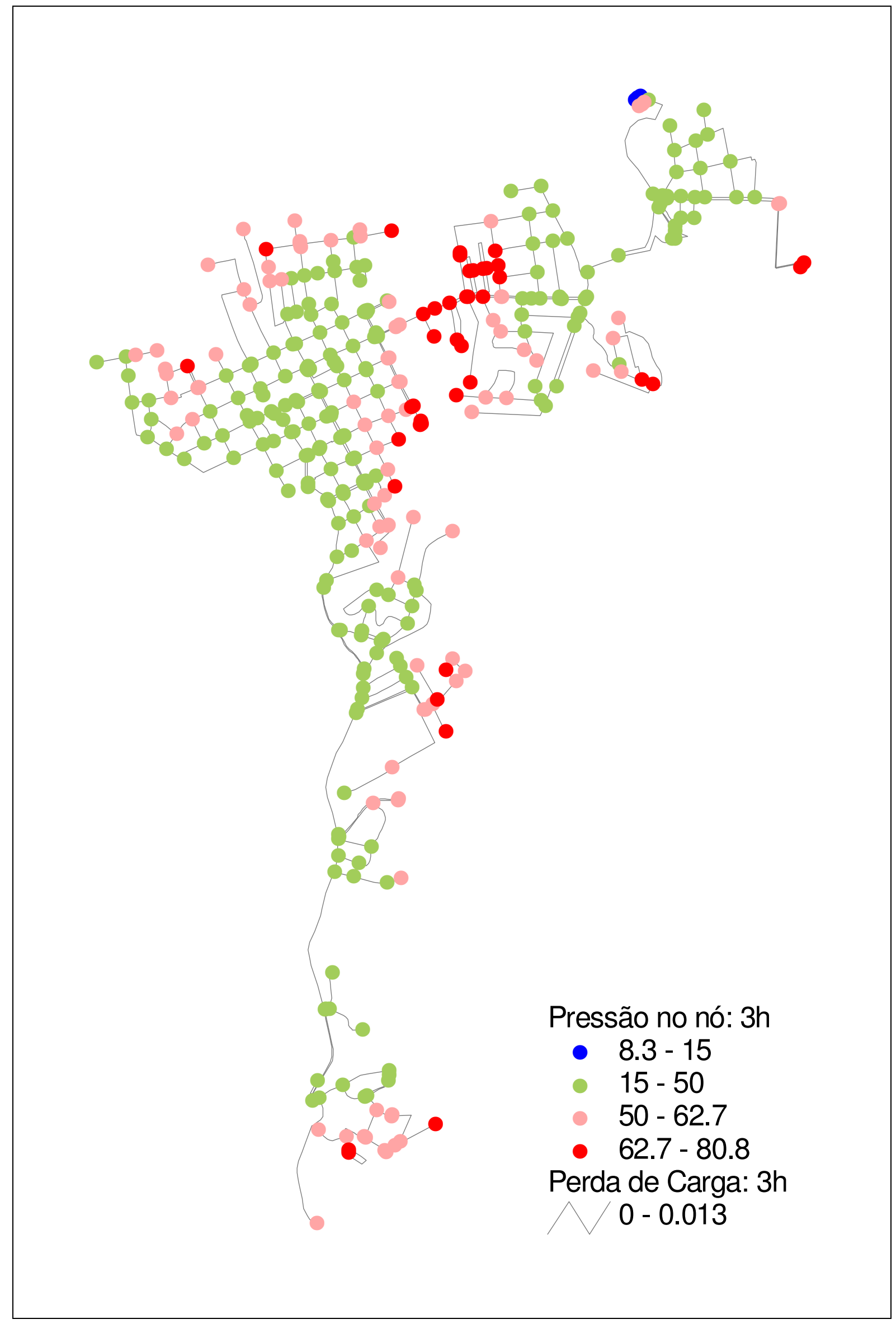

Figura 67 - 3a Versão da simulação trabalhada em ArcView- momento: 3h 


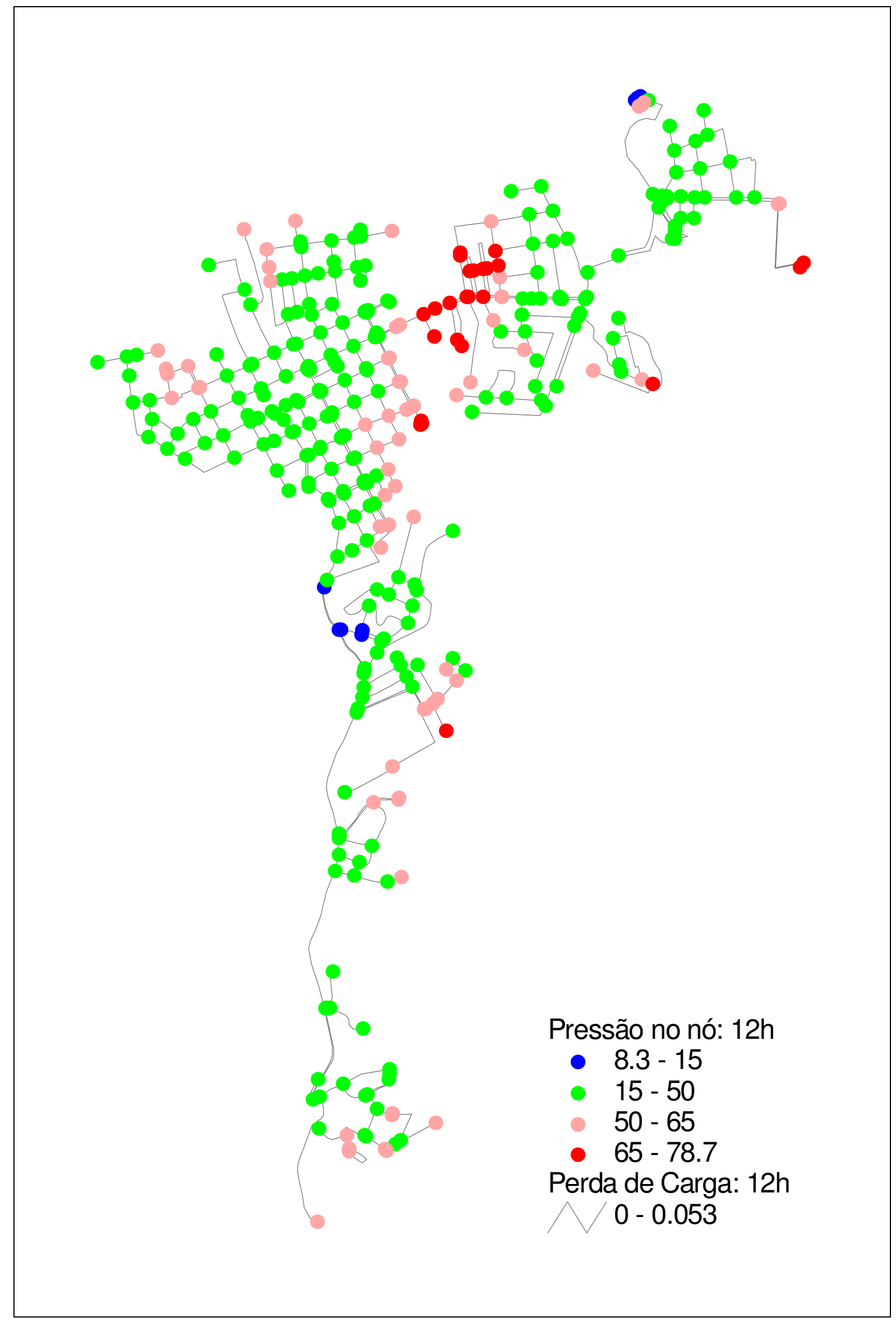

Figura 68 - 3ำ Versão da simulação trabalhada em ArcView - momento: 12h 
Não foram obtidos resultados que justificassem investigações em cada um dos trechos, senão por um sensível crescimento nas perdas de carga apresentadas em relação à $2^{\text {a }}$ Versão, o que justifica, em se tratando de uma simulação hidráulica que pode envolver um grande número de trechos, de cuidados minuciosos quanto ao uso dos fatores de rugosidade para ajuste, não justificando o investimento de tempo e recursos num primeiro momento.

Um ajuste fino pode ser realizado através do comparativo de resultados (simulados $x$ reais), acordados pontos e horários pré-determinados obtidos pela calibração in loco, de forma a serem reproduzidos nos nós e horários sugeridos, de forma ajustada, adequando a perda de carga em função de uma rugosidade maior ou menor e assim definindo o ajuste. Tomando o exemplo utilizado no estudo de caso, foram levantados os dados de campo no mesmo dia e horário em que foi realizado o ensaio para levantamento das curvas características das bombas da estação elevatória de água, em março de 2009.

A partir dos dados de campo, foi elaborado um mapa de forma a representar os pontos escolhidos, relacionados na Figura 6.9, de forma a permitir o ajuste fino, caso fosse necessário. Diversos pontos podem ser escolhidos dentro dos limites do setor e, quanto mais forem estes, melhor a garantia de resultados efetivos. O ponto crítico, essencialmente, deve fazer parte desta amostra.

\subsection{Calibração in loco}

Obtidos os primeiros resultados, vale então avaliar o comportamento do modelo diante de dados de campo, conforme é ilustrado pela figura 6.9, onde foram produzidos mapas temáticos norteando a posição de cada um dos nós amostrados, de forma a permitir um comparativo visual: 


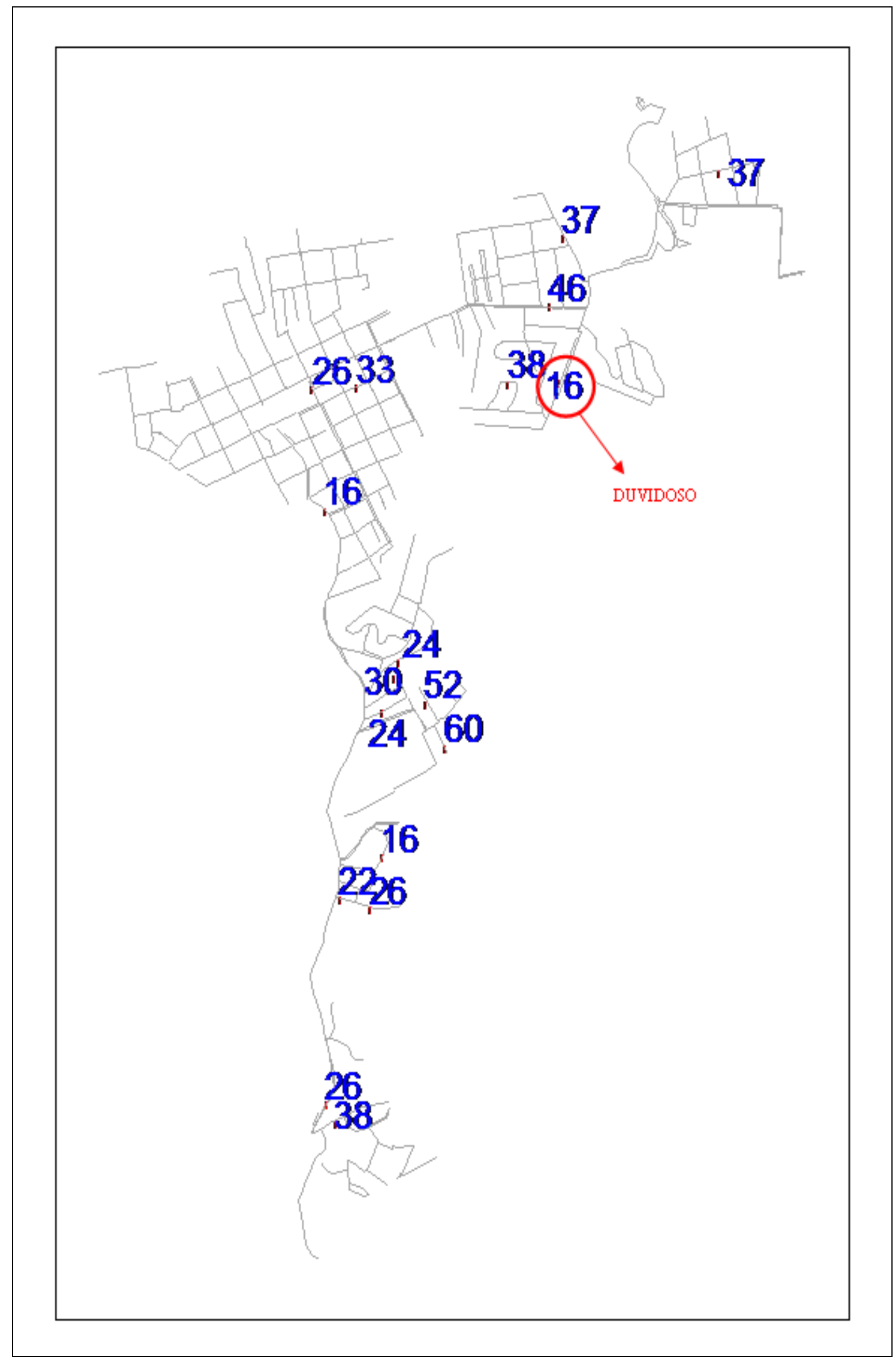

Figura 69 - Mapa temático de calibração do modelo: momento 12h 
No levantamento das informações utilizadas no exemplo, um dos dados obtidos, os do nó 41, não se mostraram confiáveis em razão da grande discrepância quando sujeito aos dados obtidos na simulação e ou intervenção no local, justificando, portanto, nova visita e investigação do motivo, visto que os resultados da simulação condiziam com a realidade, observando-se o comportamento de nós próximos. Descobriu-se, então, que as amostras haviam sido tomadas em 3 ligações que, apesar de sua posição dentro do setor, estariam ligadas em uma rede que atravessava os limites do setor e que por fazer reforço a um setor vizinho, não poderia ser considerada, justificando assim o expurgo destes dados. Assim, foram excluídos os registros referentes aos RGls 00000000020, 00000000021 e 00000000022 dos demais.

\begin{tabular}{|c|c|c|c|c|c|c|}
\hline \multirow{2}{*}{ NÓ } & \multirow{2}{*}{ RGI } & \multirow{2}{*}{$\begin{array}{c}\text { NO } \\
\text { CAMPO }\end{array}$} & \multicolumn{4}{|c|}{ NA SIMULAÇÃO } \\
\hline & & & $\mathrm{C}=90$ & DESVIO \% & CV & DESVIO \% \\
\hline 149 & 00000000001 & 33 & 37.90 & 14.8485 & 36.50 & 10.61 \\
\hline 200 & 00000000002 & 26 & 29.80 & 14.6154 & 28.40 & 9.23 \\
\hline 234 & 00000000003 & 16 & 19.80 & 23.7500 & 18.30 & 14.38 \\
\hline 246 & 00000000004 & 37 & 38.00 & 2.7027 & 37.30 & 0.81 \\
\hline 313 & 00000000005 & 46 & 47.90 & 4.1304 & 47.10 & 2.39 \\
\hline 270 & 00000000006 & 24 & 23.40 & -2.5000 & 21.30 & -11.25 \\
\hline 292 & 00000000007 & 30 & 31.50 & 5.0000 & 29.60 & -1.33 \\
\hline 297 & 00000000008 & 24 & 20.50 & -14.5833 & 18.80 & -21.67 \\
\hline 300 & 00000000009 & 52 & 42.30 & -18.6538 & 40.50 & -22.12 \\
\hline 307 & 00000000010 & 60 & 68.20 & 13.6667 & 66.30 & 10.50 \\
\hline 316 & 00000000011 & 16 & 22.90 & 43.1250 & 21.10 & 31.88 \\
\hline 323 & 00000000012 & 22 & 25.10 & 14.0909 & 23.30 & 5.91 \\
\hline 326 & 00000000013 & 26 & 25.10 & -3.4615 & 26.30 & 1.15 \\
\hline 326 & 00000000014 & 26 & 25.10 & -3.4615 & 26.30 & 1.15 \\
\hline 334 & 00000000015 & 26 & 33.00 & 26.9231 & 31.10 & 19.62 \\
\hline 334 & 00000000016 & 26 & 33.00 & 26.9231 & 31.10 & 19.62 \\
\hline 338 & 00000000017 & 38 & 33.50 & -11.8421 & 31.70 & -16.58 \\
\hline 553 & 00000000018 & 38 & 51.50 & 35.5263 & 44.20 & 16.32 \\
\hline 465 & 00000000019 & 37 & 36.70 & -0.8108 & 36.00 & -2.70 \\
\hline 41 & 00000000020 & 16 & 42.40 & 165,00 & 41.70 & 160,63 \\
\hline 41 & 00000000021 & 16 & 42.40 & 165,00 & 41.70 & 160,63 \\
\hline 41 & 00000000022 & 16 & 42.40 & 165,00 & 41.70 & 160,63 \\
\hline
\end{tabular}


Pela diferença aceitável entre os resultados, para continuidade da pesquisa, adotaram-se os resultados da modelagem em função da $2^{-a}$ versão. Novamente há a necessidade de mencionar as dificuldades encontradas quando se busca precisão absoluta em razão das inúmeras variáveis envolvidas. O preciosismo pode tornar-se inviável sob muitos aspectos, bastando ao analista avaliar o comportamento da pressão dentro do conjunto, cabendo melhorias o quanto forem viáveis como meio de garantir equilíbrio e o atendimento aos requisitos técnicos e a necessidade que justificou a concepção dos trabalhos.

\subsection{Modelo x Mapas Temáticos}

Outra forma de proporcionar calibração ao modelo é submeter seu comportamento a representando dos mapas temáticos oriundos de seu histórico de reparos de vazamentos. Vazamentos de rede, em número, representam uma pequena porcentagem das ocorrências, mas através destas, grandes volumes são perdidos. Redes enterradas só mostrarão seus vazamentos após a saturação total do solo, somando-se a estes grandes volumes que se perdem, por exemplo, ao adentrarem em galerias de águas pluviais, redes de esgoto, etc. Vazamentos de ramal são recorrentes em função da má qualidade das tomadas, material e mão de obra utilizada para este fim e os vazamentos de cavalete, por sua vez, são rapidamente notados e reparados em função da relativa facilidade de visualização de sua incidência.

As ocorrências de vazamento na rede e nos ramais de distribuição mostram a fragilidade das ligações em função das variações da pressão a que esta rede é submetida, devidas principalmente à desconexão de peças que compõem 0 conjunto. De forma a reduzir o número de intervenções e de volumes perdidos, é necessária uma gestão eficiente das variações de pressão e a golpes de aríete a que as ligações e as redes estão sujeitas. Como meio de comprovação do impacto das pressões ao número de vazamentos, por meio de associação, foram utilizados mapas temáticos por tipo de vazamento, onde é facilmente observado que os pontos de pressão mais crítica, segundo os resultados da simulação, são os mesmo que apontam maior número de ocorrências, segundo ilustram os mapas temáticos. 
Para avaliação, foram elaborados mapas mostrando a quantidade de vazamentos durante o semestre, específicos a cada tipo de ocorrência, conforme ilustram as Figuras $6.10,6.11$ e 6.12, atentando-se, em detalhe, pelas maiores concentrações de ocorrências: 


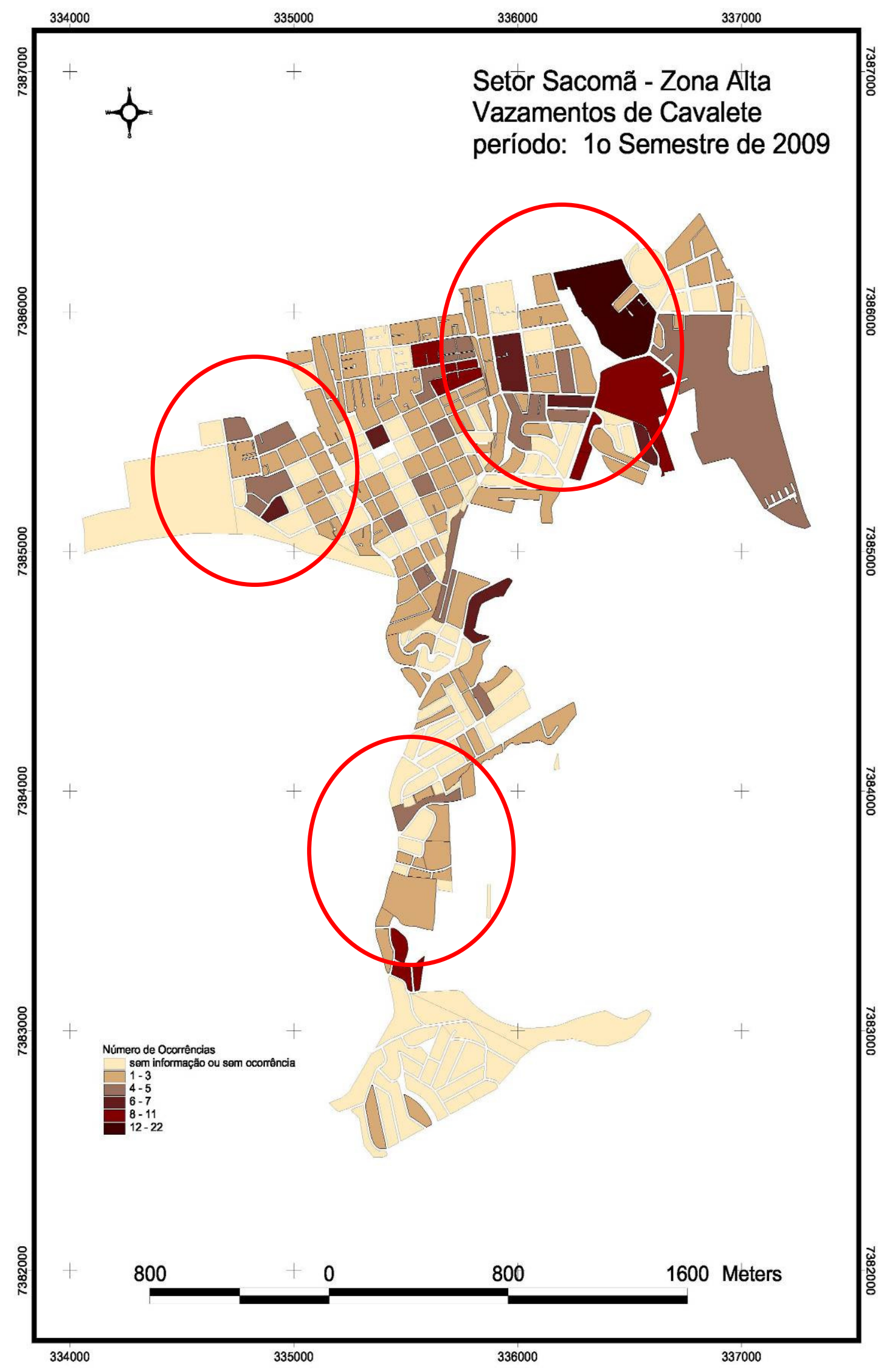

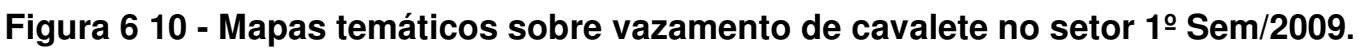




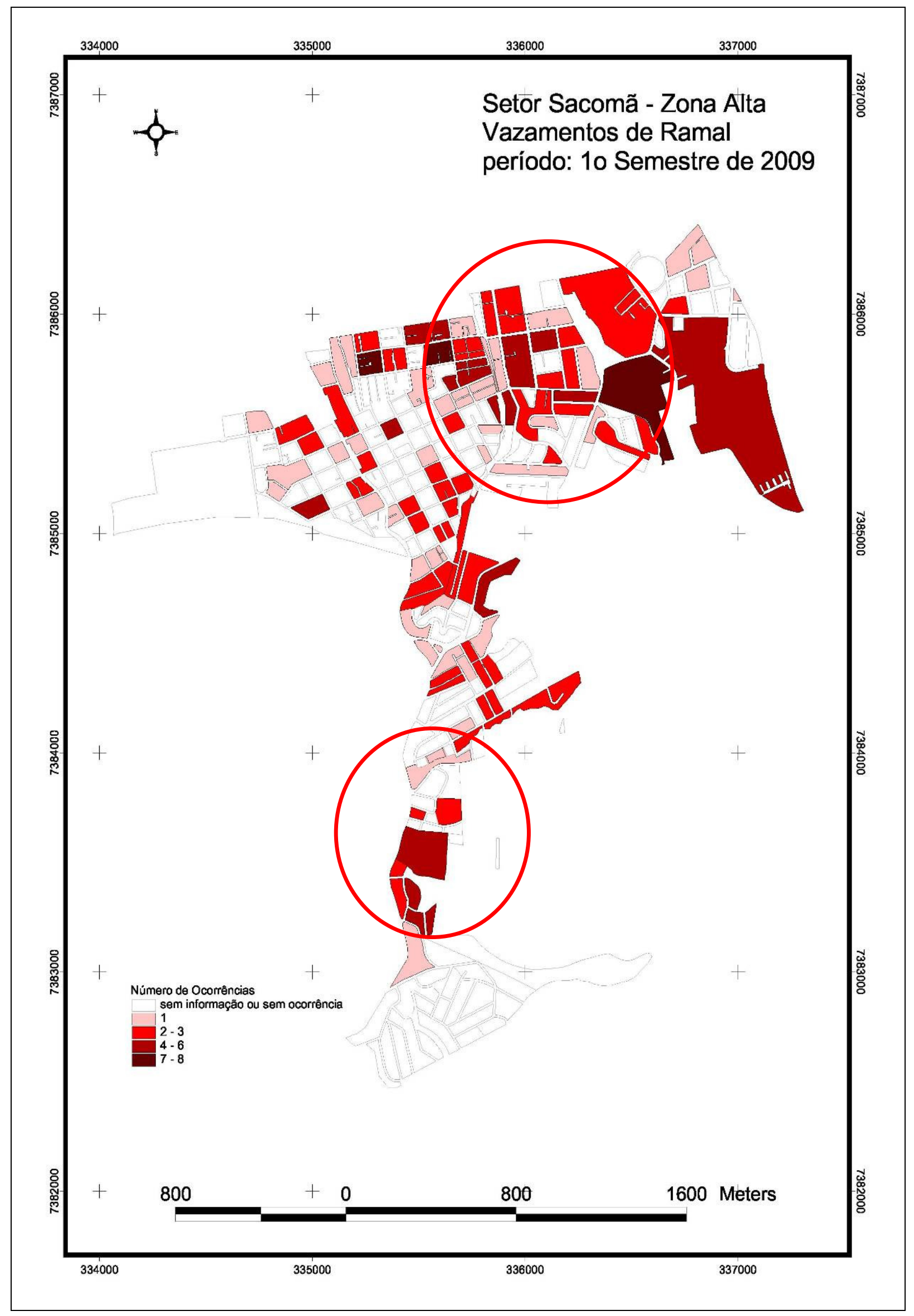

Figura 611 - - Mapas temáticos sobre vazamentos de ramal no setor 1 Sem/2009 


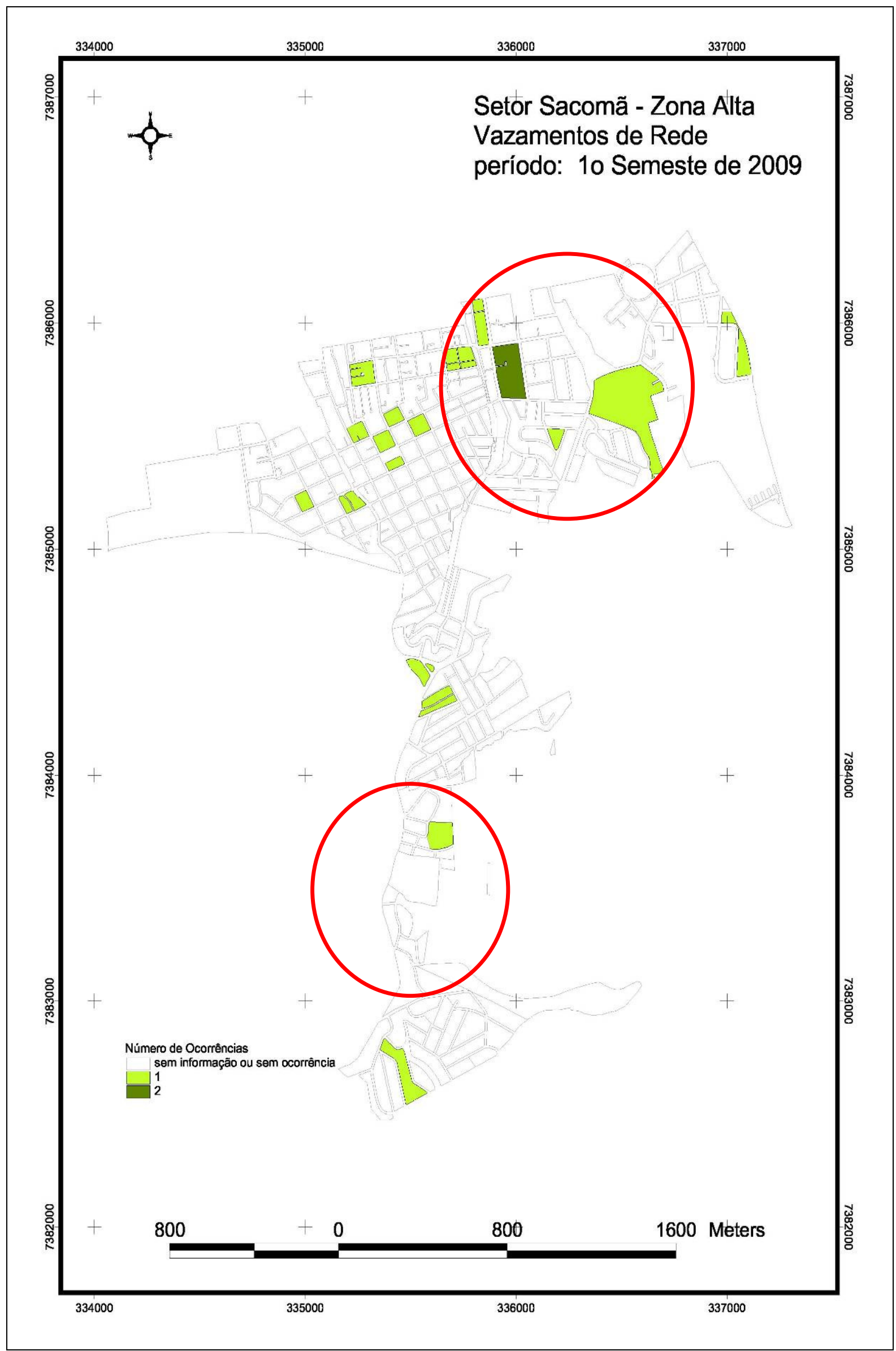

Figura 612 - Mapas temáticos sobre vazamentos de rede no setor 1 Sem/2009 
Originalmente, os mapeamentos de vazamento são utilizados pela concessionária em muitas atividades, como avaliação dos principais pontos geradores de perdas visíveis, atenção a áreas de influência de projetos piloto, avaliação e priorização de trechos de rede a serem substituídas ou reabilitadas, mapeamento de resultados após intervenções na forma de "antes e depois" ou estabelecimento de limites para instalação de válvulas reguladoras de pressão.

No exemplo adotado, a utilidade dos mapas temáticos de vazamentos vem da confirmação das áreas consideradas críticas pelo número de vazamentos concentrado num mesmo local. Altas pressões podem ser assim confirmadas, garantindo a funcionalidade das simulações hidráulicas produzidas:

1. Segundo tomadas de pressão in loco;

2. Através dos mapas temáticos.

No estudo de caso, melhor do que basear-se, por rigidez em atender critérios prédefinidos (muitas vezes inviabilizando os trabalhos em grandes setores) e por demoradas pesquisas que permitam ajustes finos ou pontuais, os mapas temáticos podem auxiliar o analista quanto à caracterização operacional do setor de abastecimento.

Quanto a pressões inferiores a 15 mca que são retratadas no modelo, tomando o rigor dos dados lançados na simulação como fatores de segurança e no número de reclamações de pressão baixa, podem-se considerar satisfeitos tais requisitos técnicos.

\subsection{Modelo x Curva de Consumo para Análise Dinâmica}

A importância da elaboração de uma análise dinâmica, variável com o tempo, é crucial quando se planeja simular um setor em tempo estendido. A curva de demandas em função do tempo, segundo a proposta de TSUTIYA (2004), é 
genérica e obviamente não representa o comportamento hidráulico real do setor em função de suas mais de 8000 ligações, cada qual com comportamento diferenciado. Opções foram avaliadas, como a de utilizar a curva de funcionamento da estação elevatória, mas esta se mostrou inviável caso existisse qualquer forma de amortecimento oriundo da operação do reservatório elevado, condição que poderia influenciar na curva de consumo em razão da mudança de sentido provocado pelo esvaziamento e enchimento do reservatório elevado, conforme sugere a Figura 6.13:

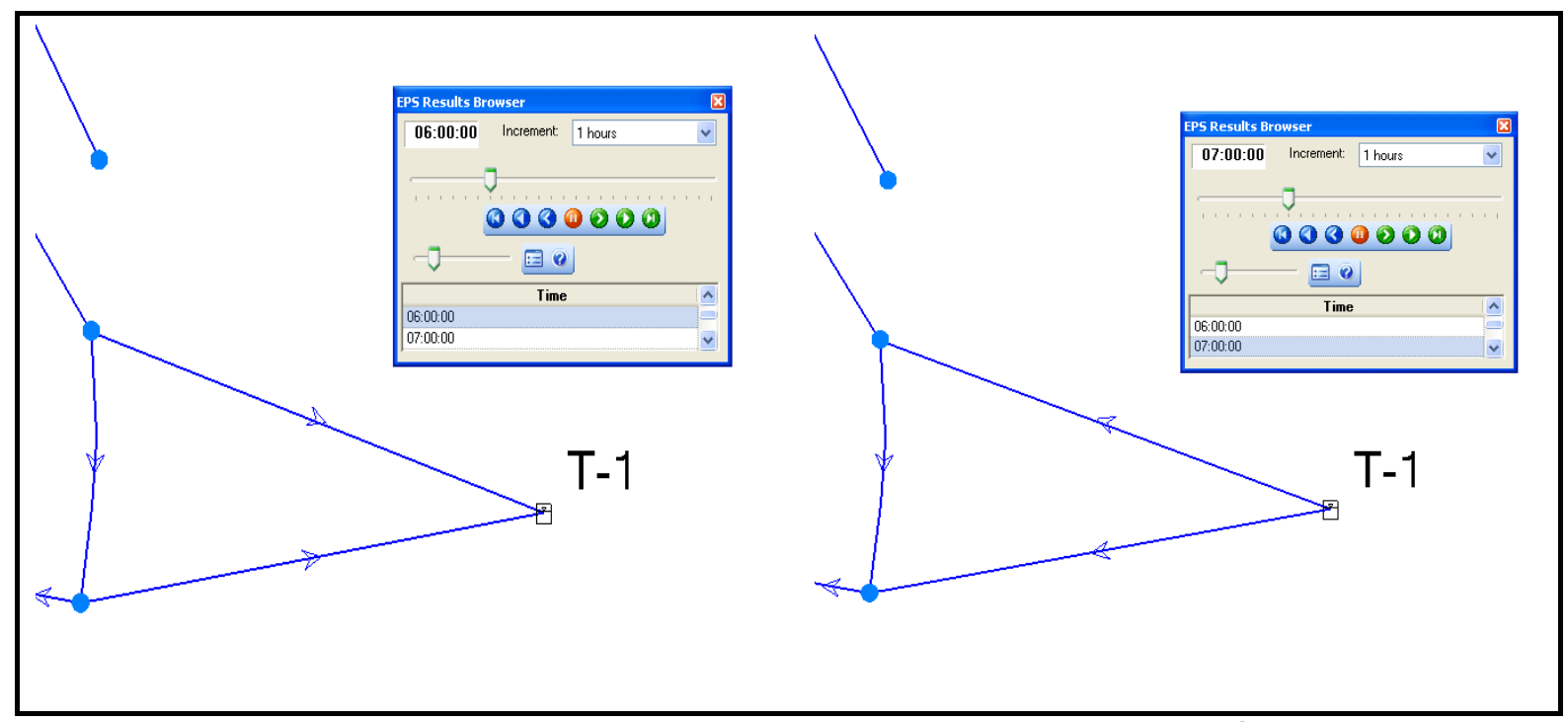

Figura 613 - Momentos de enchimento e esvaziamento do reservatório elevado

Como escolha, foi adotada a curva teórica proposta para a elaboração do modelo. Descobriu-se, porém, a possibilidade de se obter uma curva que representasse qualitativamente o comportamento do setor como um todo, aproveitando a oportunidade de avaliar se a curva neutra de variação horária poderia ser realmente utilizada. Como grande parte da vazão passa pela rede de DN 450 na Rua Simão Lopes, mais exatamente na área compreendida pelo nó 525, é possibilitada a representação do comportamento de todo o setor, independente de qualquer interferência do reservatório elevado, avaliando assim pela possibilidade de substituição da curva inicialmente proposta. Comparados seus resultados (fig. 6.14), fica ratificado o uso da curva de consumo em função do tempo de TSUTIYA (2004), através de comparativo com o gráfico da curva de consumo do dia 14/12/2009, mostrando boa aplicabilidade da curva neutra utilizada pela sua pouca dispersão em relação à curva real. 


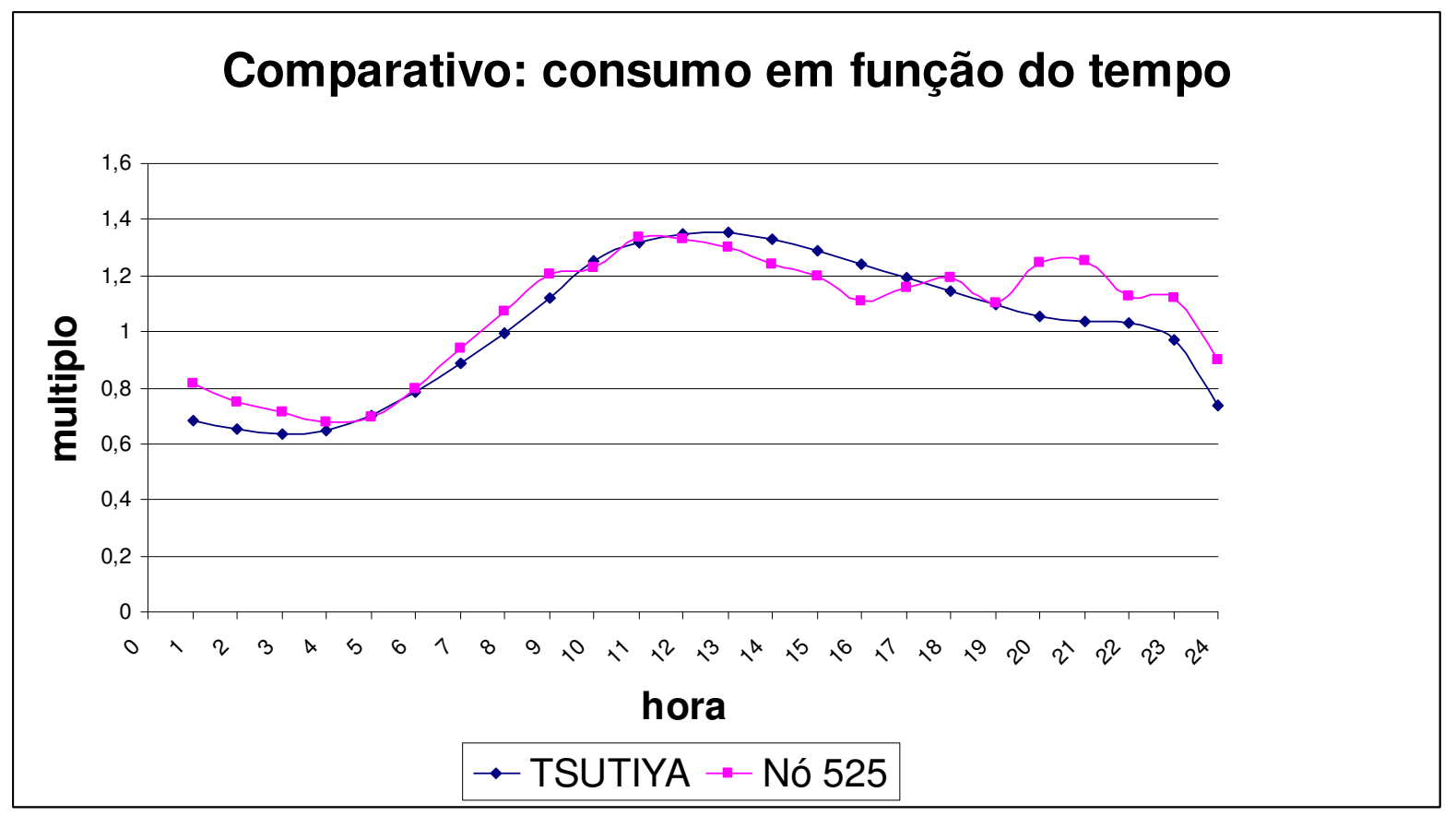

Figura 614 - Comparativo: Curva Consumo x Tempo 


\section{CONCLUSÕES}

O desenvolvimento desta forma de trabalho foi fundamental para o desenvolvimento da capacidade crítica do analista. É necessário que este não se atente somente a dados, mas também ao comportamento e a todos os erros que trabalhos desta natureza estarão sujeitos, justificando inclusive visitas à área estudada para constatações in loco. O geoprocessamento mostrou-se como um eficiente instrumento de calibração de redes secundárias de distribuição em razão das dificuldades para tomadas de amostragem comuns para redes de adução e redes primárias, mas que não serão suficientes, senão um para ajuste fino. Para tanto, o analista deve contar com um razoável sistema de informações oriundos da rotina operacional que permitam reproduzir mapas temáticos de boa qualidade e que reproduzam o comportamento operacional do setor estudado, assim como justificar discrepâncias.

As deficiências apontadas pela simulação, devidamente confirmadas pelos mapas temáticos confirmam o posicionamento das falhas, permitindo estabelecer prioridades de atenção em razão do tamanho da área envolvida e ainda permitir a elaboração de diagnóstico e de prognósticos para acompanhar a viabilidade e resultados das intervenções.

Avaliando os resultados apresentados e calibrados, mesmo que alguns dos desvios apresentados na tabela 6.3 sejam superiores aos recomendados (chegando, inclusive, a $20 \%$ de desvio), ainda é viável a adoção do modelo computacional hidráulico proposto em função do mesmo refletir com boa qualidade o comportamento real do setor de abastecimento Sacomã. Tal ajuste pode ser realizado com o uso de algoritmos próprios para calibração, fixadas as pressões nos pontos determinados para a amostragem e solicitada à adequação do modelo segundo estas restrições. Quando maior o número de pontos coletados in loco (devidamente avaliados), maior e mais confiável se mostrará o modelo, ratificando novamente a importância da calibração. 
O horário de pico testado, 12 horas, reflete a solicitação de pressões pela vazão acima da média, confirmada pelo número de intervenções apontadas nos mapas temáticos de vazamento, assim como seus resultados pontuais confirmados pelo mapa de calibração. Ainda, foram avaliados gráficos de atuação da estação elevatória e da torre, também refletindo o comportamento sugerido. A $2^{\underline{a}}$ versão, calibrada, e a $3^{\text {a }}$ versão, de rugosidade corrigida, aponta resultados condizentes, permitindo por estas a definição de estratégias de melhoria operacional.

Especificamente tratando do objeto de estudo de caso, vale destacar que a adoção de um coeficiente de rugosidade uniforme ao invés da utilização dos valores variáveis, segundo diâmetro e idade específicos de cada trecho, não trouxeram impactos significativos para análise e diagnóstico das condições operacionais do setor. Em outros casos, uma análise de sensibilidade deve ser realizada.

Os modelos podem reproduzir e permitir a avaliação, inclusive, de fatos que se mostrem num primeiro plano como incontestáveis, como foi exemplificado na dúvida em relação à adoção do dado de calibração do nó 41 , onde três pontos tomados in loco, geraram divergências com a realidade, permitindo detectar a inconsistência em tempo de investigar e diagnosticar a falha. Porém, vale ressalvar que, apesar de reconhecidamente ser uma excelente ferramenta para análise e suporte à decisão, não se pode prescindir do conhecimento e experiência do corpo técnico que nota as imprecisões e que sabe aonde procurar as respostas.

A metodologia se mostra válida e vantajosa, desde que 0 analista possa contar com:

- Cadastro técnico sempre atualizado;

- Programas confiáveis;

- Demanda cuidadosamente avaliada;

- Corpo técnico habilitado; 


\section{RECOMENDAÇÕES}

Outros trabalhos poderão ser desenvolvidos utilizando da praticidade do desenvolvimento desta simulação como, por exemplo, quanto a um comparativo de viabilidade entre a simples redução de velocidade dos conjuntos atuantes e a substituição dos conjuntos motor-bomba, concepção de matriz para avaliação de calibradores automáticos e, inclusive, quanto à melhoria operacional deste mesmo setor após sua adequação.

O incentivo a melhoria e disseminação das técnicas já conhecidas e o desenvolvimento de novos instrumentos de diagnósticos serão essenciais para a redução dos volumes até então perdidos durante o transporte de água. As técnicas de otimização visam, necessariamente, pela redução de energia empregada, desenvolvimento de técnicas de recuperação e prolongamento da vida útil de materiais e equipamentos e, para tanto, necessita do desenvolvimento de sistemas computacionais que permitam a gestão sobre o conjunto, apontando pontos críticos e avaliando o potencial das soluções empregadas, essenciais aos sistemas de abastecimento que a cada dia estão mais solicitados e proporcionalmente, limitados.

Vale observar quanto ao cuidado de reproduzir o atual estado dos conjuntos motorbomba, visto que o estado da bomba no momento atual e não o original, segundo sugerem catálogos de fabricantes. Caso usados os catálogos, convém cuidado e em razão do desgaste a qual estas estão sujeitas pelo uso. 


\section{REFERÊNCIAS BIBLIOGRÁFICAS}

AKDOGAN, T.; Design of Water distribution system by optimization using Reliability considerations. Middle East Technical University. Ankara, 2004;

AL-ZAHRANI, M. A.; MOIED, K.; Optimizing water quality monitoring stations using genetic algorithms. Arabian Journal for Science and Engineering Vol. 28, Issue.1B, 2003;

ARIKAWA, K. C. O.; Perdas reais em sistemas de distribuição de água. Proposta de metodologia para avaliação de perdas reais e definição das ações de controle. Dissertação de Mestrado: Universidade de São Paulo. São Paulo, 2005;

AZEVEDO NETTO, J. M.; Técnica de abastecimento e tratamento de água. - 2 vol. São Paulo: FSP - CTSB CETESB / ASCETESB; 1973;

AZEVEDO NETTO, J. M.; FERNANDEZ, M. F.; ARAUJO, R.; ITO, A. E.; Manual de Hidráulica 8ª Edição Ed. Edgar Blucher Ltda. São Paulo, 1998;

BARROSO, L. B.; Estudo da minimização das perdas físicas em sistemas de distribuição de água utilizando o modelo EPANET. Tese de Mestrado: Universidade Federal de Santa Maria. Rio Grande do Sul, 2005;

BRASIL, Ministério das Cidades; Documento Técnico de Apoio: DTA D1 - Controle da pressão na rede - PNCDA. Brasília: Ministério das Cidades, 2004;

CARRIJO, I. B.; Extração de regras operacionais ótimas de sistemas de distribuição de água através de algoritmos genéticos multiobjetivo e aprendizado de máquina. Tese de Doutorado: Escola de Engenharia de São Carlos - Universidade de São Paulo; São Carlos, 2004;

CASTRO, M. A. H.; ARAÚJO, F. F. V.; FURLANI, J. M. R.; Uma Interface Gráfica para o EPANET e para o LINGO. Seminário Planejamento, Projeto e Operação de Redes de Abastecimento de Água. O Estado da Arte e Questões Avançadas, 2002. João Pessoa, 2002; 
CHEUNG, P. B.; VAN ZYL, J. E.; REIS, L. F. R.; Extension Epanet for Pressure Driven Demand Modeling in Water Distribution System In: Walters, G.; Savic, D. (Org.). Computing and Control for the Water Industry. Center for Water Systems University of Exeter. UK, 2005;

COLOMBO, F.; Calibração de Modelos de Rede de Abastecimento de Água Admitindo Vazamentos. Dissertação de Mestrado: Escola de Engenharia de São Carlos - Universidade de São Paulo. São Carlos, 2007;

CONEJO, J. L.; LOPES A. G.; MARCKA, E.; Programa Nacional de Combate ao Desperdício de Água: Medidas de Redução de Perdas - Elementos para Planejamento, Documentos técnicos de apoio. Secretaria Nacional de Desenvolvimento Urbano e Secretaria de Política Urbana da Presidência da República. Brasília, 1999;

DIAS, C. H.; GOMES, A. M.; Otimização de Redes de Distribuição de Água com Estações de Bombeamento. Depto de Matemática Aplicada UNICAMP, Campinas, 2002;

FARLEY, M.; TROW, S.; Losses in water distribution networks: a practitioner's guide to assessment, monitoring and control. London, 2003;

FONSECA, E. A. M.; Manutenção de Adutoras, CETESB - Companhia Estadual de Tecnologia de Saneamento Básico, São Paulo, 1974;

FRANCO, S.C.C.S.; Cartografia digital como ferramenta de gestão operacional de redes de distribuição de água - Tese de Doutorado: Escola Politécnica da Universidade de São Paulo. São Paulo, 2000;

GALVÃO, J.R.B.; Avaliação da relação pressão $x$ consumo, em áreas controladas por válvulas redutoras de pressão (VRPs): estudo de caso - redes de distribuição de água da Região Metropolitana de São Paulo. - Dissertação de Mestrado: Escola Poltécnica da Universidade de São Paulo. São Paulo, 2007;

GERMANOPOULOS, G.; JOWITT, P. W.; Leakage reduction by excess pressure minimization in a water supply network. Proc. Inst. Civ. Engineers Part 2, June, p. 195-214, 1989;

GOBBI, J. E.; GIOF: Gerenciamento Integrado da Operação e do Faturamento em sistemas urbanos de abastecimento de água - Dissertação de Mestrado: Universidade de Campinas. Campinas, 2002; 
GOMES, H. P.; Sistemas de Abastecimento de Água - Dimensionamento econômico e operação de redes e elevatórias $2^{2}$ ed. Ed. Universitária UFPB. João Pessoa, 2004;

GOMES, H. P.; Eficiência hidráulica e energética em saneamento: Análise econômica de projetos. Ed. ABES. Rio de Janeiro, 2005;

GONÇALVES, E.; Metodologias para Controle de Perdas em Sistemas de Distribuição de Água - Estudo de Casos da CAESB. Dissertação de mestrado: Universidade de Brasília. Brasília, 1998;

GUMIER, C. C.; Aplicação de modelo matemático de simulação-otimização na gestão de perda de água em sistemas de abastecimento. Dissertação de mestrado: Universidade de Campinas. Campinas, 2005;

ITONAGA, L. C. H.; Estudo da aplicação de modelos de redes de água no controle de perdas em casos reais. Dissertação de Mestrado: Universidade de Brasília. Brasília, 2005;

JOWITT, P.W.; XU, C.; Optimal valve control in water distribution networks. Journal of Water Resources Planning and Management ASCE, vol. 116, n. 4, p. 455472, 1990;

KLUMB, A.; O Plano Nacional de Saneamento Básico - PLANASA. Revista DAE ano XXVII no 112. São Paulo, 1977;

LAMBERT, A.; HIRNER, W.; Losses from water supply systems: standard terminology and recommended performance measures. IWA Blue Pages. UK, 2000;

LUVIZOTTO JR, E.; RODRIGUES, W.; Análise do desgaste dos componentes de válvulas de controle automáticas em sistemas públicos de abastecimento de água potável. In: Planejamento, Projeto e Operação de sistemas de abastecimento de água, 200. João Pessoa, 2002;

MEGACIDADES - Grandes Reportagens, Suplemento Jornal O Estado de São Paulo de 03/08/2008. São Paulo, 2008; 
MENDES, G. M.; KOELLE, E.; RODRIGUES, J. A.; DELMONDES, T.; Gestão Integrada em Empresas de Saneamento - Fundamentos e Aplicação. Aracaju, 2002;

MORAIS, D. C.; ALMEIDA, A. T.; Modelagem multicritério em grupo para Planejamento estratégico do controle de perdas no abastecimento de água. Recife, 2005;

NOVAROSKI, M. J.; Cálculo de Pressões e Vazões em redes hidráulicas. Dissertação de Mestrado: Universidade Federal do Paraná. Curitiba, 2005;

OPAS - Organização Pan Americana de Saúde. Saúde nas Américas: Publicação Científica e Técnica № 622. Washington, D.C, 2007;

PDAA - Plano diretor de abastecimento de água da Região Metropolitana de São Paulo. Consórcio Encibra S.A./Hidroconsult. Governo do Estado de São Paulo, Secretaria de Energia, Recursos Hídricos e Meio Ambiente, São Paulo, 2006.

PIRES, I. M.; O atual estágio do PLANASA. Revista DAE. Ano XXVII ํo 112. São Paulo, 1977;

PORTO, R. M.; Hidráulica Básica. 3. Ed. São Carlos: EESC-USP São Paulo, 2004;

PROCEL.; Manual Prático de Eficiência Energética em Sistemas de Bombeamento. Rio de Janeiro, 2005;

PROENGE Engenharia e Projetos S/C Ltda.; Projeto Complementar do Reservatório do Setor Sacomã - Zona Média. São Paulo, 1995;

PROESA Engenharia Ltda.; Relatório Justificativo e Pacote Técnico das Obras de Adução, Reservação e Distribuição de Água do Setor Sacomã vols. I a V Relatórios Justificativos do Projeto. São Paulo, 1987;

RIBEIRO, G. P.; Operação Otimizada do Sistema Adutor Metropolitano Utilizando Algoritmos Genéticos - Estudo de Caso: SAM Leste da Região Metropolitana de São Paulo (RMSP). Tese de Doutorado: Universidade de São Paulo. São Paulo, 2005; 
RIGHETTO, A. M.; Operação Ótima de Sistema Urbano de Distribuição de Água. In: Seminário-Planejamento, Projeto e Operação de Redes de Abastecimento de Água. O Estado da Arte e Questões Avançadas. João Pessoa, 2002;

ROSSMAN, L. A.; EPANET 2.0 - "Users Manual" U.S. Environmental Protection Agency. Cincinnati, 2000;

SABESP; Plano Plurianual de Ações para Redução de Perdas na Unidade de Negócio Centro, Período: 2008 a 2012 ver. 1. São Paulo, 2007;

SABESP; Programa de Desenvolvimento Operacional - Subprograma de Reabilitação de Redes de Água na Metropolitana, São Paulo, 2008;

SELVAKUMAR, A.; CLARK, R. M.; SIVAGANESAN, M.; Costs for Water Supply distribution systems rehabilitation. EPA/600/JA - 02/406. New Jersey, 2002;

SEREC - Serviços de Engenharia Consultiva Ltda.; Estudo de Adequação da Rede Primária e Projeto Executivo de Distribuição de Água do Setor Sacomã. São Paulo, 1997;

SILVA, K. O.; A periferização causada pela desigual urbanização brasileira. Revista Urutágua. Maringá, no 11, dez/jan/fev/mar. 2007;

SIMÃO, A. C.; e RODRIGUES, J. M. C.; Ferramentas SIG com técnicas de 10 para agilização de intervenções em redes técnicas urbanas. Instituto de Engenharia de Sistemas e Computadores - INESC. Coimbra - Portugal, 2003;

SOARES, A. K.; Calibração de modelo de redes de distribuição de água para abastecimento considerando vazamentos e demandas dirigidas pela pressão. Dissertação de Mestrado: Universidade de São Paulo. São Carlos, 2003;

SOARES, A.K; REIS, L. F. R.; SILVA, F. G. B.; Modelos de Simulação Hidráulica Dirigidos pela Pressão (MSHDP) com o suporte do EPANET: Anais do Seminário Hispano-Brasileiro sobre Planejamento, Projeto e Operação de Redes de Abastecimento de Água, O Estado da Arte e Questões Avançadas, 2002b. In: I SEREA, João Pessoa, 2002;

SOARES, A. K; REIS, L. F. R.; SILVA, F. G. B.; Aplicação do Método Híbrido AGSimplex na Resolução do Problema Inverso de Determinação de Parâmetros de Redes de Distribuição de Água para Abastecimento. In: XXIV Iberian Latin- 
American Congress on Computational Methods in Engineering, 2003, Ouro Preto MG, 2003b;

SEADE Fundação Sistema Estadual de Análise de Dados; Projeção para o Estado de São Paulo: População e Domicílios até 2025. São Paulo, 2004;

TARDELLI FILHO, J. Controle e Redução de Perdas. In TSUTIYA, MILTON T. (Org.) et al. Abastecimento de Água. $1^{\text {a }}$ ed. São Paulo: Departamento de Engenharia Hidráulica e Sanitária da Escola Politécnica da Universidade de São Paulo, 2004;

TAVARES, M. A.; Estudo para Instalação de Válvulas Redutoras de Pressões através de Mapa Digital de Pressões Estáticas no Sistema de Distribuição de Água da Região Metropolitana de Goiânia - 21ํㅡ Congresso Brasileiro de Engenharia Sanitária e Ambiental. João Pessoa, 2001;

THORNTON, JULIAN. Water loss control manual. $1^{\text {st }}$ ed. Hightstown: McGraw-Hill Professional, 2002;

TSUTIYA, MILTON T. (Org.) et al. Abastecimento de Água. $1^{a} \underline{a}$ ed. São Paulo: Departamento de Engenharia Hidráulica e Sanitária da Escola Politécnica da Universidade de São Paulo, 2004;

VAIRAVAMOORTHY, K.; LUMBERS, J.; Leakage Reduction in Water Distribution Systems: Optimal Valve Control. Journal of Hydraulic Engineering, 1998 vol. 124, n. 11, p. 1146-1153;

VIEGAS, J. V; PAZ, M. F; GASTALDINI, M. C. C; DANIELLE, R. D.; BARROSO, L. B.; Simulação do Comportamento Hidráulico de Redes de Abastecimento de Água Utilizando o Modelo EPANET. XXVIII Congresso Interamericano de Engenharia Sanitária Ambiental. Cancun, 2002;

SILVA, F. G. B; GRATÃO, U; SANTOS, A.; REIS, L. F. R.; PORTO, R. M.; CHAUDHRY, F. H.; Controle Operacional em Sistema de Distribuição de Água para Abastecimento visando o Controle de Perdas: Experiência em SubSetores da Cidade de São Carlos, SP. In: V Simpósio do Curso de Pós Graduação em Ciências da Engenharia Ambiental. São Carlos, 1999;

WALSKI, T. M.; CHASE, D. V.; SAVIC, D. A.; HAESTAD METHODS: Water Distribution Modeling $1^{\text {st }}$ ed. Waterbury - CT, 2001; 


\section{BIBLIOGRAFIA CONSULTADA}

ABNT Associação Brasileira de Normas Técnicas; NBR 12211 - Estudos de concepção de sistemas públicos de abastecimento de água (procedimento) - Rio de Janeiro, 1992;

ABNT Associação Brasileira de Normas Técnicas; NBR 12218 - Projeto de rede de distribuição de água para abastecimento público (procedimento) -. Rio de Janeiro, 1994;

ABNT Associação Brasileira de Normas Técnicas; NBR 7968 - Diâmetros nominais em tubulações de saneamento nas áreas de rede de distribuição, adutoras, redes coletoras de esgoto e interceptores (padronização) - Rio de Janeiro, 1983;

ARAUJO, F. A. S.; MONTENEGRO, S. M. G. L.; Avaliação de perdas em setor de abastecimento de água em Cruz de Rebouças, município de Igarassu, Pernambuco, 2001;

ARAUJO, L. S.; RAMOS, H.; COELHO, S. T.; Pressure control for Leakage Minimization in Water Distribution Systems Management Water Research Management, Kluwer Academic Publishers. NL, 2004;

ARSENE C. T. C.; BARGIELA, A.; AL-DABASS, D.; Modeling and Simulation of Water Systems Based on Loop Equations In: Journal of Simulation, 2004 vol. 5, n. 1-2;

BISCOS, C.; MULLHOLLAND, M.; LE LANN, M. V.; BUCKLEY, C. A.; BROUCKAERT, C. J.; Optimal Operations of water distribution by predictive control using MINLP - Water SA Vol. 29 N. 4. Oct, 2003 pg. 393;

BURGUER, M. S.; Reabilitação de redes de ferro fundido. Estudo de caso da cidade de Curitiba. Revista Técnica da SANEPAR- SANARE, Curitiba, vol. 22, Curitiba, 2004;

CARRIJO, I. B.; TAVARES, M. A.; UNGARELLI, P. S.; COURI, R. C. C.; Gerenciamento de informações em companhias de saneamento básico aplicação aos sistemas de abastecimento de água e coleta de esgotos da cidade de Goiânia - XXVII Congresso de Engenharia Ambiental. Rio Grande do Sul, 2000; 
CESARIO, A. L.; Modeling, Analysis and Design of Water Distribution Systems. AWWA. Denver, 1995;

CORRÊA, F. M.; PALILI JR, L.; Plano de economia de água - melhorias no abastecimento de água através de modelagem hidráulica no setor Cumbica no município de Guarulhos, Guarulhos, 2006;

ENCIBRA S.A. Estudos e Projetos de Engenharia Ltda.; Estudo de Revisão e Atualização do Sistema Adutor Metropolitano - SAM 75. São Paulo, 1995.

GALVÃO, C.O.; BARBACENA, M.M.; MACHADO, E.C.M.; LACERDA, I.S.; Simulações intensivas de redes de abastecimento de água utilizando 0 EPANET em grade computacional. In: VIII Simpósio de Recursos Hídricos do Nordeste, 2006, Gravatá. Associação Brasileira de Recursos Hídricos. Porto Alegre, 2006;

LAMBERT, A.; BROWN, T. G.; TAKIZAWA, M.; WEIMER, D.A.; Review of Performance Indicators for Real Losses from Water Supply Systems, 2000 in IWA AQUA, vol. 48, n. 6;

LAMBERT, A.; MYERS, S.; TROW, S.; Managing water leakage - Economic and technical issues. London, 1998;

LAMBERT, A.; THORNTON, J.; Relatório de consultoria sobre avaliação de perdas reais: SABESP. São Paulo, 2002;

LOUCKS, D. P.; STEDINGER, J. R.; HAITH, D. A.; Water resources systems planning and analysis Cornell University. EUA: Prentice Hall, Inc.. 1981;

MACHADO, J. N. A.; Metodologia para Controle de Perdas em Sistemas Públicos de Água - Seminário ABAE. Aracaju, 2004;

ORMSBEE, L.E.; LINGIREDDY, S.; Calibrating Hydraulic Network Models, Journal American Water Works Association, Vol. 89, n. 2, pp. 42-50, 1997;

PIPE 2000; "Quick starts Guide" University of Kentucky, Lexington, KY - USA, 2001; 
PRADO, F. R. L.; Proposta de uma metodologia de otimização para expansão de capacidade de sistemas públicos de abastecimento de água: discussão para aplicação em sistemas de pequeno e grande porte. Dissertação de Mestrado: Universidade de São Paulo. São Paulo, 2005;

RIGHETTO, A. M.; Dimensionamento de Rede de Distribuição de Água através de Simulação Computacional. In: 10ำ Congresso Brasileiro de Engenharia Sanitária e Ambiental, 1979, Manaus. Anais do 10 Congresso Brasileiro de Engenharia Sanitária e Ambiental. São Paulo, 1979. vol. 3. p. 112-130;

SABESP; Diretoria de Operação. Plano de Otimização do Sistema Operacional. São Paulo, 1985;

SABESP; Norma Técnica SABESP NTS 061 - Estudo de concepção de sistema de abastecimento de água (procedimento) São Paulo, 2002. Rev.1;

SABESP; Perdas: Relatório Técnico-Gerencial, São Paulo, 2005;

SANTOS, A.; REIS, F. L. R; SILVA, F. G. B.; GRATÃO, U; PORTO, R. M.; CHAUDHRY, F. H.; Avaliação de Parâmetros do Modelo Pressão: Vazamento para o subsetor da Cidade de São Carlos, SP. IX Simpósio Luso-Brasileiro de Engenharia Sanitária e Ambiental. Bahia, 2000;

SANTOS, M. C. C.; GOMES, H. P.; Simulação de Cenários de Operação de Sistemas de Distribuição de Água Através do Método PNL2000 In: Seminário: Planejamento, Projeto e Operação de Redes de Abastecimento de Água. João Pessoa, 2002;

SOARES, A. K. ; CHEUNG, P. B.; REIS, L. F. R.; SANDIM, M. P.; Avaliação das perdas físicas de um setor da rede de abastecimento de Água de Campo Grande-MS via modelo inverso. Engenharia Sanitária e Ambiental, vol. 9, no 4, p. 312-321. São Paulo, 2004;

SOUZA, R. S; CHAUDHRY, F. H.; POLIZER, M.; Controle Operacional Otimizado de Válvulas Redutoras de Pressão em Redes de Distribuição de Água. II Simpósio de Recursos Hídricos do Centro Oeste. Campo Grande, 2002;

WALSKI, T. M.; Optimization and pipe sizing decisions. Journal of Water Resources Planning and Management, UK, 1995 vol. 121 (4), 340-343; 
WALSKI, T. M; CHASE, D. V; SAVIC D.A; GRAYMAN, W; BECKWITH S.; KOELLE, E.; HAESTAD METHODS: Advanced Water Distribution Modeling and Management $1^{\text {st }}$ ed. Waterbury - CT, 2003;

WOOD, D. J.; KYPIPE: Reference Manual. University of Kentucky, Lexington -KY, 1995;

ZATTONI, C. C.; Apostila de Materiais para tubulação. Faculdade de Tecnologia de São Paulo - FATEC. São Paulo, 2004;

ZHAO, R.; LIU, B.; Stochastic Programming Models for General Redundancy Optimization Problems. IEEE Transactions on Reliability, vol. 52 p. 181-191, Jun, 2003. 
APENDICE A

\section{VARIAÇÃO DAS PRESSÕES NOS NÓS EM FUNÇÃO DA RUGOSIDADE DOS TUBOS ÀS $12 \mathrm{H}$.}

Para o desenvolvimento deste trabalho, foram avaliadas tabelas comparativas que demonstrassem a importância da precisão relacionada aos coeficientes de rugosidade. Assim, às $12 \mathrm{~h}$, a simulação reproduziu os seguintes resultados, visualmente avaliáveis pelas tabelas 6.4 e 6.8 :

\begin{tabular}{|c|c|c|c|c|c|c|}
\hline \multirow{2}{*}{ NÓ } & \multirow{2}{*}{$\operatorname{COTA}(\mathrm{m})$} & \multirow{2}{*}{ DEMANDA (//s) } & \multicolumn{2}{|c|}{$\mathrm{CHW}=90$ (mca) } & \multicolumn{2}{|c|}{$\mathrm{CHW}=$ VARIOS $(\mathrm{mca})$} \\
\hline & & & $\mathrm{HGL}$ & PRESSÃO & HGL & PRESSÃO \\
\hline 25 & 784 & 0.39175 & 846.78 & 62.70 & 845.36 & 61.30 \\
\hline 27 & 786 & 0.19006 & 841.86 & 55.50 & 834.92 & 48.60 \\
\hline 29 & 810 & 0.14113 & 847.46 & 37.40 & 846.75 & 36.70 \\
\hline 30 & 810 & 0.31049 & 847.46 & 37.40 & 846.75 & 36.70 \\
\hline 33 & 796 & 0.51621 & 844.02 & 47.40 & 840.29 & 43.70 \\
\hline 34 & 791 & 0.90379 & 843.80 & 52.70 & 839.87 & 48.80 \\
\hline 35 & 775 & 0.71820 & 842.97 & 67.70 & 838.58 & 63.40 \\
\hline 36 & 779 & 0.16768 & 846.77 & 67.40 & 845.34 & 65.90 \\
\hline 37 & 794 & 0.40167 & 843.90 & 50.00 & 840.09 & 46.20 \\
\hline 38 & 768 & 0.30157 & 842.16 & 73.80 & 837.29 & 69.00 \\
\hline 39 & 788 & 2.68020 & 837.86 & 49.80 & 830.44 & 42.40 \\
\hline 40 & 783 & 0.21112 & 842.13 & 59.40 & 837.24 & 54.50 \\
\hline 41 & 805 & 0.40169 & 847.46 & 42.40 & 846.75 & 41.70 \\
\hline 42 & 801 & 0.22019 & 847.46 & 46.70 & 846.74 & 46.00 \\
\hline 43 & 803 & 0.11063 & 847.46 & 43.90 & 846.74 & 43.20 \\
\hline 47 & 776 & 0.26881 & 846.73 & 70.50 & 845.27 & 69.00 \\
\hline 58 & 775 & 0.00000 & 846.72 & 71.40 & 845.26 & 70.00 \\
\hline 69 & 772 & 0.45273 & 846.69 & 74.10 & 845.22 & 72.60 \\
\hline 72 & 783 & 0.20762 & 845.72 & 63.00 & 844.22 & 61.50 \\
\hline 76 & 797 & 0.31035 & 845.73 & 48.30 & 844.24 & 46.80 \\
\hline 77 & 796 & 0.27977 & 845.73 & 49.40 & 844.23 & 47.90 \\
\hline 80 & 771 & 0.10396 & 846.69 & 75.10 & 845.22 & 73.60 \\
\hline 84 & 799 & 0.15500 & 845.70 & 46.30 & 844.17 & 44.80 \\
\hline
\end{tabular}




\begin{tabular}{|c|c|c|c|c|c|c|}
\hline 85 & 805 & 0.34301 & 845.68 & 40.60 & 844.14 & 39.00 \\
\hline 90 & 802 & 0.25979 & 845.72 & 43.90 & 844.21 & 42.40 \\
\hline 91 & 791 & 0.66094 & 846.90 & 55.90 & 845.58 & 54.60 \\
\hline 92 & 796 & 0.05493 & 845.73 & 50.00 & 844.23 & 48.50 \\
\hline 93 & 797 & 0.36329 & 845.78 & 49.10 & 844.34 & 47.70 \\
\hline 95 & 800 & 0.28873 & 845.77 & 45.70 & 844.33 & 44.20 \\
\hline 96 & 803 & 0.31030 & 845.77 & 43.10 & 844.33 & 41.60 \\
\hline 101 & 811 & 0.22748 & 845.87 & 35.00 & 844.50 & 33.60 \\
\hline 104 & 804 & 0.50349 & 845.78 & 42.10 & 844.35 & 40.60 \\
\hline 107 & 795 & 0.16839 & 845.79 & 50.20 & 844.38 & 48.80 \\
\hline 108 & 795 & 0.08601 & 845.79 & 50.50 & 844.38 & 49.10 \\
\hline 109 & 796 & 0.37722 & 845.80 & 49.70 & 844.38 & 48.30 \\
\hline 110 & 802 & 0.27115 & 845.81 & 43.90 & 844.41 & 42.50 \\
\hline 111 & 791 & 0.11092 & 845.80 & 55.00 & 844.38 & 53.50 \\
\hline 113 & 806 & 0.27456 & 847.31 & 41.10 & 846.54 & 40.30 \\
\hline 115 & 795 & 0.31119 & 845.54 & 50.40 & 843.78 & 48.60 \\
\hline 116 & 798 & 0.31069 & 845.61 & 47.20 & 843.95 & 45.60 \\
\hline 117 & 799 & 0.88194 & 845.33 & 46.30 & 843.32 & 44.30 \\
\hline 118 & 806 & 0.20790 & 845.60 & 39.30 & 843.92 & 37.70 \\
\hline 120 & 808 & 0.31099 & 845.86 & 37.70 & 844.49 & 36.30 \\
\hline 121 & 810 & 0.24258 & 845.88 & 35.40 & 844.52 & 34.00 \\
\hline 122 & 814 & 0.31852 & 845.93 & 32.00 & 844.59 & 30.70 \\
\hline 124 & 804 & 0.48137 & 847.36 & 42.90 & 846.58 & 42.20 \\
\hline 125 & 813 & 0.47429 & 845.97 & 33.00 & 844.65 & 31.70 \\
\hline 127 & 810 & 0.09364 & 845.93 & 35.50 & 844.60 & 34.20 \\
\hline 128 & 810 & 0.03227 & 845.93 & 35.80 & 844.60 & 34.40 \\
\hline 129 & 802 & 0.05831 & 845.98 & 43.70 & 844.66 & 42.40 \\
\hline 130 & 810 & 0.02675 & 845.93 & 35.70 & 844.60 & 34.40 \\
\hline 132 & 798 & 0.09314 & 845.93 & 48.00 & 844.59 & 46.70 \\
\hline 134 & 797 & 0.00000 & 845.93 & 48.90 & 844.60 & 47.60 \\
\hline 135 & 810 & 0.13510 & 847.51 & 37.40 & 846.81 & 36.70 \\
\hline 137 & 809 & 0.19831 & 845.93 & 36.40 & 844.59 & 35.10 \\
\hline 140 & 800 & 0.06168 & 845.99 & 45.70 & 844.69 & 44.40 \\
\hline 141 & 791 & 0.15363 & 845.85 & 54.60 & 844.52 & 53.20 \\
\hline 142 & 800 & 0.00000 & 845.99 & 45.40 & 844.68 & 44.10 \\
\hline
\end{tabular}




\begin{tabular}{|c|c|c|c|c|c|c|}
\hline 143 & 800 & 0.11674 & 845.98 & 46.10 & 844.67 & 44.80 \\
\hline 144 & 801 & 0.21783 & 845.98 & 45.10 & 844.67 & 43.80 \\
\hline 145 & 794 & 0.13208 & 845.97 & 51.50 & 844.66 & 50.10 \\
\hline 146 & 792 & 0.25952 & 845.85 & 53.60 & 844.52 & 52.20 \\
\hline 148 & 808 & 0.21127 & 845.71 & 37.70 & 844.33 & 36.30 \\
\hline 149 & 808 & 0.17816 & 845.68 & 37.90 & 844.28 & 36.50 \\
\hline 150 & 809 & 0.25684 & 845.57 & 36.10 & 844.13 & 34.70 \\
\hline 151 & 802 & 0.34760 & 845.53 & 43.40 & 844.14 & 42.00 \\
\hline 152 & 795 & 1.23950 & 845.36 & 50.30 & 843.91 & 48.80 \\
\hline 153 & 793 & 0.11950 & 845.72 & 52.60 & 844.36 & 51.30 \\
\hline 154 & 794 & 0.22203 & 845.72 & 52.00 & 844.36 & 50.60 \\
\hline 155 & 782 & 0.12468 & 845.58 & 63.70 & 844.20 & 62.40 \\
\hline 156 & 786 & 0.64312 & 845.53 & 59.60 & 844.14 & 58.20 \\
\hline 158 & 806 & 0.18312 & 847.46 & 41.40 & 846.74 & 40.70 \\
\hline 159 & 787 & 0.80206 & 845.45 & 58.10 & 844.05 & 56.70 \\
\hline 162 & 776 & 0.08674 & 845.54 & 69.90 & 844.14 & 68.50 \\
\hline 164 & 775 & 0.02882 & 845.54 & 70.40 & 844.14 & 69.00 \\
\hline 165 & 775 & 0.38958 & 845.54 & 70.40 & 844.13 & 69.00 \\
\hline 167 & 790 & 0.57098 & 845.11 & 55.10 & 843.62 & 53.60 \\
\hline 168 & 790 & 1.33035 & 845.33 & 55.20 & 843.90 & 53.80 \\
\hline 170 & 780 & 0.69727 & 845.16 & 65.10 & 843.67 & 63.60 \\
\hline 171 & 790 & 0.37616 & 844.98 & 54.80 & 843.43 & 53.30 \\
\hline 173 & 783 & 0.31984 & 844.96 & 62.30 & 843.40 & 60.70 \\
\hline 176 & 799 & 0.23757 & 844.98 & 46.30 & 843.43 & 44.70 \\
\hline 177 & 790 & 0.37398 & 844.95 & 54.70 & 843.38 & 53.20 \\
\hline 178 & 808 & 0.03538 & 845.00 & 37.20 & 843.48 & 35.60 \\
\hline 179 & 803 & 0.27178 & 845.11 & 42.30 & 843.61 & 40.80 \\
\hline 181 & 814 & 0.42588 & 845.93 & 31.80 & 844.59 & 30.40 \\
\hline 182 & 815 & 0.07513 & 845.95 & 30.90 & 844.63 & 29.60 \\
\hline 183 & 810 & 0.23445 & 845.91 & 35.90 & 844.55 & 34.50 \\
\hline 186 & 787 & 0.42130 & 845.54 & 58.80 & 843.79 & 57.00 \\
\hline 189 & 782 & 0.60070 & 845.56 & 63.90 & 843.82 & 62.20 \\
\hline 191 & 769 & 0.86412 & 845.80 & 76.20 & 843.13 & 73.50 \\
\hline 192 & 786 & 0.53684 & 845.54 & 59.40 & 843.78 & 57.70 \\
\hline 195 & 815 & 0.14530 & 845.94 & 30.50 & 844.62 & 29.20 \\
\hline
\end{tabular}




\begin{tabular}{|c|c|c|c|c|c|c|}
\hline 196 & 815 & 0.00000 & 845.95 & 30.90 & 844.63 & 29.60 \\
\hline 197 & 815 & 0.05914 & 845.81 & 30.70 & 844.43 & 29.40 \\
\hline 200 & 816 & 0.05873 & 845.84 & 29.80 & 844.45 & 28.40 \\
\hline 201 & 816 & 0.04392 & 845.79 & 30.00 & 844.38 & 28.60 \\
\hline 203 & 815 & 0.03094 & 845.79 & 30.40 & 844.38 & 29.00 \\
\hline 204 & 818 & 0.06266 & 845.42 & 27.10 & 843.94 & 25.60 \\
\hline 205 & 818 & 0.04740 & 845.41 & 26.90 & 843.93 & 25.50 \\
\hline 206 & 818 & 0.14937 & 845.41 & 27.10 & 843.93 & 25.70 \\
\hline 207 & 818 & 0.11053 & 845.38 & 27.60 & 843.88 & 26.10 \\
\hline 208 & 816 & 0.25814 & 845.33 & 29.30 & 843.85 & 27.90 \\
\hline 210 & 816 & 0.12450 & 845.29 & 28.80 & 843.81 & 27.30 \\
\hline 211 & 818 & 0.06700 & 845.28 & 27.20 & 843.72 & 25.60 \\
\hline 213 & 770 & 0.06236 & 845.79 & 76.10 & 843.11 & 73.40 \\
\hline 215 & 820 & 0.27693 & 845.28 & 25.20 & 843.72 & 23.70 \\
\hline 216 & 806 & 0.22333 & 845.21 & 39.20 & 843.74 & 37.80 \\
\hline 217 & 807 & 0.01781 & 845.21 & 38.00 & 843.73 & 36.60 \\
\hline 218 & 808 & 0.03052 & 845.21 & 37.00 & 843.73 & 35.50 \\
\hline 219 & 809 & 0.21216 & 845.20 & 36.30 & 843.71 & 34.90 \\
\hline 220 & 804 & 0.39054 & 845.09 & 41.20 & 843.59 & 39.70 \\
\hline 221 & 812 & 0.55423 & 845.00 & 33.20 & 843.44 & 31.70 \\
\hline 222 & 820 & 0.34680 & 845.15 & 25.50 & 843.59 & 24.00 \\
\hline 223 & 819 & 0.13994 & 845.14 & 25.80 & 843.56 & 24.20 \\
\hline 225 & 822 & 0.11561 & 845.14 & 23.20 & 843.56 & 21.70 \\
\hline 228 & 822 & 0.22517 & 845.17 & 23.00 & 843.59 & 21.50 \\
\hline 229 & 825 & 0.11777 & 845.16 & 20.10 & 843.58 & 18.50 \\
\hline 230 & 825 & 0.33995 & 844.99 & 19.90 & 843.42 & 18.40 \\
\hline 231 & 809 & 0.04633 & 845.00 & 35.80 & 843.48 & 34.30 \\
\hline 232 & 822 & 0.08343 & 844.88 & 23.20 & 843.35 & 21.70 \\
\hline 234 & 825 & 0.04905 & 844.88 & 19.80 & 843.35 & 18.30 \\
\hline 236 & 822 & 0.13180 & 844.88 & 23.00 & 843.35 & 21.50 \\
\hline 238 & 815 & 0.37245 & 844.78 & 29.90 & 843.24 & 28.30 \\
\hline 239 & 822 & 0.16304 & 844.76 & 23.20 & 843.21 & 21.60 \\
\hline 240 & 799 & 0.19689 & 844.78 & 46.00 & 843.23 & 44.40 \\
\hline 241 & 788 & 0.24537 & 844.76 & 56.20 & 843.21 & 54.60 \\
\hline 242 & 796 & 0.16083 & 844.78 & 49.10 & 843.23 & 47.50 \\
\hline
\end{tabular}




\begin{tabular}{|c|c|c|c|c|c|c|}
\hline 243 & 794 & 0.48861 & 844.67 & 50.60 & 843.11 & 49.00 \\
\hline 244 & 809 & 0.10859 & 844.98 & 36.30 & 843.47 & 34.80 \\
\hline 245 & 808 & 0.04676 & 844.99 & 37.40 & 843.48 & 35.90 \\
\hline 246 & 809 & 0.21764 & 847.47 & 38.00 & 846.76 & 37.30 \\
\hline 248 & 784 & 0.26101 & 844.68 & 60.20 & 843.14 & 58.70 \\
\hline 249 & 785 & 1.12276 & 844.68 & 59.50 & 843.14 & 58.00 \\
\hline 250 & 788 & 0.14365 & 844.67 & 56.10 & 843.13 & 54.60 \\
\hline 251 & 826 & 0.12174 & 844.45 & 18.30 & 842.86 & 16.70 \\
\hline 252 & 820 & 0.24823 & 844.55 & 24.50 & 842.97 & 22.90 \\
\hline 253 & 812 & 0.46565 & 844.62 & 32.30 & 843.05 & 30.70 \\
\hline 255 & 828 & 1.37020 & 844.43 & 16.20 & 842.83 & 14.60 \\
\hline 256 & 830 & 0.01845 & 844.24 & 14.20 & 842.63 & 12.60 \\
\hline 257 & 830 & 0.21703 & 844.22 & 14.20 & 842.61 & 12.60 \\
\hline 260 & 827 & 0.28267 & 843.63 & 16.30 & 841.56 & 14.20 \\
\hline 261 & 827 & 0.35944 & 843.56 & 16.80 & 841.42 & 14.70 \\
\hline 262 & 817 & 0.55366 & 843.07 & 26.40 & 840.68 & 24.00 \\
\hline 269 & 810 & 3.84100 & 847.47 & 37.40 & 846.76 & 36.70 \\
\hline 270 & 820 & 0.32586 & 843.50 & 23.40 & 841.34 & 21.30 \\
\hline 271 & 821 & 0.07927 & 843.53 & 22.60 & 841.43 & 20.50 \\
\hline 272 & 823 & 0.09532 & 843.53 & 20.00 & 841.46 & 18.00 \\
\hline 273 & 825 & 0.10934 & 844.22 & 19.20 & 842.60 & 17.60 \\
\hline 274 & 825 & 0.06388 & 843.65 & 18.60 & 841.92 & 16.90 \\
\hline 276 & 811 & 0.41285 & 843.05 & 32.40 & 840.65 & 30.00 \\
\hline 279 & 802 & 0.67351 & 842.67 & 40.70 & 840.07 & 38.10 \\
\hline 280 & 810 & 0.07884 & 847.46 & 37.40 & 846.76 & 36.70 \\
\hline 282 & 798 & 0.36624 & 842.67 & 44.30 & 840.06 & 41.70 \\
\hline 284 & 793 & 0.53055 & 842.59 & 49.40 & 839.94 & 46.80 \\
\hline 285 & 800 & 0.57473 & 842.59 & 42.10 & 839.94 & 39.50 \\
\hline 286 & 800 & 0.25338 & 842.81 & 42.50 & 840.29 & 40.00 \\
\hline 287 & 807 & 0.18458 & 842.82 & 35.70 & 840.31 & 33.20 \\
\hline 288 & 795 & 0.34189 & 842.58 & 47.00 & 839.92 & 44.30 \\
\hline 290 & 788 & 0.20093 & 842.57 & 54.90 & 839.90 & 52.20 \\
\hline 291 & 805 & 0.40091 & 847.30 & 41.90 & 846.52 & 41.10 \\
\hline 292 & 812 & 0.44148 & 843.13 & 31.50 & 841.29 & 29.60 \\
\hline 296 & 808 & 0.44488 & 843.14 & 34.70 & 841.31 & 32.80 \\
\hline
\end{tabular}




\begin{tabular}{|c|c|c|c|c|c|c|}
\hline 297 & 823 & 0.22107 & 843.46 & 20.50 & 841.70 & 18.80 \\
\hline 298 & 806 & 0.48850 & 843.14 & 36.90 & 841.31 & 35.00 \\
\hline 299 & 821 & 0.19152 & 843.32 & 21.90 & 841.54 & 20.20 \\
\hline 300 & 801 & 0.45040 & 843.14 & 42.30 & 841.31 & 40.50 \\
\hline 301 & 820 & 0.00000 & 843.18 & 23.10 & 841.38 & 21.30 \\
\hline 302 & 805 & 0.18375 & 847.30 & 41.90 & 846.52 & 41.10 \\
\hline 303 & 820 & 0.41336 & 843.14 & 23.10 & 841.33 & 21.30 \\
\hline 304 & 786 & 0.16351 & 843.13 & 56.60 & 841.32 & 54.80 \\
\hline 305 & 786 & 0.06429 & 843.13 & 56.80 & 841.32 & 55.00 \\
\hline 306 & 784 & 0.07443 & 843.13 & 59.10 & 841.32 & 57.30 \\
\hline 307 & 775 & 0.76311 & 842.99 & 68.20 & 841.10 & 66.30 \\
\hline 308 & 781 & 0.29379 & 843.13 & 62.20 & 841.32 & 60.40 \\
\hline 309 & 809 & 5.20990 & 843.05 & 34.10 & 841.21 & 32.30 \\
\hline 310 & 810 & 0.01430 & 843.05 & 33.20 & 841.21 & 31.30 \\
\hline 312 & 788 & 0.78869 & 843.05 & 55.00 & 841.21 & 53.20 \\
\hline 313 & 799 & 0.31833 & 847.25 & 47.90 & 846.42 & 47.10 \\
\hline 314 & 785 & 0.01582 & 843.05 & 57.60 & 841.21 & 55.70 \\
\hline 315 & 786 & 0.19307 & 843.05 & 56.60 & 841.21 & 54.80 \\
\hline 316 & 820 & 0.88425 & 842.99 & 22.90 & 841.13 & 21.10 \\
\hline 317 & 809 & 0.06300 & 843.05 & 33.50 & 841.20 & 31.70 \\
\hline 318 & 808 & 0.03247 & 843.02 & 34.70 & 841.17 & 32.90 \\
\hline 319 & 820 & 0.27071 & 843.00 & 23.00 & 841.14 & 21.10 \\
\hline 322 & 808 & 1.79930 & 843.00 & 34.80 & 841.15 & 33.00 \\
\hline 323 & 818 & 0.35397 & 843.00 & 25.10 & 841.15 & 23.30 \\
\hline 324 & 767 & 0.40434 & 846.52 & 79.80 & 845.43 & 78.70 \\
\hline 326 & 800 & 0.73237 & 843.00 & 43.30 & 841.15 & 41.50 \\
\hline 328 & 790 & 0.65380 & 843.00 & 52.90 & 841.15 & 51.00 \\
\hline 329 & 803 & 0.10798 & 842.84 & 39.60 & 840.97 & 37.70 \\
\hline 330 & 802 & 0.07218 & 842.84 & 40.30 & 840.97 & 38.40 \\
\hline 331 & 801 & 0.02369 & 842.84 & 41.30 & 840.97 & 39.40 \\
\hline 332 & 797 & 0.22172 & 842.84 & 45.30 & 840.97 & 43.40 \\
\hline 333 & 799 & 0.38280 & 842.76 & 44.00 & 840.85 & 42.10 \\
\hline 334 & 810 & 0.12234 & 842.83 & 33.00 & 840.94 & 31.10 \\
\hline 335 & 798 & 0.16013 & 847.00 & 48.40 & 845.86 & 47.30 \\
\hline 336 & 810 & 0.01040 & 842.39 & 32.30 & 840.52 & 30.50 \\
\hline
\end{tabular}




\begin{tabular}{|c|c|c|c|c|c|c|}
\hline 337 & 808 & 0.01781 & 842.27 & 34.30 & 840.40 & 32.40 \\
\hline 338 & 808 & 0.99520 & 842.03 & 33.50 & 840.15 & 31.70 \\
\hline 339 & 802 & 0.00000 & 842.03 & 40.40 & 840.15 & 38.50 \\
\hline 340 & 806 & 1.06984 & 841.36 & 35.50 & 839.44 & 33.60 \\
\hline 341 & 806 & 4.23400 & 841.32 & 35.50 & 839.40 & 33.60 \\
\hline 342 & 803 & 0.91782 & 841.15 & 37.90 & 839.18 & 35.90 \\
\hline 343 & 802 & 2.15027 & 841.08 & 38.60 & 839.26 & 36.70 \\
\hline 344 & 794 & 1.60341 & 841.14 & 46.60 & 839.21 & 44.60 \\
\hline 345 & 788 & 0.99002 & 840.91 & 52.50 & 838.94 & 50.50 \\
\hline 347 & 789 & 2.54770 & 840.91 & 52.10 & 838.94 & 50.10 \\
\hline 350 & 789 & 2.66675 & 839.24 & 50.40 & 836.82 & 48.00 \\
\hline 351 & 790 & 0.52482 & 839.22 & 49.30 & 836.79 & 46.80 \\
\hline 353 & 778 & 1.44956 & 838.76 & 61.10 & 836.19 & 58.60 \\
\hline 354 & 792 & 0.54579 & 841.10 & 49.20 & 839.16 & 47.30 \\
\hline 355 & 787 & 1.13615 & 841.09 & 54.00 & 839.15 & 52.10 \\
\hline 356 & 787 & 1.19188 & 841.09 & 54.30 & 839.15 & 52.40 \\
\hline 357 & 808 & 0.56162 & 847.35 & 39.60 & 846.55 & 38.80 \\
\hline 358 & 791 & 0.18681 & 846.77 & 55.20 & 845.35 & 53.70 \\
\hline 359 & 792 & 0.59159 & 841.10 & 48.90 & 839.16 & 46.90 \\
\hline 361 & 784 & 0.60510 & 841.08 & 57.00 & 839.14 & 55.10 \\
\hline 362 & 781 & 0.00000 & 841.07 & 59.70 & 839.14 & 57.80 \\
\hline 363 & 780 & 1.08060 & 841.07 & 60.50 & 839.14 & 58.60 \\
\hline 365 & 796 & 0.15745 & 841.07 & 45.40 & 839.13 & 43.50 \\
\hline 366 & 789 & 4.40931 & 841.76 & 52.90 & 840.06 & 51.20 \\
\hline 370 & 788 & 0.51894 & 842.79 & 54.40 & 840.79 & 52.40 \\
\hline 372 & 798 & 0.17674 & 842.78 & 44.40 & 840.78 & 42.40 \\
\hline 373 & 811 & 0.19782 & 845.93 & 35.30 & 844.61 & 33.90 \\
\hline 375 & 801 & 0.56393 & 845.71 & 44.60 & 844.22 & 43.10 \\
\hline 376 & 809 & 0.23316 & 845.70 & 37.10 & 844.20 & 35.60 \\
\hline 377 & 795 & 0.81927 & 845.21 & 49.90 & 843.09 & 47.80 \\
\hline 381 & 786 & 0.46133 & 845.05 & 59.10 & 842.82 & 56.90 \\
\hline 382 & 795 & 0.60118 & 845.21 & 50.00 & 843.10 & 47.90 \\
\hline 383 & 808 & 0.17282 & 845.86 & 37.90 & 844.46 & 36.50 \\
\hline 384 & 808 & 0.07650 & 845.93 & 37.60 & 844.60 & 36.20 \\
\hline 386 & 794 & 0.19548 & 845.19 & 50.70 & 843.05 & 48.60 \\
\hline
\end{tabular}




\begin{tabular}{|c|c|c|c|c|c|c|}
\hline 388 & 809 & 0.14768 & 845.93 & 36.90 & 844.60 & 35.60 \\
\hline 389 & 810 & 0.09357 & 845.93 & 36.10 & 844.60 & 34.80 \\
\hline 390 & 805 & 0.34327 & 845.83 & 40.80 & 844.42 & 39.40 \\
\hline 391 & 791 & 0.13046 & 846.77 & 55.40 & 845.34 & 54.00 \\
\hline 392 & 797 & 0.18473 & 845.82 & 48.60 & 844.41 & 47.20 \\
\hline 393 & 789 & 0.19383 & 845.69 & 56.60 & 844.16 & 55.00 \\
\hline 394 & 789 & 0.01601 & 845.69 & 57.00 & 844.15 & 55.40 \\
\hline 395 & 788 & 0.29529 & 845.69 & 57.30 & 844.15 & 55.70 \\
\hline 396 & 780 & 0.26053 & 845.67 & 65.30 & 844.13 & 63.70 \\
\hline 397 & 801 & 0.34386 & 845.74 & 44.70 & 844.27 & 43.30 \\
\hline 398 & 811 & 0.26015 & 845.90 & 34.80 & 844.56 & 33.50 \\
\hline 400 & 813 & 0.16996 & 845.88 & 32.70 & 844.54 & 31.40 \\
\hline 401 & 813 & 0.18792 & 845.87 & 32.40 & 844.53 & 31.10 \\
\hline 402 & 778 & 0.24823 & 845.91 & 67.60 & 843.41 & 65.10 \\
\hline 403 & 812 & 0.41875 & 845.86 & 33.40 & 844.51 & 32.10 \\
\hline 404 & 812 & 0.12931 & 845.77 & 33.40 & 844.35 & 32.00 \\
\hline 405 & 813 & 0.12431 & 845.75 & 33.20 & 844.30 & 31.70 \\
\hline 408 & 815 & 0.19966 & 845.59 & 30.60 & 844.07 & 29.10 \\
\hline 409 & 819 & 0.12069 & 845.28 & 26.40 & 843.72 & 24.90 \\
\hline 410 & 819 & 0.07153 & 845.28 & 26.20 & 843.72 & 24.60 \\
\hline 411 & 813 & 0.06243 & 845.28 & 32.20 & 843.72 & 30.70 \\
\hline 412 & 815 & 0.11154 & 845.28 & 30.40 & 843.72 & 28.80 \\
\hline 413 & 789 & 0.75692 & 845.80 & 56.50 & 843.18 & 53.90 \\
\hline 415 & 815 & 0.11938 & 845.75 & 30.50 & 844.29 & 29.00 \\
\hline 418 & 820 & 0.55120 & 845.29 & 25.70 & 843.70 & 24.10 \\
\hline 421 & 825 & 0.13243 & 845.28 & 20.20 & 843.70 & 18.70 \\
\hline 423 & 814 & 0.39246 & 845.65 & 31.30 & 844.15 & 29.80 \\
\hline 424 & 773 & 0.17440 & 845.65 & 72.60 & 842.80 & 69.70 \\
\hline 427 & 816 & 0.50225 & 845.66 & 29.30 & 844.15 & 27.80 \\
\hline 429 & 806 & 0.33576 & 845.60 & 39.10 & 844.05 & 37.50 \\
\hline 430 & 796 & 2.01013 & 845.64 & 49.40 & 844.08 & 47.90 \\
\hline 431 & 805 & 0.48467 & 845.85 & 40.60 & 844.50 & 39.30 \\
\hline 432 & 797 & 1.39023 & 845.65 & 49.00 & 844.11 & 47.50 \\
\hline 433 & 805 & 0.37080 & 845.83 & 40.60 & 844.47 & 39.30 \\
\hline 434 & 805 & 0.84993 & 845.70 & 40.80 & 844.20 & 39.40 \\
\hline
\end{tabular}




\begin{tabular}{|c|c|c|c|c|c|c|}
\hline 435 & 772 & 0.23013 & 845.65 & 73.30 & 842.79 & 70.40 \\
\hline 436 & 805 & 0.26145 & 845.83 & 40.70 & 844.46 & 39.40 \\
\hline 437 & 803 & 0.20629 & 845.71 & 42.70 & 844.21 & 41.20 \\
\hline 438 & 805 & 0.22513 & 845.83 & 40.70 & 844.46 & 39.40 \\
\hline 439 & 790 & 0.28140 & 845.68 & 55.70 & 844.14 & 54.10 \\
\hline 442 & 787 & 0.24558 & 845.66 & 58.60 & 844.10 & 57.00 \\
\hline 444 & 787 & 0.38022 & 845.65 & 59.00 & 844.09 & 57.40 \\
\hline 450 & 795 & 0.22702 & 845.80 & 50.60 & 844.40 & 49.20 \\
\hline 452 & 797 & 0.03353 & 845.83 & 48.50 & 844.46 & 47.10 \\
\hline 453 & 785 & 0.41191 & 845.76 & 60.80 & 844.32 & 59.40 \\
\hline 454 & 797 & 0.00706 & 845.83 & 48.50 & 844.46 & 47.10 \\
\hline 455 & 801 & 0.30961 & 845.83 & 44.30 & 844.46 & 43.00 \\
\hline 456 & 814 & 0.22300 & 847.77 & 33.40 & 847.16 & 32.80 \\
\hline 458 & 815 & 0.00000 & 847.77 & 33.00 & 847.16 & 32.40 \\
\hline 459 & 814 & 0.16950 & 847.71 & 33.60 & 847.05 & 33.00 \\
\hline 460 & 814 & 0.13420 & 847.74 & 33.30 & 847.10 & 32.70 \\
\hline 461 & 815 & 0.05374 & 847.72 & 32.80 & 847.06 & 32.10 \\
\hline 462 & 815 & 0.02306 & 847.72 & 32.70 & 847.07 & 32.00 \\
\hline 463 & 812 & 0.20718 & 847.69 & 35.30 & 847.01 & 34.70 \\
\hline 464 & 792 & 0.01104 & 847.77 & 55.90 & 847.16 & 55.30 \\
\hline 465 & 811 & 0.25972 & 847.71 & 36.70 & 847.04 & 36.00 \\
\hline 466 & 811 & 2.77519 & 847.77 & 36.50 & 847.16 & 35.90 \\
\hline 467 & 807 & 0.68049 & 847.62 & 40.70 & 846.86 & 39.90 \\
\hline 468 & 798 & 0.44489 & 847.15 & 48.90 & 846.14 & 47.80 \\
\hline 469 & 778 & 0.90046 & 845.11 & 67.00 & 841.76 & 63.70 \\
\hline 470 & 807 & 0.25309 & 847.63 & 41.00 & 846.90 & 40.20 \\
\hline 471 & 799 & 0.24955 & 847.60 & 48.60 & 846.84 & 47.80 \\
\hline 472 & 779 & 0.00000 & 847.77 & 69.00 & 847.16 & 68.40 \\
\hline 473 & 793 & 0.10802 & 847.56 & 54.60 & 846.77 & 53.80 \\
\hline 475 & 779 & 2.31257 & 847.56 & 68.90 & 846.77 & 68.10 \\
\hline 478 & 806 & 0.92257 & 847.62 & 41.10 & 846.85 & 40.30 \\
\hline 479 & 799 & 0.06103 & 847.61 & 48.40 & 846.85 & 47.60 \\
\hline 481 & 808 & 0.17328 & 847.71 & 40.10 & 847.04 & 39.40 \\
\hline 482 & 809 & 1.01821 & 847.77 & 39.00 & 847.16 & 38.40 \\
\hline 483 & 806 & 2.64687 & 847.77 & 42.10 & 847.16 & 41.50 \\
\hline
\end{tabular}




\begin{tabular}{|c|c|c|c|c|c|c|}
\hline 484 & 799 & 0.07598 & 847.23 & 48.30 & 846.39 & 47.50 \\
\hline 486 & 793 & 0.55400 & 843.13 & 50.10 & 841.32 & 48.20 \\
\hline 487 & 817 & 0.17773 & 845.75 & 28.60 & 844.29 & 27.20 \\
\hline 488 & 825 & 0.08612 & 844.87 & 19.80 & 843.34 & 18.30 \\
\hline 492 & 785 & 1.32649 & 843.09 & 57.50 & 841.29 & 55.70 \\
\hline 493 & 783 & 0.00000 & 843.09 & 60.10 & 841.29 & 58.30 \\
\hline 494 & 795 & 1.62093 & 843.03 & 47.90 & 841.25 & 46.20 \\
\hline 495 & 795 & 1.47308 & 842.83 & 47.70 & 841.11 & 46.00 \\
\hline 496 & 814 & 0.00000 & 847.77 & 33.90 & 847.16 & 33.20 \\
\hline 497 & 814 & 0.00687 & 847.78 & 33.80 & 847.17 & 33.20 \\
\hline 498 & 814 & 0.17961 & 847.78 & 33.90 & 847.18 & 33.30 \\
\hline 499 & 814 & 0.02209 & 847.78 & 33.80 & 847.18 & 33.20 \\
\hline 500 & 815 & 0.14269 & 847.78 & 32.70 & 847.17 & 32.10 \\
\hline 501 & 805 & 0.00000 & 850.89 & 45.70 & 851.18 & 46.00 \\
\hline 503 & 815 & 0.05631 & 847.81 & 32.70 & 847.21 & 32.10 \\
\hline 504 & 815 & 0.00000 & 847.80 & 32.70 & 847.20 & 32.10 \\
\hline 505 & 815 & 0.30673 & 847.79 & 32.70 & 847.19 & 32.10 \\
\hline 507 & 811 & 1.37680 & 847.74 & 36.80 & 847.11 & 36.10 \\
\hline 508 & 810 & 3.61992 & 843.46 & 33.40 & 837.44 & 27.40 \\
\hline 513 & 770 & 0.95144 & 845.25 & 75.10 & 841.90 & 71.80 \\
\hline 517 & 770 & 0.69408 & 846.39 & 76.20 & 845.24 & 75.10 \\
\hline 518 & 771 & 0.11802 & 846.41 & 75.70 & 845.28 & 74.50 \\
\hline 523 & 777 & 0.28711 & 846.33 & 69.60 & 845.16 & 68.40 \\
\hline 524 & 775 & 0.19755 & 846.32 & 71.50 & 845.14 & 70.30 \\
\hline 525 & 793 & 0.10261 & 846.16 & 53.20 & 844.92 & 52.00 \\
\hline 527 & 780 & 0.76342 & 846.84 & 66.90 & 845.47 & 65.60 \\
\hline 539 & 781 & 0.14790 & 845.58 & 64.90 & 844.20 & 63.50 \\
\hline 540 & 804 & 0.29562 & 847.02 & 43.30 & 845.94 & 42.20 \\
\hline 541 & 799 & 0.41544 & 846.90 & 47.70 & 845.73 & 46.50 \\
\hline 544 & 796 & 1.34414 & 846.77 & 51.10 & 845.51 & 49.90 \\
\hline 546 & 795 & 0.34376 & 846.72 & 51.50 & 845.45 & 50.30 \\
\hline 548 & 796 & 0.57708 & 846.82 & 50.40 & 845.63 & 49.20 \\
\hline 549 & 798 & 0.75984 & 847.05 & 49.40 & 845.94 & 48.30 \\
\hline 550 & 797 & 0.03498 & 842.71 & 45.80 & 836.28 & 39.40 \\
\hline 552 & 804 & 0.21909 & 841.93 & 37.60 & 835.04 & 30.70 \\
\hline
\end{tabular}




\begin{tabular}{c|c|c|c|c|c|c}
\hline 553 & 790 & 0.80455 & 841.26 & 51.50 & 833.97 & 44.20 \\
\hline 555 & 785 & 0.37998 & 841.21 & 56.30 & 833.88 & 49.00 \\
\hline 557 & 777 & 0.46002 & 841.15 & 63.70 & 833.80 & 56.40 \\
\hline 558 & 802 & 0.18348 & 841.89 & 39.70 & 834.97 & 32.80 \\
\hline 559 & 810 & 0.49311 & 841.72 & 31.70 & 834.69 & 24.60 \\
\hline 1227 & 796 & 0.00000 & 850.90 & 54.70 & 851.20 & 55.00 \\
\hline 1229 & 796 & 0.00000 & 850.91 & 54.80 & 851.22 & 55.10 \\
\hline 1231 & 796 & 0.75464 & 850.99 & 54.80 & 851.42 & 55.30 \\
\hline 1235 & 797 & 0.00000 & 805.00 & 8.30 & 805.00 & 8.30 \\
\hline 1241 & 797 & 0.00000 & 805.00 & 8.30 & 805.00 & 8.30 \\
\hline 1246 & 797 & 0.00000 & 805.00 & 8.30 & 805.00 & 8.30 \\
\hline
\end{tabular}




\section{RESUMO EXECUTIVO}

\section{INTRODUÇÃO}

A questão da redução de custos tem sido uma constante para todas as empresas concessionárias responsáveis pela distribuição de água no Brasil e por todo o mundo. Para tanto, foram aplicados recursos no desenvolvimento de vários segmentos tecnológicos que permitiram não só a descoberta de novos materiais e instrumentos hidro-mecânicos, mas também ferramentas que ampliaram a capacidade de promover a gestão eficaz de todo o sistema, permitindo reproduzir o comportamento da rede de distribuição de água e intervir nos pontos mais frágeis do conjunto. Os simuladores hidráulicos e o geoprocessamento estão entre estas ferramentas, permitindo ao analista priorizar e planejar de forma preventiva.

Entretanto, para uma reprodução confiável do comportamento real, há a necessidade de um levantamento minucioso das muitas variáveis a que um sistema de distribuição está sujeito, tarefa esta muito complexa em razão da falta de atualização contínua das adequações realizadas geradas pela perda de informações, crescimento ocupacional e por intervenções oriundas de diferentes interesses de origem comercial, de manutenção ou para promover o abastecimento de forma emergencial, realizado por equipes e interesses diferentes. Assim, viu-se a necessidade de não apenas recolher e aplicar dados, mas selecioná-los e averiguar inconsistências do sistema de distribuição de forma a garantir e promover a aplicabilidade das ferramentas, onde é proposta a aplicação das facilidades do geoprocessamento à elaboração das simulações hidráulicas. Estudando especificamente as redes secundárias de distribuição, complexas e relativamente pouco exploradas em razão das dificuldades para sua reprodução e para a sua calibração somente por meio de amostras de campo, este trabalho se propõe a explorar o geoprocessamento e o histórico operacional da região de interesse com este fim. 


\section{OBJETIVO}

Definir metodologia para a elaboração de simulações hidráulicas, apoiadas em aplicativos de geoprocessamento e de dados relacionados ao histórico operacional da região adotada, conferindo e garantindo à simulação maior confiabilidade como ferramenta de análise e instrumento de suporte a decisão, de forma a buscar eficiência operacional a sistemas de distribuição de água.

\section{DESENVOLVIMENTO}

O foco do trabalho é pelo desenvolvimento de uma metodologia de conferência e calibração de simulações hidráulicas, através de aplicativos de geoprocessamento, utilizando-as comparativamente, permitindo uma interpretação coerente do funcionamento do sistema. Para tanto, as técnicas usuais de calibração in loco não serão dispensadas e para avaliação visual destes aplicativos auxiliares serão elaborados mapas temáticos que permitiriam acompanhar o retrato históricooperacional da região estudada. Com este produto, será possível diagnosticar a consequência da incidência de variações de pressão no setor, como falta d'água, vazamentos e pelo número de reclamações por parte dos usuários como norteadores de falhas na reprodução de redes secundárias de distribuição.

Com informações de qualidade e de boa confiabilidade, é possível realizar uma simulação representativa do setor, destacando suas vulnerabilidades e pontos críticos de forma a permitir o acompanhamento de seus pontos mais críticos, possibilidades de expansão e a priorização de melhorias e adequações.

Um setor de abastecimento é, conceitualmente, uma determinada área abastecida através de um ou mais reservatórios - possivelmente subdividida, segundo critérios, em zonas de pressão e áreas especiais sujeitas a medição e controle específico -, em que sejam geridos os seus volumes de entrada e saída dos reservatórios e aqueles volumes efetivamente entregues pelas redes de distribuição, contabilizados por meio de hidrômetros e a diferença entre estes volumes, as denominada perdas. Praticamente como regra, tais áreas contemplam sistemas mecânicos que regulam 
pressões e vazões disponibilizadas, como válvulas reguladoras de pressão e outras que produzem incremento piezométrico, como estações elevatórias e "boosters" de rede, garantindo assim que as pressões e vazões disponíveis estejam em acordo com as exigências da Norma Técnica Brasileira e outras condicionantes que permitam satisfação ao consumidor final sem refletir em prejuízo às concessionárias.

Para tanto, foi escolhido como estudo de caso o setor de abastecimento Sacomã, situado no município de São Paulo. Contando com uma rede de distribuição com idade de implantação média de 40 anos, apresenta grandes empreendimentos, comércios, indústrias e residências num total de quase 8000 ligações. Apresenta dois reservatórios: um semi-enterrado e um elevado que hoje sequer é utilizado como piezômetro de acionamento dos conjuntos motores.

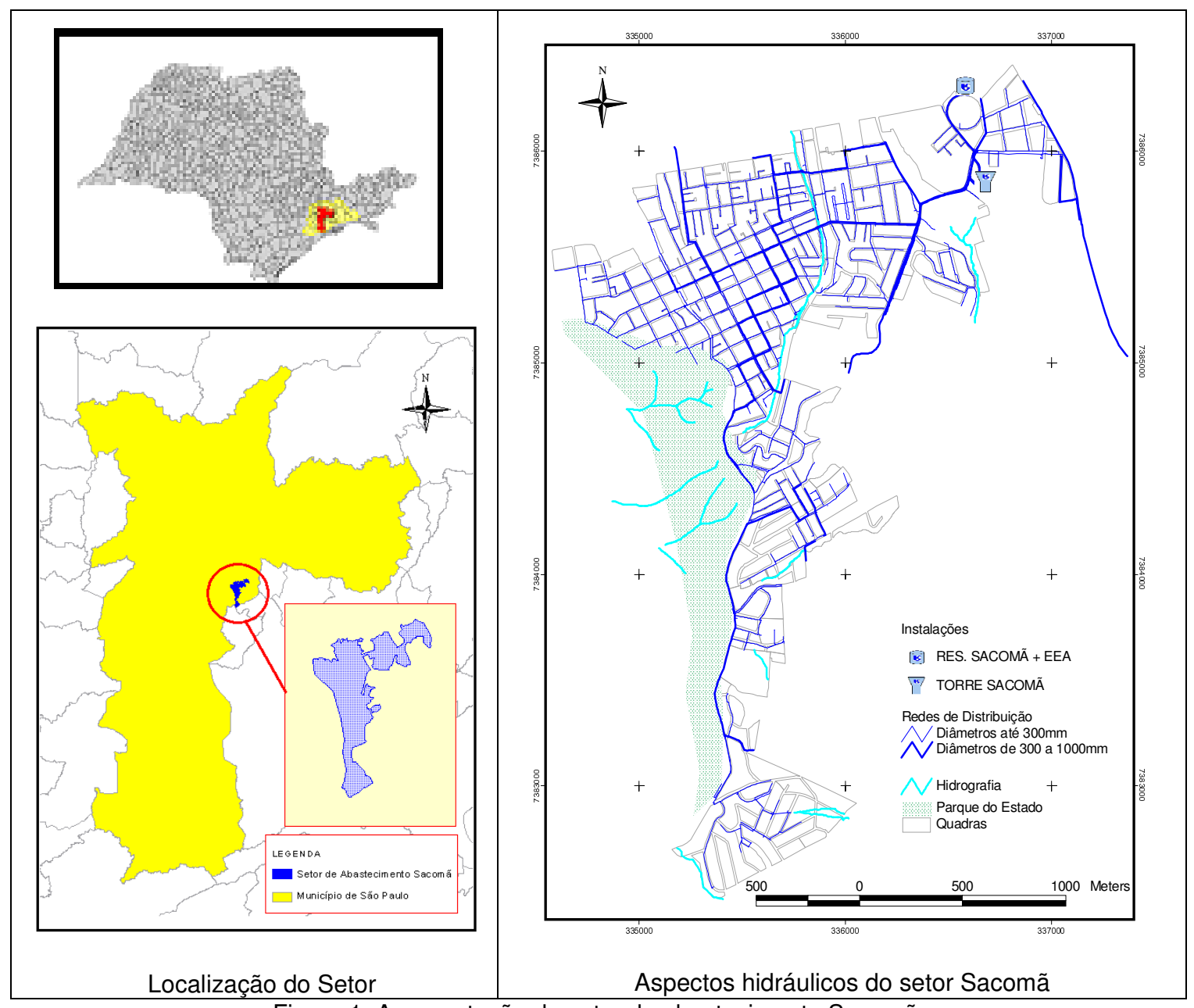

Figura 1: Apresentação do setor de abastecimento Sacomã

Devido à redução da área a que o mesmo foi originalmente dimensionado, apresenta um superdimensionamento de suas instalações, provocando um sistema 
de recalque que entra em operação em intervalos médios de 30 minutos, provocando progressivos picos de consumo. Como curiosidade, este setor foi escolhido justamente por estar em fase de adequação, onde está prevista uma provável substituição dos conjuntos motores existentes por outros proporcionais as atuais dimensões do setor e dotados de variadores de rotação, dispensando o uso do reservatório elevado que atualmente reflete em custos inviáveis de recuperação.

A tarefa inicia-se com a tomada de informações pertinentes a elaboração de simulação hidráulica, como dados topológicos, cadastrais e todas as complexidades existentes, assim como avaliar limites, válvulas presumidamente abertas ou fechadas, regime de abastecimento, demanda e curvas de consumo que, constantemente, reflete em grandes erros visíveis à simulação inicial. Assim, foi apresentada uma primeira versão, oriunda de dados obtidos do sistema sem consulta a especialistas ou técnicos diretamente envolvidos.

Como primeira forma de calibração, o modelo foi comparado com a realidade apontada por meio de mapas temáticos. A primeira comparação foi feita a partir da realidade do número de reclamações por parte dos usuários, onde estava visível a baixa incidência de reclamações por falta d' água na região - o que contradizia os resultados da simulação e permitiu a investigação destes pontos duvidosos.
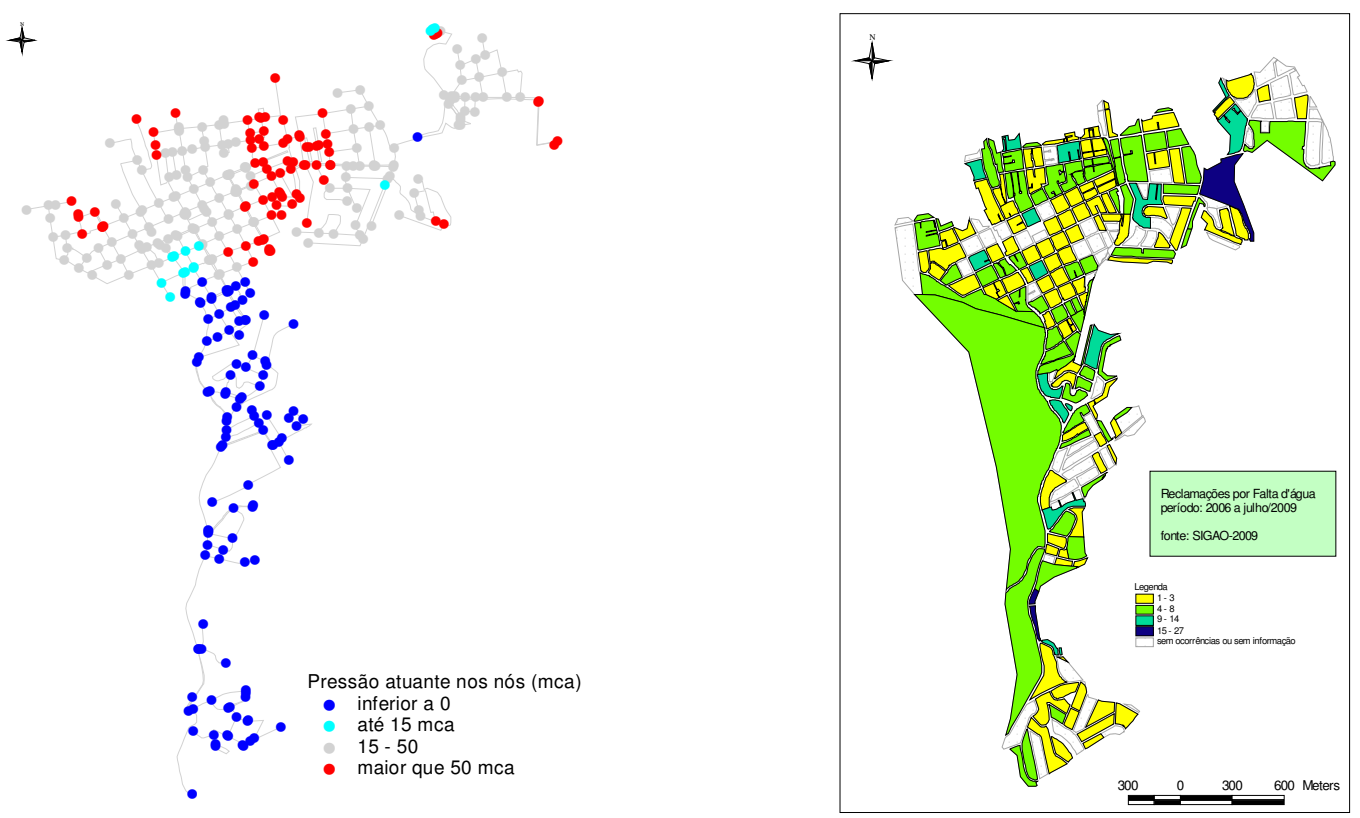

Figura 2: Comparativo da simulação com mapa temático: Reclamações por Falta d' água (2006 a julho de 2009) 
Como resultado, ao investigar-se os pontos de maior discrepância, foram localizadas ligações que pertenciam originalmente a um setor vizinho, redes lançadas com diâmetros incorretos, mas destacando-se, o maior problema foi provocado quando a ligação de um grande consumidor, com uma vazão de aproximadamente $3 \mathrm{l} / \mathrm{s}$, foi ligada a uma rede de DN 75 gerando, segundo apontou simulação a maior parte da falta d'água apontada pelo do modelo. Tal erro foi corrigido quando tal ligação foi colocada em sua posição correta, deslocada a aproximadamente $1,5 \mathrm{~km}$ da posição original, averiguada a partir de visita ao local. Esta, corretamente ligada a uma rede de DN 300, permitiu a equalização dos resultados do modelo.

Devidamente corrigida, como próxima etapa foram produzidas duas versões da simulação: a primeira com coeficiente Hazen-Williams comum $(C=90)$ e uma segunda por coeficientes interpolados a partir da proposta de variação segundo seu diâmetro, material e idade de implantação (Azevedo Netto, 1998). Estas foram então comparadas, segundo reproduz a tabela, em função dos dados obtidos em campo, em março de 2009.

\begin{tabular}{|c|c|c|c|c|c|c|}
\hline \multirow{2}{*}{ NÓ } & \multirow{2}{*}{ RGI } & \multirow{2}{*}{ NO CAMPO } & \multicolumn{4}{|c|}{ NA SIMULAÇÃO } \\
\hline & & & $C=90$ & DESVIO \% & $\mathrm{CV}$ & DESVIO \% \\
\hline 149 & 00000000001 & 33 & 37.90 & 14.85 & 36.50 & 10.61 \\
\hline 200 & 00000000002 & 26 & 29.80 & 14.62 & 28.40 & 9.23 \\
\hline 234 & 00000000003 & 16 & 19.80 & 23.75 & 18.30 & 14.38 \\
\hline 246 & 00000000004 & 37 & 38.00 & 2.70 & 37.30 & 0.81 \\
\hline 313 & 00000000005 & 46 & 47.90 & 4.13 & 47.10 & 2.39 \\
\hline 270 & 00000000006 & 24 & 23.40 & -2.50 & 21.30 & -11.25 \\
\hline 292 & 00000000007 & 30 & 31.50 & 5.00 & 29.60 & -1.33 \\
\hline 297 & 00000000008 & 24 & 20.50 & -14.58 & 18.80 & -21.67 \\
\hline 300 & 00000000009 & 52 & 42.30 & -18.65 & 40.50 & -22.12 \\
\hline 307 & 00000000010 & 60 & 68.20 & 13.67 & 66.30 & 10.50 \\
\hline 316 & 00000000011 & 16 & 22.90 & 43.13 & 21.10 & 31.88 \\
\hline 323 & 00000000012 & 22 & 25.10 & 14.09 & 23.30 & 5.91 \\
\hline 326 & 00000000013 & 26 & 25.10 & -3.46 & 26.30 & 1.15 \\
\hline 326 & 00000000014 & 26 & 25.10 & -3.46 & 26.30 & 1.15 \\
\hline 334 & 00000000015 & 26 & 33.00 & 26.92 & 31.10 & 19.62 \\
\hline 334 & 00000000016 & 26 & 33.00 & 26.92 & 31.10 & 19.62 \\
\hline 338 & 00000000017 & 38 & 33.50 & -11.84 & 31.70 & -16.58 \\
\hline 553 & 00000000018 & 38 & 51.50 & 35.53 & 44.20 & 16.32 \\
\hline 465 & 00000000019 & 37 & 36.70 & -0.81 & 36.00 & -2.70 \\
\hline 41 & 00000000020 & 16 & 42.40 & 165,00 & 41.70 & 160,63 \\
\hline 41 & 00000000021 & 16 & 42.40 & 165,00 & 41.70 & 160,63 \\
\hline 41 & 00000000022 & 16 & 42.40 & 165,00 & 41.70 & 160,63 \\
\hline
\end{tabular}

Tabela 1: Pressões tomadas em ligações para calibração dos nós - 19/03/2009 


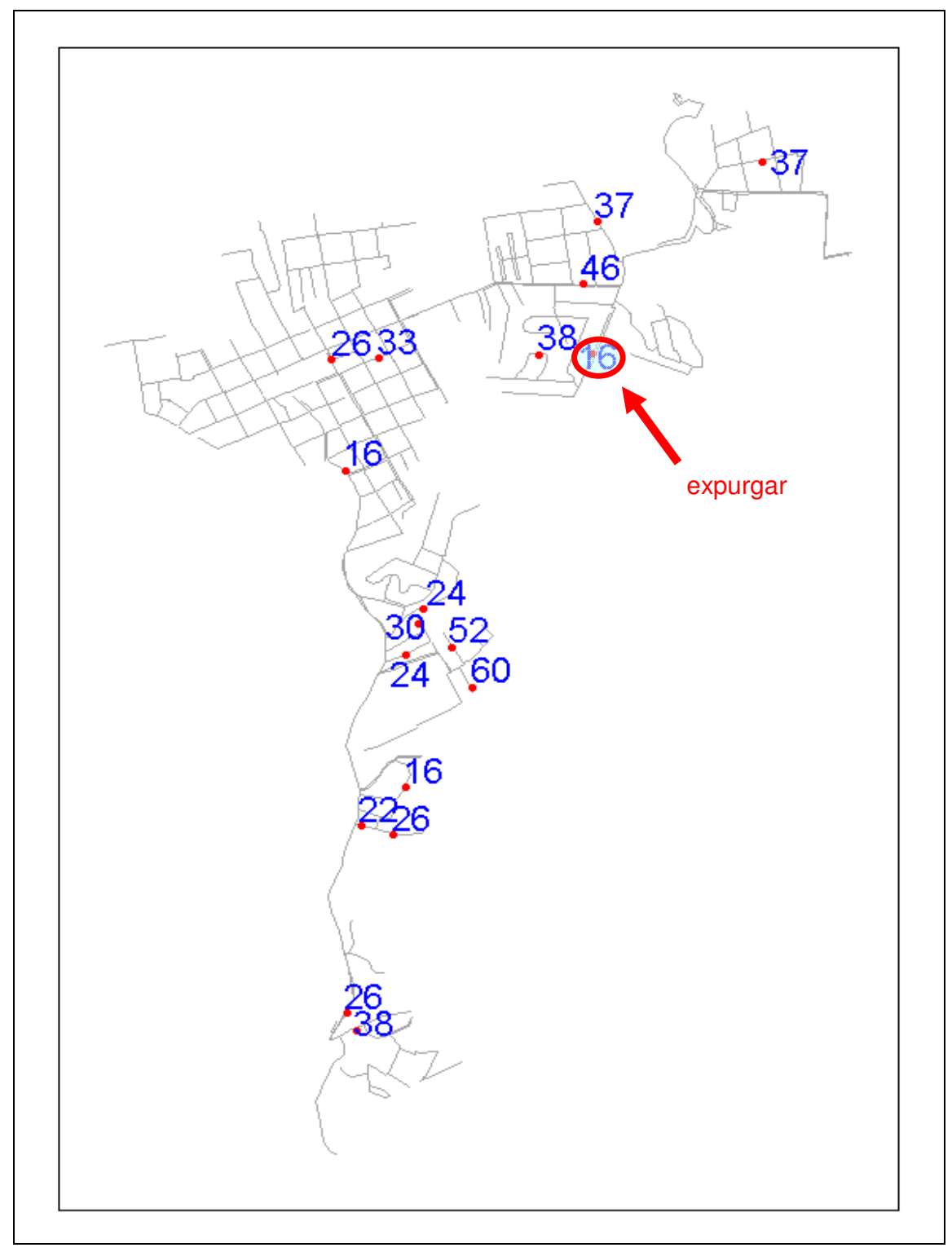

Figura 2: Dados para calibração dos nós - 19/03/2009

Durante a confirmação por meio de dados de campo, 3 das 22 amostras de pressão, foram tomadas equivocadamente, visto não fazerem parte do setor estudado apesar de instaladas dentro de seus limites, comprovando que não existe informação totalmente confiável, cabendo avaliar cada condição. Vale ressaltar que deverão ser considerados os desvios em razão de imprecisão como a gerada por perdas singulares, imprecisão dos equipamentos e da curva consumo x hora.

Tal problema representa a fragilidade da tratativa com dados, independente da origem ou da qualidade das informações. Até mesmo práticas muito disseminadas, como é o caso da calibração por amostragem in loco, está sujeita a falha, cabendo atenção e investigação caso a caso. 
Para ratificação de resultados, achou-se por bem elaborar-se um novo comparativo, desta vez a partir de dados operacionais. Assim, foi feita a comparação da segunda versão a realidade operacional apontada por mapas temáticos de vazamentos de cavalete, ramal e rede durante o $1^{\circ}$ Semestre de 2009, de forma a relacionar a ocorrência de vazamentos a problemas de pressão.

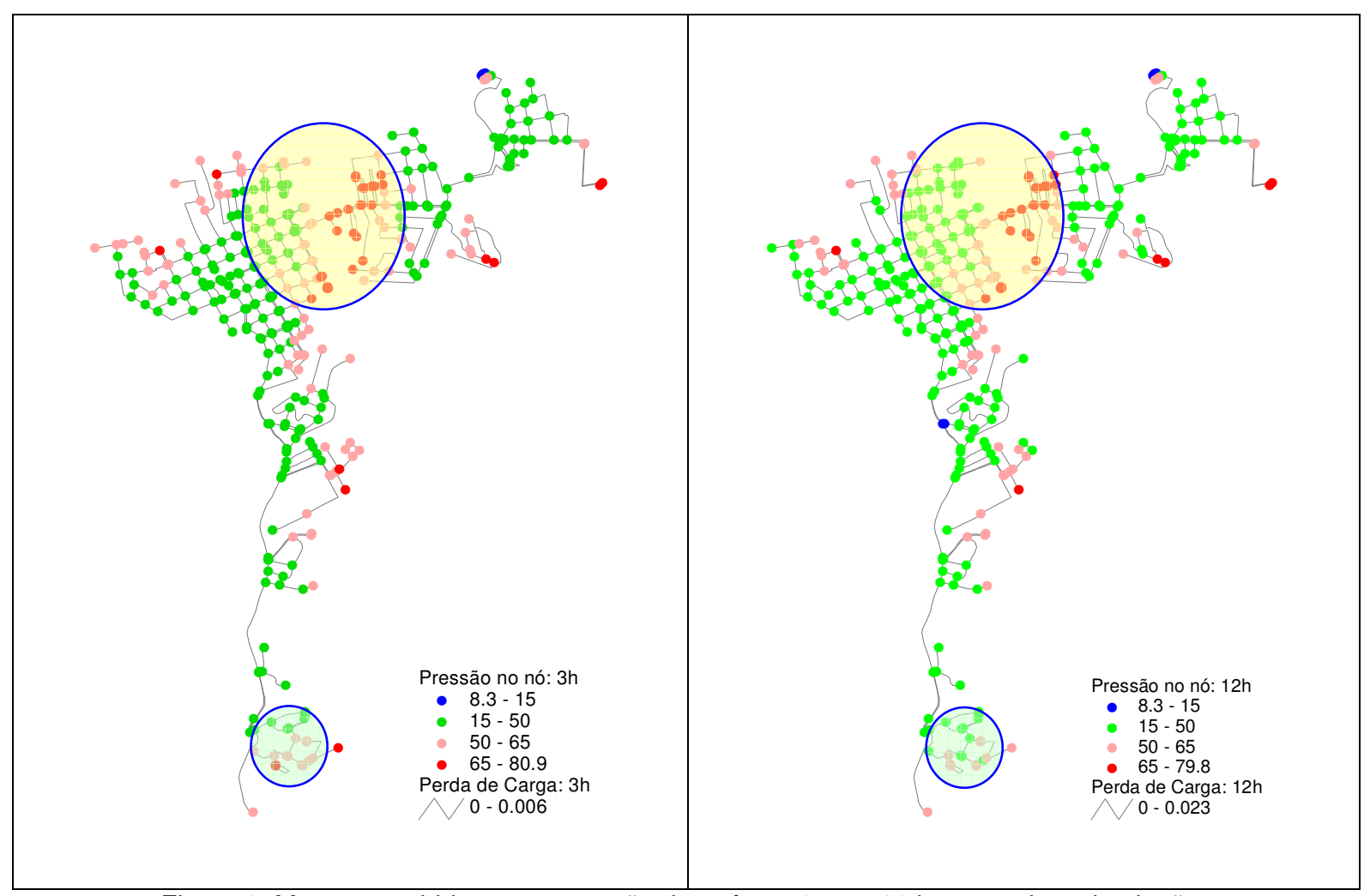

Figura 3: Mapa concebido com a pressão dos nós as 3 e as 12 h, segundo a simulação

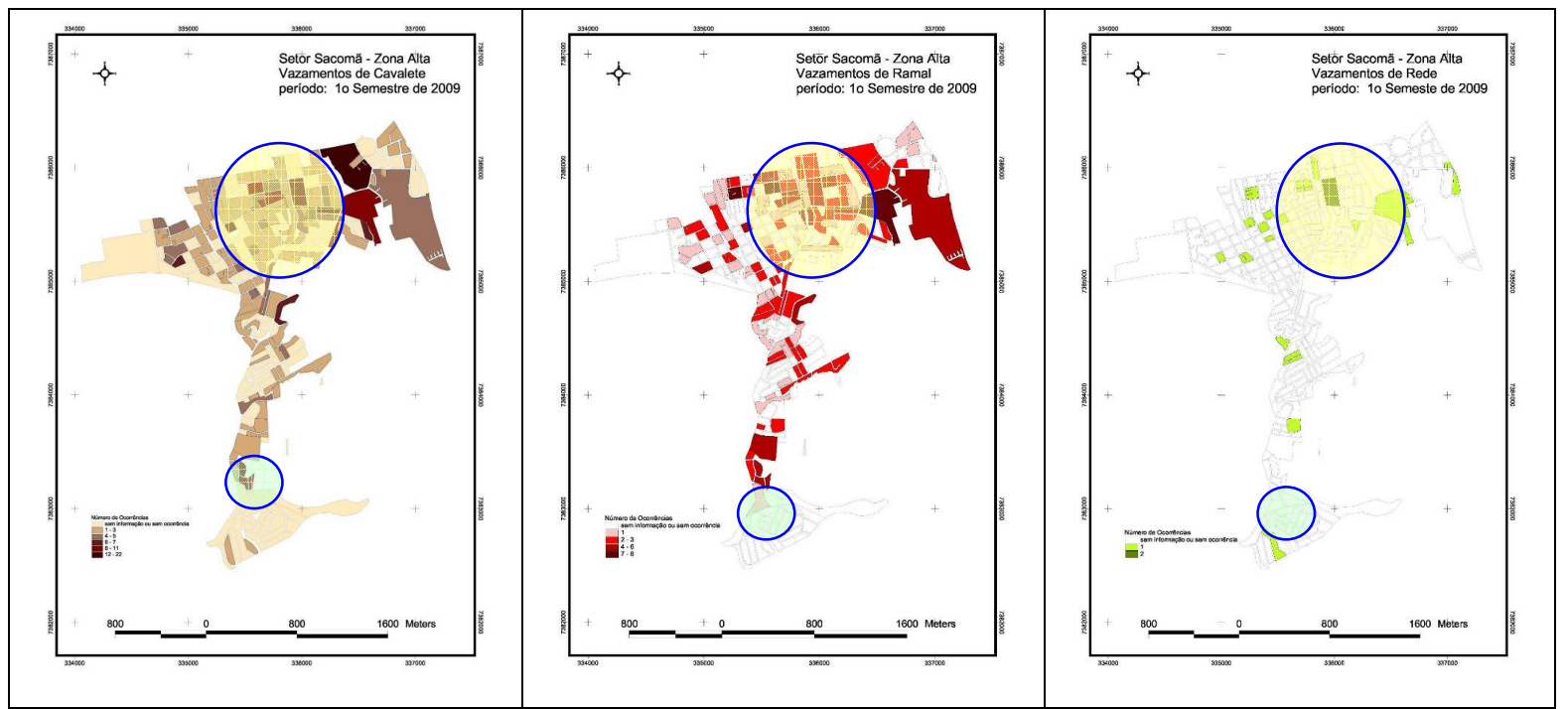

Figura 4: Mapas temáticos de vazamentos em cavalete, ramal e rede no 1ํs sem/2009 respectivamente. 
A partir de uma análise visual, fica evidente que a alta pressão é uma das causas de vazamentos, destacando sua evidência nos mapeamentos de vazamento de ramal e cavalete que na Região Metropolitana de São Paulo respondem por mais de $90 \%$ das intervenções. Outras razões também colaboram para o número de vazamentos, tais como condições de material, desgaste natural, falta de treinamento da mão de obra e idade da rede, contribuindo assim para o crescimento do número de intervenções. Em destaque nas figuras 3 e 4 as áreas comuns de maior incidência de vazamentos, ratificando mais uma vez os resultados reproduzidos na simulação.

De forma a garantir mais uma vez a reprodução de funcionamento do setor segundo a operação dos conjuntos motor-bomba. Observando o gráfico de operação do grupo $\mathrm{n}^{-} \mathbf{1}$, pode ser identificada a condição de recalque coerentemente reproduzida pela simulação hidráulica, mostrando o acionamento do conjunto em intervalos médios de 30 minutos, resultando, consequentemente, em golpes sucessivos na rede provocados pela atuação direta do recalque.

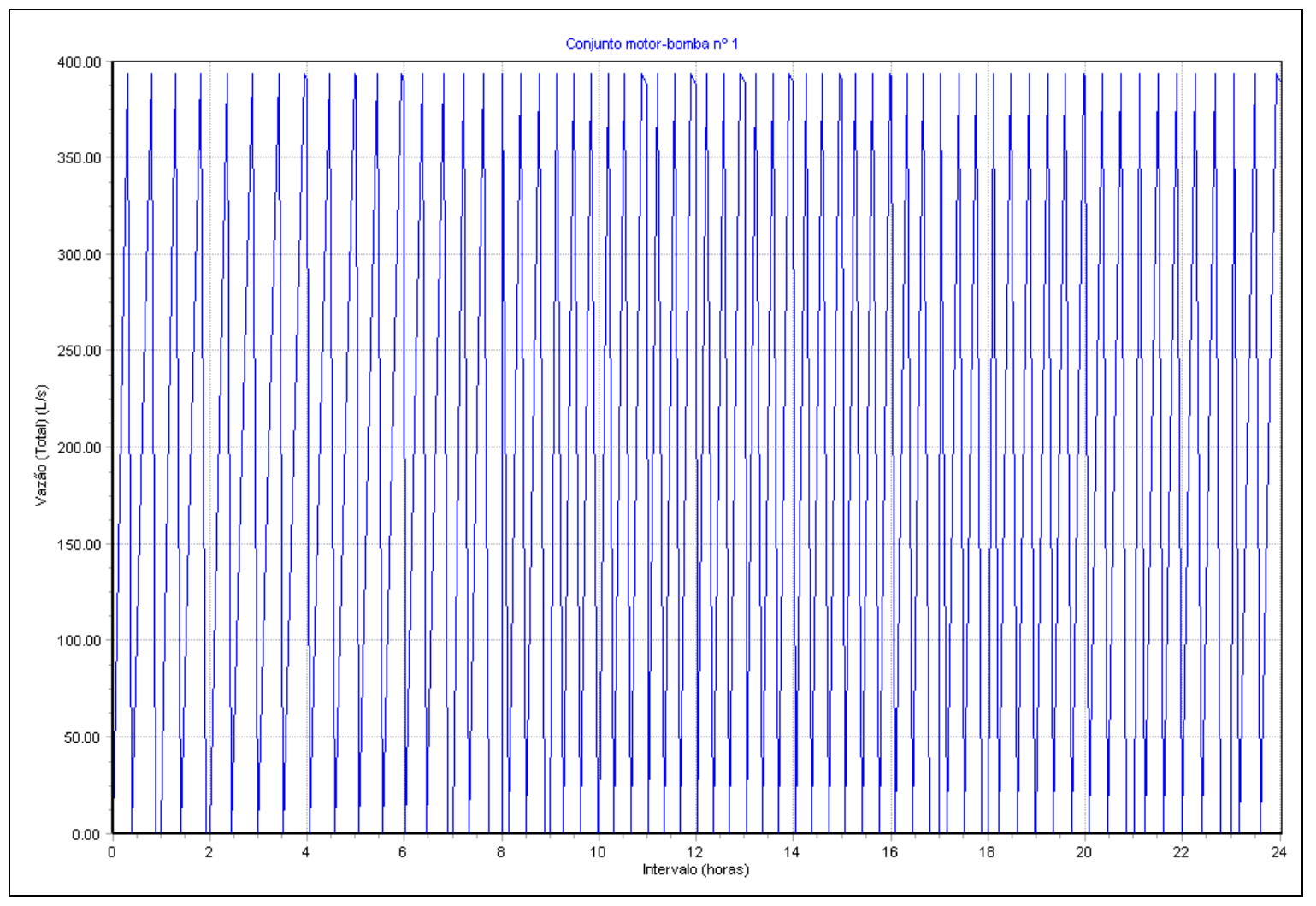

Figura 5 - Gráfico de operação do grupo № 1 segundo a simulação hidráulica do setor: 24h 
O estudo do modelo hidráulico do setor Sacomã usando a metodologia proposta, apresentou bons resultados. A proposta de utilizar as informações prontamente disponibilizadas no histórico operacional através do geoprocessamento se mostrou bastante viável, principalmente em termos práticos, onde os mapas temáticos permitiram apontar as principais discrepâncias da simulação, conduzindo a uma investigação mais minuciosa. Será necessária a experiência previamente adquirida por todos aqueles que atuam na operação do sistema e alguma perícia por parte do analista que fará uma análise de sensibilidade das variáveis e de como se apresentam.

As técnicas de geoprocessamento e o histórico operacional contribuíram com para o desenvolvimento de mais um método de calibração de redes secundárias, conferindo confiabilidade ao modelo simulador de apoio a decisão, permitindo a avaliação global da malha de distribuição, auxiliando o processo regular de calibração dos simuladores que tem posicionamento pontual, além de servir como meio de diagnóstico para o acompanhamento de resposta do sistema a variações de pressão na rede de distribuição.

Quanto às simulações computacionais de redes de distribuição reproduzidas no estudo de caso, por avaliação de representativa parte das pressões nos nós e nos tubos, estas não atenderiam as regras de limitação sugeridas para a calibração previstas pela Water Research Center (Hydraulic Research "Tables of Hydraulic Design of Pipes and Sewers" 1983 apud WALSKI, 2001), mas, do ponto de vista operacional, tais simulações poderiam atender a maior parte dos requisitos operacionais que a justificaram.

BIBLIOGRAFIA

AZEVEDO NETTO, J. M.; FERNANDEZ, M. F.; ARAUJO, R.; ITO, A. E.; Manual de Hidráulica 8ª Edição Ed. Edgar Blucher Ltda. São Paulo, 1998;

WALSKI, T. M.; CHASE, D. V.; SAVIC, D. A.; HAESTAD METHODS: Water Distribution Modeling $1^{\text {st }}$ ed. Waterbury - CT, 2001; 